\title{
$1 \quad$ PBP1 of Staphylococcus aureus has multiple essential functions in cell
}

\section{2 division}

3

4 Katarzyna Wacnik ${ }^{1,2}$, Vincenzo A Rao ${ }^{3}$, Xinyue Chen ${ }^{2,4}$, Lucia Lafage ${ }^{1,2}$, Manuel Pazos ${ }^{5}$,

5 Simon Booth ${ }^{3}$, Waldemar Vollmer ${ }^{5}$, Jamie K Hobbs ${ }^{2,4}$, Richard J Lewis ${ }^{3 \ddagger}$ and Simon J

6 Foster $^{1,2 *}$

7

$8 \quad{ }^{1}$ School of Biosciences, University of Sheffield, Sheffield, UK

$92^{2}$ The Florey Institute for Host-Pathogen Interactions, University of Sheffield, Sheffield, UK

$10 \quad{ }^{3}$ Biosciences Institute, Newcastle University, Newcastle upon Tyne, UK.

$11{ }^{4}$ Department of Physics and Astronomy, University of Sheffield, Sheffield, UK

$12{ }^{5}$ Centre for Bacterial Cell Biology, Bioscience Institute, Newcastle University, Newcastle

13 upon Tyne, UK.

14

$15 \$$ Current address: The Royal Society for the Protection of Birds, The Lodge, Sandy,

16 Bedfordshire SG19 2DL

$17 *$ To whom correspondence should be sent. E-mail: s.foster@sheffield.ac.uk. 


\section{Abstract}

19 Bacterial cell division is a complex process requiring the coordination of multiple components, to allow the appropriate spatial and temporal control of septum formation and cell scission. Peptidoglycan (PG) is the major structural component of the septum, and our recent studies in the human pathogen Staphylococcus aureus have revealed a complex, multistage PG architecture that develops during septation. Penicillin binding proteins (PBPs) are essential for the final steps of PG biosynthesis - their transpeptidase activity links together the peptide sidechain of nascent glycan strands together. PBP1 is required for cell division in

S. aureus and here we demonstrate that it has multiple essential functions associated with its enzymatic activity and as a regulator of division. Loss of PBP1, or just its C-terminal PASTA domains, results in cessation of division at the point of septal plate formation. The PASTA domains can bind PG and thus coordinate the cell division process. The transpeptidase activity of PBP1 is also essential but its loss leads to a strikingly different phenotype of thickened and aberrant septa, which is phenocopied by the morphological effects of adding the PBP1-specific $\beta$-lactam, meropenem. Together these results lead to a model for septal PG synthesis where PBP1 enzyme activity is responsible for the characteristic architecture of the septum and PBP1 protein molecules coordinate cell division allowing septal plate formation.

\section{Introduction}

Peptidoglycan (PG) is the major structural component of the bacterial cell wall and is essential for maintaining cell shape, integrity and survival (Silhavy et al., 2010; Turner et al., 2014; Vollmer et al., 2008). The final assembly stages of assembly of this large polymeric molecule are mediated by penicillin-binding proteins (PBPs), key PG synthases that, through their transglycosylase (TG) and transpeptidase (TP) activities, polymerise glycan chains and cross-link them into a mesh-like hydrogel (Pasquina-Lemonche et al., 2020; Typas et al., 
2011). Since the cell wall is essential for maintaining bacterial life, PBPs and PG synthesis are a target of some of the most important antibiotics, $\beta$-lactams (penicillins) and glycopeptides (vancomycin) (Schneider \& Sahl, 2010; Zapun et al., 2008). The major human pathogen Staphylococcus aureus has a minimalist PBP system as it encodes only four PBPs, PBP1 to PBP4 (Pinho et al., 2013). Only PBP1 (class B PBP with only TP activity, bPBP) and PBP2 (class A bifunctional PBP with both TG and TP activities, aPBP) are essential and sufficient for septal and peripheral PG synthesis in S. aureus (Lund et al., 2018; Pinho et al., 2013). PBP2 is the major PG synthase of $S$. aureus, and the septal formation activity of PBP2 is mediated by its substrate, Lipid II (Pinho \& Errington, 2005). Although PBP2 is essential, loss of its TP activity can be compensated for by a horizontally acquired class B PBP2A in methicillin-resistant $S$. aureus (MRSA) (Pinho, Filipe, et al., 2001). PBP2A, however, cannot replace PBP1, whose loss is detrimental to the viability of $S$. aureus (Pereira et al., 2007). PBP1 and PBP3 form cognate pairs with the monofunctional TGs, FtsW and RodA, belonging to the SEDS (shape, elongation, division and sporulation) family (Meeske et al., 2016) to facilitate septum formation (PBP1-FtsW) and to maintain the prolate cell shape (PBP3-RodA) of S. aureus, respectively (Reichmann et al., 2019). PBP4 is a class C PBP with D,D-carboxypeptidase activity (cPBP) and has a TP activity that contributes to the high-

60 level cross-linking of PG and MRSA resistance to $\beta$-lactams (Loskill et al., 2014; Srisuknimit et al., 2017).

62

Although $S$. aureus PBPs have been studied over many years, the specific roles of PBP1 in cell division, PG synthesis and architecture have remained elusive. Previous studies have shown that whilst PBP1 is essential, its TP activity is not, implying another role (Pereira et al., 2007; Reichmann et al., 2019). However, this work was performed in an MRSA background that contains PBP2A, encoded by mecA, which is non-native to $S$. aureus (Pinho, 
de Lencastre, et al., 2001). Whilst PBP2A cannot replace PBP1, how these proteins interact is

combined roles of $S$. aureus PBPs both in the presence and absence of the exogenous PBP2A, as the vast majority of $S$. aureus infections are caused by methicillin sensitive strains.

\section{Results}

\section{S. aureus PBP1 PASTA domains are essential for growth and PBP1 functionality}

PBP1 has a cytoplasmic N-terminal region, a membrane spanning sequence, an

exocytoplasmic dimerization domain and a C-terminal region consisting of the TP domain and two PASTA domains (for penicillin-binding protein and serine/threonine kinase associated domain) (Yeats et al., 2002). We created a set of conditional mutants of pbpl to investigate the role of PBP1 in cell division and PG synthesis. An ectopic copy of pbpl under the control of the Pspac promoter $\left(\mathrm{P}_{\text {spac }}-p b p 1\right)$ was placed at the lipase locus $\left(g e h:: \mathrm{P}_{\text {spac }}-p b p 1\right)$ of $S$. aureus $\mathrm{SH} 1000$, and a series of changes were made in this genetic background at the native $p b p 1$ locus: (i) an in-frame deletion of $p b p 1$ ( $\triangle p b p 1)$, (ii) a deletion of the region encoding the two PASTA domains ( $\left.p b p 1 \Delta_{\mathrm{PASTA}}\right)$, and (iii) the substitution of the catalytic Ser314 to Ala in the TP domain ( $\left.p b p 1^{*}\right)$ (Fig. 1a, b). We examined the essentiality of PBP1, the PASTA domains and the active TP domain with these mutants. Depletion of PBP1 via IPTG removal (Fig. 1c and Fig. 1 - figure supplement 1a, b) resulted in cell death, confirming the essentiality of PBP1 (Fig. 1c, d and Fig. 1 - figure supplement 1c, d,). Deletion of the PASTA domains also led to growth inhibition and more than $99 \%$ cell death within 4 h (Fig. 1d and Fig. 1 - figure supplement 1c, d). Importantly, this phenotype was not

91 associated with PBP1 $1_{\triangle \mathrm{PASTA}}$ instability (Fig. 1c and Fig. 1 - figure supplement 1a) or loss of its ability to bind its substrate analogue BocillinFL (Fig. 1 - figure supplement 1b). By 
contrast, deletion of the PASTA domains of Streptococcus pneumoniae PBP2x, a PBP1

orthologue, resulted in a complete loss of BocillinFL binding (Maurer et al., 2012). These

functionality but not its enzymatic activity.

During construction of the $p b p 1^{*}$ mutant we obtained, by serendipity, a $p b p 1_{\text {STOP }}$ mutant in which a SNP in the codon for Glu292 resulted in its replacement with a premature stop codon and the truncation of the entire TP and PASTAs region of PBP1 (Fig. 1 - figure supplement the PBP1 $1_{\text {STOP }}$ protein in the $p b p 1_{\text {STOP }}$ mutant (Fig. 1 - figure supplement $1 \mathrm{~g}$ ), suggesting that stability of the N-terminal domain of PBP1 is dependent on its $\mathrm{C}$-terminus.

103 Although inactivation of PBP1 TP activity (PBP1*) did not affect protein stability (Fig. 1c), it did remove the ability of PBP1 to bind BocillinFL (Fig. 1 - figure supplement 1b). The loss of PBP1 TP activity resulted in severely compromised growth on solid media (Fig. 1d and Fig. 1 - figure supplement 1c) and reduced cellular viability in liquid culture (Fig. 1e and Fig.

1071 - figure supplement $1 d$ ). Thus, the TP activity of PBP1 is required for growth in the SH1000 background. Inactivation of the PBP1 TP activity was reported previously not to affect growth in the COL strain background (Reichmann et al., 2019). The differences in the necessity for the PBP1 TP activity could result from COL being MRSA whereas SH1000 is a

111 methicillin sensitive S. aureus (MSSA).

\section{PBP1 TP activity is crucial in MSSA but not in MRSA}

114 We have recently developed a set of defined strains where high-level $\beta$-lactam resistance of

115 MRSA is mediated by mecA encoding PBP2A and a mutation in either $r p o B$ or $r p o C$

116 (Panchal et al., 2020). This combination of genetic alterations $\left(m e c A^{+} r p o B\right)$ are present in

117 COL (Panchal et al., 2020). To test if the apparent disparity in PBP1 role is associated with 
118 MRSA, we developed a high-level resistant mutant of $p b p 1 *$ in the well-characterised $S$.

119 aureus $\mathrm{SH} 1000$ by adding the $m e c A r p o B^{\mathrm{H} 929 \mathrm{Q}}$ to the MSSA $p b p 1^{*}$ mutant, resulting in

120 SH1000 MRSA $p b p 1$ * (Fig. 1 - figure supplement 2a). Inactivating PBP1 TP did not affect the

121 ability of SH1000 MRSA $p b p 1 *$ to grow in the absence of IPTG, whereas $p b p 1$ depletion led to growth inhibition in the isogenic $\triangle p b p 1$ MSSA and MRSA strains (Fig. 1d, e and Fig. $1-$ be studied in an MSSA background as otherwise the role of PBP1 can be confounded by the presence of the MRSA resistance apparatus.

\section{PBP1 PASTA domains are required for septum progression}

PG synthesis still occurred in $\Delta p b p 1, p b p 1_{\triangle \mathrm{PASTA}}$ and $p b p 1^{*}$ in the absence of IPTG, despite

cell growth inhibition, as measured by the incorporation of the fluorescent D-amino acid

130 derivative HADA (Fig. 2a). This was not a consequence of the non-synthesis, exchange reaction carried out by PBP4 as it occurred in $p b p 4$ as well as with the dipeptide ADA-DA cell volume upon depletion of $p b p 1$, whereas $p b p 1_{\triangle \mathrm{PASTA}}$ was enlarged by almost twice as much as $\Delta p b p 1$ and $p b p 1 *$ (Fig. 2a, b and Fig. 2 - figure supplement 2a). Despite differences in cell size, both $\triangle p b p 1$ and $p b p 1_{\triangle \mathrm{PASTA}}$ decreased the number of cells with complete septa (Fig. 2a, c). Transmission electron microscopy (TEM) showed that more than $80 \%$ of the population had growth defects including cell wall thickening, PG blebs, mis-shapen and/or multiple, incomplete septa. (Fig 2d, e and Fig. 2 - figure supplement 2b, c). Such septa had abnormally thick bases and sharply pointed leading edges, suggesting that cell growth arrest

140 was not due to a lack of septal initiation but instead arrest of inward septum progression.

141 Atomic force microscopy (AFM) has revealed previously that the first step in cell division is the formation of a PG feature called the "piecrust", prior to the septal plate(Turner et al., 
2010). The S. aureus septal plate has two PG architectures: disordered mesh facing the cell

144 membrane and concentric rings in the septum core (Pasquina-Lemonche et al., 2020). Here

145 lack of PBP1 or the PBP1 PASTA domains led to formation of more than one, and often

146 misplaced, piecrust. These mutations also caused an increase in unfinished septal annuli and

147 alterations in the ring surface architecture (Fig $2 \mathrm{f}$ and Fig. 2 - figure supplement 3a, c -

148 arrowheads), a characteristic feature of the division plane, freshly revealed immediately after

149 cell scission (Pasquina-Lemonche et al., 2020). Thus, depletion of PBP1 did not stop septum

150 initiation but the loss of the PASTA domains was enough to cause formation of irregular

151 piecrusts, arrest septal plate formation and lead to an altered septal PG architecture.

\section{PBP1 TP activity regulates septal PG architecture}

154 The $p b p 1^{*}$ mutant gave a novel phenotype quite distinct from loss of entire PBP1 or the PASTA domains. Inactivation of PBP1 TP activity did not prevent initiation and closing of

156 the septa, but instead resulted in accumulation of cells with aberrant septa and separation

157 defects in about $80 \%$ of the population (Fig. 2a, c, e). The septa in such cells had a rounded

158 leading edge, were curved, abnormally thick (Fig. 2d, e and Fig. 2 - figure supplement 2b, c),

159 had agglomerations of mesh-like material close to the septal centre in addition to irregular

160 piecrusts as observed by AFM (Fig. 2f and Fig. 2 - figure supplement 3a, b). The

161 intracellular agglomerations are PG as they stain heavily with HADA and ADA-DA (Fig. 2a

162 and Fig. 2 - figure supplement 1c, f) and could be observed in purified sacculi (Fig. $2 \mathrm{f}$ and

163 Fig. 2 - figure supplement 3b). No ring architecture, only mesh structured PG could be

164 observed on the surface of the $p b p 1^{*}$ mutant. Importantly, using fluorescence microscopy the

$165 p b p 1^{*} p b p 3 p b p 4$ mutant, in which PBP2 is the only active TP, presented a similar phenotype

166 upon IPTG removal as $p b p 1^{*}$, exemplified by misshapen septa and agglomerations of PG

167 material marked by HADA (Fig. 2 - figure supplement 2d). Therefore, septal synthesis and 
progression still occurred in the $p b p 1^{*}$ mutant, however, they resulted from PBP2 transpeptidase activity and potentially the transglycosylase activity of FtsW.

The $p b p 1^{*}$ phenotype occurred specifically because of the loss of the TP activity of this essential enzyme. This phenotype is mirrored by the mode of action of $\beta$-lactam antibiotics, which bind to and inhibit the TP activity of PBPs (Schneider \& Sahl, 2010). Our results suggest that PBP1 TP activity has a specific role in septal plate formation and without this the septum is mis-shapen. The conditional lethal strains made here allow for functional analysis of the genes concerned. However, phenotypes tend to accumulate on depletion of the wildtype protein over time confusing the precise roles for individual components. To independently corroborate the role of the TP activity of PBP1 we utilized an approach to directly, and selectively, inhibit its activity. Meropenem (MEM) has a higher affinity for PBP1 than PBP2 (Berti et al., 2013; Yang et al., 1995) and, therefore, we hypothesised that its effect on S. aureus would match $p b p 1^{*}$. In a MEM-titration, treatment with 1x MIC MEM was sufficient to lead to cell death and a significant increase in SH1000 WT cell volume after $1 \mathrm{~h}$ (Fig. 3a, b and Fig. 3 - figure supplement 1a). More than 70\% of MEM treated cells had growth defects that manifested as aberrantly shaped septa and accumulation of PG as shown by HADA labelling (Fig. 3a, c, d Fig. 3 - figure supplement 1c, e), similar to observations made with the $p b p 1^{*}$ mutants (Fig. 2a, c-e, Fig. 2 - figure supplement 1c, f). The MEM phenotype of malformed septa was not linked to PBP3 or PBP4 as it was also observed in the corresponding double mutant (Fig. 3c, d and Fig. 3 - figure supplement 1b, d, f), which corroborated the role of PBP2 in misshapen septal genesis.

\section{PASTA domains mediate PBP1 interaction with division components}


The morphologies of the $\Delta p b p 1$ and $p b p 1_{\triangle \mathrm{PASTA}}$ mutants resemble $S$. aureus depleted of

193 DivIB in which EzrA and FtsZ form multiple rings and the synthesis of the cross wall is

194 blocked, despite the normal recruitment of early cell division proteins and piecrust formation

195 (Bottomley et al., 2014). In the $\Delta p b p 1$ ezrA-gfp mutant, EzrA, which here acts as an early cell

196 division marker, was localised at midcell in the majority of cells and formed additional arcs

197 or rings in $33.5 \%$ of the population (Fig. 4a, d). Multiple EzrA rings were observed in 42.7\%

198 of the $p b p 1_{\triangle \mathrm{PASTA}}$ ezrA-gfp mutant cells (Fig. 4b, d), supporting the requirement for PBP1

199 PASTA domains for correct selection of the division site. Alternatively, the multiple division

200 rings could result from a lack of the septal progression whereby the unproductive division

201 machinery results in futile additional alternative initiation attempts, suggesting that PASTA

202 domains are involved in the progression from piecrust to septal plate formation. While the

203 number of cells with complete septa (EzrA-GFP visible as a line or focus) reduced by at least

204 6-fold in $\triangle p b p 1$ ezrA-gfp and $p b p 1_{\triangle \mathrm{PASTA}}$ ezrA-gfp, it only halved in $p b p 1^{*}$ ezrA-gfp (12.5\%

205 to $6.3 \%$ of $p b p 1 *$ ezrA-gfp in +/-IPTG, respectively; Fig. 4c, d), confirming that septum

206 progression, although reduced, still occurred when PBP1 TP was inactive implying that TP

207 activity is necessary for correct septal architecture during cell division.

208

209 The cell wall of Gram-positive bacteria is decorated with wall teichoic acid (WTA)

210 glycopolymers (Neuhaus \& Baddiley, 2003). WTA regulates cell shape, ion homeostasis,

211 autolytic enzymes, growth and division (Swoboda et al., 2010). In S. aureus, WTA plays a

212 crucial role in virulence, MRSA resistance to $\beta$-lactam antibiotics, PBP4 localisation at the

213 septum and PG cross-linking (Atilano et al., 2010; Campbell et al., 2011; Farha et al., 2013;

214 Weidenmaier et al., 2005). Loss of WTA also results in a proportion of cells with aberrant

215 septa (Campbell et al., 2011) suggesting a link with PBP1 function. Loss of tarO (leading to a

216 lack of WTA) caused minor cell division defects in SH1000 (Fig. 4 - figure supplement 1a, e, 
217 f). Combining $\operatorname{tar} O$ with the mutations in $p b p 1$ exacerbated the observed morphological

218 defects, with the appearance of distinct septal and off-septal PG foci appeared (marked with

219 HADA) in $\triangle p b p 1$ tarO and $p b p 1_{\triangle \mathrm{PASTA}} \operatorname{tar} O$ (Fig. 4 - figure supplement $1 \mathrm{~b}$-f), demonstrating

220 that both WTA and PBP1 are involved in cell cycle control in parallel.

221

222

As PBP1 PASTA has a role in the regulation of septal plate formation, this may be

determined by interacting with other protein components. In order to examine this hypothesis

we performed a bacterial two-hybrid assay, in which PBP1 has previously been found to have multiple interactions (Steele et al., 2011). Truncation of the PASTA domains not only reduced $S$. aureus PBP1 interaction with DivIB but also with FtsW, whilst recognition of other known interacting partners of PBP1 (EzrA, PBP2 and DivIC) were unaffected by the

PASTA truncation (Fig. 5 - figure supplement 1a, b), suggesting that these wider interactions involve the N-terminal domain of PBP1.

\section{PBP1 PASTA domains bind peptidoglycan}

Impaired interaction with DivIB could be one explanation for why cells depleted of PBP1

PASTA domains initiate irregular piecrusts and septation defects accrue as a consequence.

PASTA domains have long been associated with PG binding because of work performed mainly on serine/threonine protein kinases (STPK) (Mir et al., 2011; Shah et al., 2008;

236 Squeglia et al., 2011; Yeats et al., 2002). Therefore, we assessed whether S. aureus PBP1 and

237 its PASTA domains could recognise PG by measuring their affinities for S. aureus cell wall

238 PG with or without WTA (+/-WTA) with a semi-quantitative fluorescence binding assay

239 (Bottomley et al., 2014) and S. aureus PBP1 derivatives produced in Escherichia coli (Fig. 5a

240 and Fig. 5 - figure supplement 1c). Both $S a \mathrm{PBP} 1\left(K_{d} 19 \pm 4 \mathrm{nM}(+\mathrm{WTA}), 115 \pm 21 \mathrm{nM}(-\right.$

241 WTA)) and its PASTA domains (SaPASTApBp1; $K_{d} 198 \pm 42$ nM (+WTA), $109 \pm 23$ nM (- 
WTA) bound PG (Fig. 5b). Inactive $S a P B P 1 *$ was still able to bind PG with a preference for PG with WTA present ( $K_{d} 53 \pm 8 \mathrm{nM}$ (+WTA), $227 \pm 46 \mathrm{nM}$ (-WTA); Fig. 5b), similar to active $S a$ PBP1. Although removal of the PASTA domains did not abolish BocillinFL binding

(Fig. 5 - figure supplement 1c), it considerably reduced the ability of $S a \mathrm{PBP} 1_{\triangle \mathrm{PASTA}}$ to bind PG and binding was completely abolished in the presence of WTA $\left(K_{d}>2000 \mathrm{nM}(+\mathrm{WTA})\right.$, $440 \pm 57$ nM (-WTA); Fig. 5b). By contrast, the PASTA domains (SaPASTAPBP1) on their own bind to $S$. aureus PG but are incapable of binding BocillinFL (Fig. $5 \mathrm{~b}$ and Fig. 5 - figure supplement 1c). These results demonstrate unequivocally that PBP1 is a PG binding protein, and the PASTA domains have a dominant role in this interaction. Sequence conservation analysis of PASTA domains revealed the presence of either Arg or Glu residues in classifying a PASTA domain as a PG-binder (Calvanese et al., 2017). The PASTA domains of $S$. aureus PBP1 each have proline at the equivalent positions (residues Pro603 and Pro661) and thus PBP1 would be predicted as a non-PG binder, which clearly is not the case from the experimental evidence presented herein. Not only have we demonstrated the existence of such an interaction but we have also quantified it, suggesting that the predicted significance of conserved Arg or Glu residues with regard to PG binding is either only relevant to PASTA domains found in STPKs, linear arrangements of tandem PASTA repeats, or is too simplistic a prediction for proteins with multiple and complex functions like PBPs.

262 (SaPASTAPBP1), we determined their structure by X-ray crystallography. Soluble recombinant protein was obtained in high yield from the cytoplasm of E. coli cells and wellordered crystals were subsequently produced that diffracted to a maximum resolution of 1.78 
267 García et al., 2018), which shares $26 \%$ sequence identity with $S a P A S T A$ PBP1. The asymmetric

268 unit contains two monomers (labelled A and B), each forming a 2-layer sandwich comprising

269 an $\alpha$-helix and a three-stranded antiparallel $\beta$-sheet, distinct from the TP domain (Fig. 5c).

270 Clear and continuous electron density allowed the modelling and unambiguous assignment of

271 both PASTA domains (Fig. 5c). When $\mathrm{SaPASTAPBP1}$ is compared with other structures

272 deposited in the PDB using DALI (Holm, 2020), the top hit identified was S. pneumoniae

273 PBP2x (Z-score; 15.7), showing a significant conservation of the PASTA fold, despite low

274 sequence identity (Fig. 5c). Unlike the linear arrangement observed for PASTA domains in

275 serine/threonine kinases (Barthe et al., 2010; Ruggiero et al., 2011), $\mathrm{SaPASTA}$ PBP1 adopts a

276 compact upside-down globular arrangement (Fig. 5c). The arrangement of the two PASTA

277 domains solved here, in isolation from the TP domain in comparison to structural analyses of

$\operatorname{SpPBP} 2 \mathrm{x}$, is entirely consistent with a non-linear PASTA domain arrangement. First, the

$2.2 \AA$ over $114 \mathrm{C} \alpha$ and when $S a$ PASTAPBP1 is superimposed on the PASTA domains of

SpPBP2x there are no steric clashes with the TP domain. Second, the linker between PASTAs

in $\mathrm{SaPASTA} \mathrm{PBP}_{1}$ has a sequence of DGDLTMPDMSGW, is neither glycine- nor alanine-rich, interface between the PASTA domains is more reminiscent of the hydrophobic core of a

286 globular protein than the more polar interface observed between molecules in crystal packing.

287 It would therefore seem unlikely that the two PASTA domains open and close in a hinged

288 manner, akin to the movement of a butterfly's wings, in the presence and absence of

289 endogenous PG. Finally, the two proline residues that apparently define PBP1 as a non-binder

290 of PG are found buried from solvent either at the interface of PASTA domain 1 with the TP

291 domain (Pro603) or at the interface between the TP domain and PASTA domains 1 and 2 
292 (Pro661). This latter interface includes the only tryptophan (Trp666) in the sequence of

293 SaPASTAPBP1; tryptophan residues are frequent 'markers' of carbohydrate binding sites in

294 proteins (Hudson et al., 2015) and in the absence of any obvious grooves or surface features

295 associated with conserved sequence distributions and/or electrostatics it remains unclear how

296 the PASTA domains of SaPBP1 recognise PG.

297

\section{Discussion}

299 S. aureus has just two essential PBPs (Reed et al., 2015) and so forms an apparently simple

300 system to understand cell wall growth and division. Even the transpeptidase activity of these

301 two enzymes can be substituted by a single enzyme in the presence of $\beta$-lactam antibiotics

302 via the acquisition of PBP2A, encoded by $m e c A$, in MRSA strains. Our recent study has

303 revealed that the presence of $m e c A$ and associated genetic lesions have a profound effect on

304 S. aureus, even in the absence of antibiotics (Panchal et al., 2020), leading to the discovery

305 herein that the PG biosynthetic activity of PBP1 is essential in MSSA but not in MRSA (Fig.

306 1d). This observation has important ramifications for many studies in $S$. aureus where the use

307 of an MRSA background can complicate phenotype interpretation. To understand the

308 fundamental role of PBP1 activity in basic cell physiology we have thus used a MSSA strain

309 with a defined genetic background.

311 The essential function of PBP1 is associated with its crucial role in septal PG synthesis

312 (Pereira et al., 2009; Reichmann et al., 2019). Here we show that PBP1 is a multifunction

313 regulatory and PG synthetic protein involved in both early and later stages of septum

314 synthesis. PBP1 can interact with other cell division components, make and bind to PG. PG

315 binding is primarily mediated by the PASTA domains that are essential for cell division.

316 There is clear overall structural similarity between $S$. aureus PBP1 and S. pneumoniae PBP2x 
317 PASTA domains in the way that the two tandem PASTA domains associate into an anti-

318 parallel bundle (Fig. 5c); this is in marked contrast to the head-to-tail linear PASTA domain

319 repeats more typically found in STPKs. The highly hydrophobic interface between the two

320 PASTA domains means it is unlikely to open up like butterfly wings to bind to PG; similarly

321 an extensive, linear interaction with PG, which is likely to occur with the head-to-tail PASTA

322 domain arrangements seen in STPKs and that may require their dimerization (Barthe et al.,

323 2010), does not occur in $S a P B P 1$. Despite the successful production of diffracting crystals of

$324 \mathrm{SaPASTAPBP1}$ grown in the presence of PG fragments (including an $\mathrm{N}$-acetylglucosamine: $N$ -

325 acetylmuramic acid disaccharide) none of the structures yielded electron density features

326 consistent with the stable binding of PG fragments. There are several potential explanations,

327 including a lack of affinity of PASTA domains for small PG fragments, unrepresentative of

328 the sacculus of S. aureus; our sedimentation assay does not permit the analysis of the binding

329 of PASTA domains to small, soluble PG precursors. Consequently, and in common with all

330 other PASTA domain structural analyses, the molecular details of PG recognition by SaPBP1

331 remain elusive.

333 S. aureus is a spheroid coccus that can divide successively in three orthogonal planes

334 (Saraiva et al., 2020; Turner et al., 2010). Septation is first observed as the formation of a

335 thick band of PG known as the piecrust (Turner et al., 2010). This then transitions to the

336 production of the septal plate itself, an initially V-shaped structure with a narrower leading

337 edge (Lund et al., 2018). After closure of the septal annulus, the now bowed septum fills out

338 to yield the mature structure prior to septal scission. The septal plate has two distinct PG

339 architectures with a ring-like pattern at its core, which is exposed upon scission, and a

340 subsequently-synthesised fine mesh, akin to the rest of the peripheral cell wall (Pasquina-

341 Lemonche et al., 2020). Loss of the entire PBP1, or just its PASTA domains, does not 
342 prevent piecrust formation but does result in multi- and/or off-centre piecrusts without the

343 ability to produce the septal plate (Fig 2f). Thus, piecrust formation does not require PBP1

344 but is likely the result of the activity of the essential PBP2. PBP1 may regulate division site

345 selection through PG cell wall recognition via its PASTA domains. Alternatively, as the

346 division apparatus is unable to progress effectively to septal plate formation due to the lack of

347 PBP1, this may lead to further rounds of initiation and piecrust formation. PBP1 has a clear

348 role in septal plate formation where in the absence of PBP1 or the PASTA domains, cells

349 form aberrantly shaped septa that do not close their annuli (Fig. 2a-e). In stark contrast,

350 inactivation of PBP1 TP activity ( $p b p 1^{*}$ ) does not stop inward septum progression as

351 observed with loss of PBP1 or the PASTA domains, however, such septa are mis-shapen,

352 curved and abnormally thick (Fig. 2a-e and Fig. 3). The use of the PBP1-specific antibiotic

353 MEM at 1x MIC led to the similar morphology of thickened and mis-shapen septa. Two

354 independent avenues of research both lead to the conclusion that PBP1 TP activity is

355 essential and, whilst septum formation is disturbed, it is not entirely prevented. Therefore

356 PBP1 retains its regulatory function(s) regardless of activity loss. As well as binding to the

357 cell wall, PBP1 also interacts with multiple protein partners including EzrA, DivIB/C, PBP2

358 and FtsW (Fig. 5 - figure supplement 1a, b) (Steele et al., 2011; Reichmann et al., 2019).

359 Recently, the PASTA domains from B. subtilis PBP2B were shown to regulate PBP2B

360 interaction with DivIB (Morales Angeles et al., 2020). S. aureus DivIB is a PG binding

361 protein essential for division, which depletion leads to septal plate formation loss (Bottomley

362 et al., 2014; Steele et al., 2011)'. Here the PBP1 PASTA domains were found to bind DivIB

363 and FtsW, alluding to their essential role in cell division. FtsW is a SEDS protein, whose TG

364 activity requires the presence of PBP1 (Taguchi et al., 2019). Bifunctional aPBPs (including

365 PBP2) and bPBP-SEDS (including PBP1-FtsW) pairs share similar activities but the fact they

366 coexist in many bacterial species implies there is a division of responsibilities between them. 
Indeed, it has been proposed lately that bPBP-SEDS pairs likely lay the primary PG matrix, while aPBPs support the initial PG by modifying, filling in and adding PG to it (Cho et al.,

369 2016; Straume et al., 2020). The S. aureus septal plate PG has two distinct architectures, a

370 disordered mesh present on its cytoplasm facing side and a ring structure at its core, which is

371 revealed after the cells have split (Pasquina-Lemonche et al., 2020; Turner et al., 2010) (Fig.

3725 - figure supplement 2). Recent AFM analysis from Staphylococcus warneri also describes

373 the distinct PG architectures during septation as piecrust and septal plate rings/mesh (Su et

374 al., 2020). When sacculi are purified from $S$. warneri, the septum can split apart revealing

375 the rings, even in septa that have not closed their annulus, showing that the rings are not a

376 result of PG hydrolysis during cell scission. We hypothesise (Fig. 5 - figure supplement 2)

377 that once the piecrust has been produced, PBP1 and FtsW use this as a foundation to initiate

378 septal plate formation. Together they make the rings of material that become the core of the

379 developing septum, providing the framework for PBP2 to make the bulk of the septal plate as

380 a tight mesh alongside PBP4 and the insertion of WTA via the tar pathway. Loss of PBP1 TP

381 activity in the presence of active PBP2 leads to the lack of the ring framework and aberrant,

382 unproductive septum formation. The rings that form the centre of the developing septum also

383 provide the cleavage plane during scission.

384

385 Cell division is a fundamental requirement for life. A central question to this in bacteria is how

386 is the division septum synthesised and then split to yield two daughter cells whilst maintaining

387 cellular integrity in the face of internal turgor? Here we have begun to answer this question by

388 revealing the complex synthesis coordination mechanisms that allow this biological

389 engineering feat to be accomplished. 
Materials and methods

\section{$391 \quad$ Bacterial growth conditions}

392 Strains used in this study are listed in Appendix Table 1.

393 All Staphylococcus aureus strains were grown in tryptic soy broth (TSB) containing

394 appropriate antibiotics at $37^{\circ} \mathrm{C}$, unless otherwise indicated, with aeration.

395 All Escherichia coli strains, unless otherwise stated, were grown in Lysogeny broth (LB)

396 containing appropriate antibiotics at temperatures ranging from $20^{\circ} \mathrm{C}$ to $37^{\circ} \mathrm{C}$ with aeration.

397 For solid media 1.5\% (w/v) agar was added.

398 When necessary, growth medium was supplemented with kanamycin $\left(50 \mu \mathrm{g} \mathrm{ml}^{-1}\right)$,

399 tetracycline $\left(1 \mu \mathrm{g} \mathrm{ml}^{-1}\right)$, chloramphenicol $\left(10 \mu \mathrm{g} \mathrm{ml}^{-1}\right.$, S. aureus; $30 \mu \mathrm{g} \mathrm{ml} \mathrm{l}^{-1}$, E. coli $)$,

400 erythromycin $\left(5 \mu \mathrm{g} \mathrm{ml} l^{-1}\right)$, spectinomycin $\left(250 \mu \mathrm{g} \mathrm{ml} \mathrm{ml}^{-1}\right)$, ampicillin $\left(100 \mu \mathrm{g} \mathrm{ml}^{-1}\right)$,

401 meropenem $\left(0.4 \mu \mathrm{g} \mathrm{ml}^{-1}, 1 \times \mathrm{MIC}\right.$ for SH1000 WT; $0.2 \mu \mathrm{g} \mathrm{ml}^{-1}, 1 \times \mathrm{MIC}$ for $\left.p b p 3 p b p 4\right)$, 5-

402 bromo-4-chloro-3-indolyl $\beta$-d-thiogalactopyranoside (X-Gal; $80 \mu \mathrm{g} \mathrm{ml}^{-1}$, S. aureus;

$40340 \mu \mathrm{g} \mathrm{ml} l^{-1}$, E. coli) or isopropyl $\beta$-d-thiogalactopyranoside (IPTG, $50 \mu \mathrm{M}$ or $1 \mathrm{mM}$ ).

404

$405 \quad$ Plasmid construction

406 Plasmids and oligos used in this study are listed in Appendix Table 2 and Appendix Table 3, 407 respectively.

408 Plasmids were cloned using E. coli NEB5 $\alpha$ following previously described methods (Gibson 409 et al., 2009; Sambrook et al., 1989).

410

$411 \quad$ pKB-Pspac-pbp1

412 A fragment containing RBS and coding region of $S$. aureus pbpl was PCR amplified from

413 the genomic DNA of S. aureus SH1000 using pCQ-pbp1-F/-R primers and cloned into NheI

414 and AscI cut pCQ11-FtsZ-SNAP by Gibson assembly, resulting in pCQ11-Pspac-pbp1. Next 
417 Gibson assembly giving pKB-Pspac-pbp1.

\section{pMAD- $\Delta p b p 1$}

420 Fragments encompassing $1 \mathrm{~kb}$ regions flanking upstream (from -980 bp upstream of $p b p 1$ to

421 first $20 \mathrm{bp}$ of $p b p 1$ ) and downstream of (from $2214 \mathrm{bp}$ of $p b p 1$ to $970 \mathrm{bp}$ downstream of 422 pbp1) pbpl were PCR amplified from S. aureus SH1000 genomic DNA using primer pairs pbp1-A/-B and pbp1-C/-D, respectively, and cloned into BamHI and EcoRI cut pMAD by

424 Gibson assembly, creating a deletion vector pMAD- $\Delta p b p 1$.

\section{pMAD-pbp1 $1_{\triangle \mathrm{PASTA}}$}

427 Fragments encompassing $1.5 \mathrm{~kb}$ regions flanking the region encoding $p b p 1$ PASTA domains 428 (upstream, from $286 \mathrm{bp}$ to $1785 \mathrm{bp}$ of $\mathrm{pbpl}$; downstream, from $2214 \mathrm{bp}$ of $p b p 1$ to $970 \mathrm{bp}$ 429 downstream of $p b p 1$ ) were PCR amplified from S. aureus SH1000 genomic DNA using 430 pbp1-E/-F and pbp1-G/-H primers and cloned into BamHI and EcoRI cut pMAD by Gibson assembly, resulting in a deletion vector $\mathrm{pMAD}-p b p 1_{\triangle \mathrm{PASTA}}$.

\section{pMAD-pbp1*}

$434 \mathrm{~A} \sim 1.3 \mathrm{~kb}$ fragment covering an upstream region of the active site of $p b p 1$ (from $-334 \mathrm{bp}$ 435 upstream of $p b p 1$ to first $950 \mathrm{bp}$ of the $p b p 1$ coding sequence), and a $\sim 1.3 \mathrm{~kb}$ fragment 436 comprising the $3^{\prime}$ fragment of $p b p l$ (930-2235 bp region of $p b p l$ ) were PCR amplified from

437 S. aureus SH1000 genomic DNA using primer pairs pbp1*5'-F/-R and pbp1*3'-F/-R, 438 respectively. Primers pbp $1 * 5^{\prime}-\mathrm{R}$ and $\mathrm{pbp} 1 * 3{ }^{\prime}-\mathrm{F}$ were designed to introduce a $\mathrm{T}$ to $\mathrm{G}$ point 
mutation resulting in a Ser314Ala substitution. The PCR products were ligated with pMAD

440 cut with EcoRI and BamHI by Gibson assembly, resulting in pMAD-pbpl*.

\section{T25-PBP1 ${ }_{\triangle P A S T A}$}

443 A fragment encoding S. aureus pbpl without the PASTA domains (M1-S595) was PCR

444 amplified from S. aureus SH1000 genomic DNA using T25-pbp1-F and T25-pbp1pasta-R and cloned into BamHI and EcoRI cut pKT25, resulting in T25-PBP1 ${ }_{\triangle \mathrm{PASTA}}$.

\section{pVR plasmids}

448 Full-length pbp1 (M1-D744) was E. coli codon optimised, synthesised by GenScript, PCR 449 amplified using VR47F/R and cloned into KpnI and HindIII cut pOPINRSF using In-Fusion 450 cloning (Takara Bio), resulting in pVR01. Construction of pVR02 (SaPBP1, M37-D744) and pVR06 (SaPASTAPBP1, S595-D744) was performed using inverse PCR (iPCR) (Erster \& Liscovitch, 2010), pVR01 as a template and primer pairs VR49F/VR49R and

(SaPBP1 $\left.1_{\triangle \mathrm{PASTA}}, \mathrm{M} 37-\mathrm{S} 595\right)$, were constructed by QuikChange Site-Directed Mutagenesis of pVR02 using VR51 and VR53, respectively.

In order to construct an overexpression plasmid for sPBP1-BAP, A51-D744 fragment of $E$. coli codon optimised pbp1 was PCR amplified using primers OPPF20018F/OPPF20018R

460 and cloned into KpnI and SfoI cut pOPINJB by In-Fusion cloning (Takara Bio). The resulting construct, pSA50 contains an N-terminal hexahistidine-tag fused to Glutathione-S-transferase 


\section{Construction of $S$. aureus mutants}

466 All vectors were passed through a restriction-deficient S. aureus RN4220 before being

467 transduced into a final $S$. aureus SH1000 strain. Transformation and phage transduction of $S$.

468 aureus were carried out as described previously (Novick \& Morse, 1967; Schenk \& Laddaga, 469 1992).

470

\section{$\Delta p b p 1, p b p 1_{\triangle \mathrm{PASTA}}$ and $p b p 1^{*}$}

472 For construction of $p b p 1$ mutation strains, first an ectopic copy of $p b p 1$ under the control of the Pspac promoter was introduced at the lipase (geh) locus. Electrocompetent CYL316 was transformed with pKB-Pspac-pbpl. The chromosomal fragment containing the integrated plasmid was moved into $S$. aureus $\mathrm{SH} 1000$ by phage transduction, resulting in SJF4588 (S. aureus SH1000 geh::Pspac-pbp1). Next electrocompetent RN4220 was transformed with pMAD- $\Delta p b p 1$, pMAD- $p b p 1_{\triangle \mathrm{PASTA}}$ or pMAD- $p b p 1 *$ and the plasmids were moved to SJF4588 by phage transduction. Integration at $42^{\circ} \mathrm{C}$ and excision at $28^{\circ} \mathrm{C}$ of pMAD- $\Delta p b p 1$, pMAD-pbp1 $1_{\triangle \mathrm{PASTA}}$ or pMAD-pbp1*, resulted in strains SJF5116, SJF5275 and SJF4590, respectively. To allow controlled expression of $p b p 1$ from Pspac, pGL485, a multi-copy plasmid carrying lacI, was introduced creating strains $\Delta$ pbpl (S. aureus SH1000 geh::Pspac-

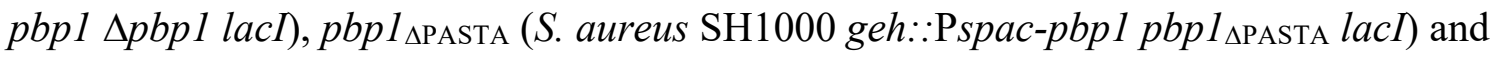
$\operatorname{pbpl}^{*}($ S. aureus SH1000 geh::Pspac-pbpl pbpl*lacl).

\section{MRSA $\triangle p b p 1$ and MRSA $p b p 1 *$}

486 In order to construct high-level $\beta$-lactam resistant mutants, $\Delta p b p 1$ and $p b p 1 *$ were

487 transformed with a phage lysate from SJF5046 (S. aureus $\mathrm{SH} 1000$ lys A::pmecA rpo ${ }^{\mathrm{H} 929 \mathrm{Q}}$ )

488 with selection for erythromycin resistance, resulting in low-level $\beta$-lactam resistant $\Delta p b p 1$ 
$\mathrm{pmec} A$ and $p b p 1^{*}$ pmecA. The low-level resistant mutants were transduced again with the

490 phage lysate from SJF5046 and selected for kanamycin resistance, resulting in MRSA $\Delta p b p 1$

491 (S. aureus SH1000 geh::Pspac-pbp1 $\Delta p b p 1$ lacI lys A::pmecA rpoB ${ }^{\mathrm{H} 929 \mathrm{Q}}$ ) and MRSA pbp1*

492 pbpl (S. aureus SH1000 geh::Pspac-pbpl pbpl * lacI lysA::pmecA rpoB $\left.{ }^{\mathrm{H} 929 \mathrm{Q}}\right)$. MIC values

493 were determined using antibiotic susceptibility tests using E-test M.I.C. Evaluator (Oxoid)

494 strips.

495

$496 \quad$ pbp3 pbp4

497 SH1000 was transduced with a phage lysate from NE420 (S. aureus JE2 pbp3::Tn) resulting in SH4421 (S. aureus SH1000 pbp3::Tn). To swap the erythromycin resistance cassette to a kanamycin cassette, SH4425 (S. aureus SH1000 pbp4::Tn) was transduced with a phage

500 lysate from NE3004 (S. aureus RN4220 pKAN). Integration at $42^{\circ} \mathrm{C}$ and excision at $28^{\circ} \mathrm{C}$ of 501 pSPC resulted in strain SH5115 (S. aureus SH1000 pbp4::kan). SH4421 was subsequently transduced with a phage lysate from SH5115 (S. aureus SH1000 pbp4::Tn) resulting in pbp3 pbp4 (SH5483; S. aureus SH1000 pbp3::Tn pbp4::kan).

\section{$\Delta p b p 1$ pbp4, pbp1 $1_{\triangle \mathrm{PASTA}} p b p 4$ and $p b p 1 * p b p 4$}

$\triangle p b p 1, p b p 1_{\triangle \mathrm{PASTA}}$ and $p b p 1^{*}$ were transduced with a phage lysate from SH5115 (S. aureus

507 SH1000 pbp $4: \because k a n)$, resulting in $\Delta p b p 1$ pbp4 (S. aureus SH1000 geh::Pspac-pbp1 $\Delta p b p 1$

508 lacI pbp $4:: k a n), p b p 1_{\triangle \mathrm{PASTA}}$ pbp 4 (S. aureus SH1000 geh::Pspac-pbp1 pbp $1_{\triangle \mathrm{PASTA}}$ lacI

509 pbp4::kan) and pbp1*pbp4 (S. aureus SH1000 geh::Pspac-pbp1 pbp1* lacI pbp4::kan),

510 respectively.

511 
pbp1*pbp4 (S. aureus SH1000 geh::Pspac-pbp1 pbp1*lacI pbp4::kan) was transduced with

514 a phage lysate from SH4421 (S. aureus SH1000 pbp3::Tn), resulting in pbp1* pbp3 pbp4 (S. aureus SH1000 geh::Pspac-pbp1 pbp1*lacI pbp3::Tn pbp4::kan).

516

\section{$\triangle p b p 1 e z r A-g f p, p b p 1_{\triangle \mathrm{PASTA}} e z r A-g f p$ and $p b p 1^{*} e z r A-g f p$}

$\Delta p b p 1, p b p 1_{\triangle \mathrm{PASTA}}$ and $p b p 1^{*}$ were transduced with a phage lysate from JGL227 (S. aureus

SH1000 ezrA-gfp+), resulting in $\Delta p b p 1$ ezrA-gfp (S. aureus SH1000 geh::Pspac-pbp1 $\Delta p b p 1$ lacI ezrA-gfp) and pbp1* ezrA-gfp (S. aureus SH1000 geh::Pspac-pbp1 pbpl* lacI ezrA-gfp), respectively.

$\triangle p b p 1 \operatorname{tar} O, p b p 1_{\triangle \mathrm{PASTA}} \operatorname{tarO}$ and $p b p 1 * \operatorname{tar} O$

$\Delta p b p 1, p b p 1_{\triangle \mathrm{PASTA}}$ and $p b p 1^{*}$ were transduced with a phage lysate from $\operatorname{tar} O \operatorname{tar} O+(S$.

geh::Pspac-pbpl pbpl* lacI $\Delta$ tarO::ery), respectively.

\section{PBP1 depletion}

532 Pspac-pbpl strains were grown from an $\mathrm{OD}_{600}$ of 0.1 to exponential phase $\left(\mathrm{OD}_{600} \sim 0.5\right)$ in

533 TSB containing $10 \mu \mathrm{g} \mathrm{ml}^{-1}$ chloramphenicol and $50 \mu \mathrm{M}$ IPTG. Cells were washed three

534 times by centrifugation and resuspension in TSB. Washed cells were then used to inoculate

535 TSB $10 \mu \mathrm{g} \mathrm{ml}^{-1}$ chloramphenicol. Cultures were inoculated to an $\mathrm{OD}_{600} 0.05$ for phenotypic studies and an $\mathrm{OD}_{600} 0.005$ for growth studies. For phenotypic analysis, cultures were 
were grown in TSB supplemented with $10 \mu \mathrm{g} \mathrm{ml}^{-1}$ chloramphenicol and $1 \mathrm{mM}(50 \mu \mathrm{M}$, ezrA$g f p$ mutants) IPTG.

540 For the plating efficiency test, cells grown in the presence of $10 \mu \mathrm{g} \mathrm{ml}^{-1}$ chloramphenicol and dilutions of washed cells were plated on TSB $10 \mu \mathrm{g} \mathrm{ml}^{-1}$ chloramphenicol with or without 1 mM IPTG. Relative plating efficiency $(\% C F U)$ is expressed as the number of cells that grow on plates without IPTG $\left(C F U_{\text {no IPTG }}\right)$ to cells that grow in the presence of IPTG $\left(C F U_{I P T G}\right)$ multiplied by $100 \%$ :

$$
\% C F U=\frac{C F U_{\text {no IPTG }}}{C F U_{I P T G}} \times 100 \%
$$

\section{Meropenem activity assays}

549 S. aureus strains were grown overnight in TSB. The overnight cultures were used to inoculate

550 fresh TSB media to an $\mathrm{OD}_{600}$ of 0.05 . When cells reached an $\mathrm{OD}_{600}$ of $0.2-0.4$, meropenem

551 was added, and the change of bacterial count was monitored. The colony-forming units per

$552 \mathrm{ml}$ of culture $(\mathrm{CFU} / \mathrm{ml})$ measures were normalized to the initial $\mathrm{CFU} / \mathrm{ml}$ at the time of the

553 antibiotic addition, at time zero $\left(t_{0}\right)$.

$$
\text { Relative } C F U / m l=\frac{C F U / m l_{t n}}{C F U / m l_{t 0}}
$$

For phenotypic analysis, cells were treated for $1 \mathrm{~h}$ with 1x MIC meropenem before microscopy imaging.

\section{Fractionation of $S$. aureus membranes}

559 The membrane fraction of $S$. aureus was prepared as previously described (García-Lara et al.,

5602015 ) with the following modifications. S. aureus cells grown to the appropriate growth

561 phase were recovered by centrifugation $\left(5,000 \mathrm{xg}, 10 \mathrm{~min}, 4^{\circ} \mathrm{C}\right)$, washed three times by 
resuspension and centrifugation $\left(5,000 \mathrm{xg}, 10 \mathrm{~min}, 4^{\circ} \mathrm{C}\right)$ in PBS. Cells were resuspended in

563 TBSI and broken using $0.1 \mathrm{~mm}$ silica spheres (Lysing Matrix B) and FastPrep Homogenizer

564 (MP Biomedicals) in 12 cycles of $30 \mathrm{~s}$, at maximum speed $\left(6.5 \mathrm{~m} \mathrm{~s}^{-1}\right)$, with 5 min incubation

565 on ice between cycles. Cell lysates were centrifuged $\left(5,000 \mathrm{x} \mathrm{g}, 10 \mathrm{~min}, 4^{\circ} \mathrm{C}\right)$ to remove

566 unbroken cells. The supernatant was then spun $\left(5,000 \mathrm{xg}, 10 \mathrm{~min}, 4^{\circ} \mathrm{C}\right)$ to sediment cell wall

567 material. The membrane fraction was recovered from the supernatant by centrifugation

$568\left(35,000 \mathrm{x} \mathrm{g}, 20 \mathrm{~min}, 4^{\circ} \mathrm{C}\right)$ and the pellet (membranes) was resuspended in PBS. The total

569 protein concentration was estimated by Bradford assay.

\section{In vitro labelling of $S$. aureus $\mathrm{PBPs}$ with BocillinFL}

572 This method was adopted from a published protocol (Zhao et al., 1999) with minor modifications. Membrane proteome samples (25 $\mu \mathrm{g}$ in $20 \mu \mathrm{l}$ PBS $)$ and purified proteins $(2.5$ $\mu \mathrm{g}$ in $25 \mu$ l HEPES pH $7.5150 \mathrm{mM} \mathrm{NaCl}$ ) were incubated with $25 \mu \mathrm{M}$ BocillinFL (Invitrogen) for $20 \mathrm{~min}$ at $37^{\circ} \mathrm{C}$. Additionally for competition assay, purified $\mathrm{SaPBP} 1$ was mixed with $2.5 \mu \mathrm{g}\left(\sim 286 \mu \mathrm{M}\right.$ final concentration) ampicillin and incubated at $37^{\circ} \mathrm{C}$ for 10 min prior to the addition of BocillinFL. The reaction was stopped by the addition of $5 \mathrm{x}$ SDSPAGE loading buffer. Membrane proteome was additionally incubated for $10 \mathrm{~min}$ at $90^{\circ} \mathrm{C}$. The samples were run on a $6-20 \%(\mathrm{w} / \mathrm{v})$ SDS-PAGE gradient or 10\% (w/v) SDS-PAGE gel and visualized using a BioRad ChemiDoc MP Imaging system or a GE Typhoon FLA 9500.

\section{Labelling $S$. aureus DAAs}


Click chemistry

588 ADA-DA containing an azide functional group was fluorescently labelled with Alexa Fluor 488 Alkyne at $5 \mu \mathrm{g} \mathrm{ml}^{-1}$ via the Click reaction (copper (I)-catalysed alkyne-azide

590 cycloaddition). This was carried out using the Click-iT Cell Reaction Buffer Kit

591 (ThermoFisher) according to the manufacturer's protocol.

592

\section{Labelling $S$. aureus with fluorescent NHS-ester}

594 Fixed cells wells were resuspended in PBS containing $8 \mu \mathrm{g} \mathrm{ml}{ }^{-1}$ Alexa Fluor 555 NHS ester

595 (Invitrogen) and incubated at room temperature for $30 \mathrm{~min}$. Cells were washed twice by

596 centrifugation and resuspension in PBS.

597

598

Fixing for fluorescence microscopy

599 Cells were fixed by incubation in $1.6 \%(\mathrm{w} / \mathrm{v})$ paraformaldehyde at room temperature for 30 $600 \quad \min$.

601

\section{Fluorescence microscopy}

603 Fixed cells were dried onto a poly-1-Lysine coated slide, mounted in PBPS and imaged on a

604 Nikon Ti Inverted microscope fitted with a Lumencor Spectra X light engine. Images were 605 taken using a 100x PlanApo (1.4 NA) oil objective using 1.518 RI oil and detected by an 606 Andor Zyla sCMOS camera.

607

\section{Cell volume estimation}

609 Cell volume calculations were carried out as previously described (Zhou et al., 2015). The

610 long and short axis of cells were measured using Fiji. The volume was then calculated based 611 on a prolate spheroid shape with volume: 


$$
V=\frac{4}{3} \pi a b^{2}
$$

613 where $a$ and $b$ are the radii along the long and short axis, respectively.

614

\section{Transmission electron microscopy}

616 S. aureus strains were prepared for electron microscopy as previously described (Sutton et

617 al., 2021).

618

\section{Preparation of $\boldsymbol{S}$. aureus sacculi}

620 Peptidoglycan from $S$. aureus cells was extracted and if required HF treated to remove cell 621 wall polymers as previously described (Sutton et al., 2021).

622

\section{Sacculi immobilisation for AFM Imaging}

624 Immobilisation surface was prepared by adding the solution mixed by $171 \mu \mathrm{L} 100 \mathrm{mM}$

$625 \mathrm{NaHCO}_{3}, 3 \mu \mathrm{l}$ of $1 \mathrm{M} \mathrm{NaOH}$ and $6 \mu \mathrm{l}$ of Cell-Tak (Corning, 5\% (w/v) in acetic acid) on 626 freshly cleaved mica. After 30 min incubation, the surface was washed by $5 \times 200 \mu 1$ HPLC

627 grade water. Sacculi stocks were 10 times diluted in HPLC grade water and briefly tip628 sonicated to re-suspend in prior to immobilisation. $10 \mu \mathrm{l}$ of the sacculi suspension was added 629 to $40 \mu \mathrm{l}$ of HPLC grade water on the Cell-Tak immobilisation surface and incubated for $1 \mathrm{~h}$.

630 The surface was then thoroughly rinsed with HPLC grade water, blow-dried with nitrogen 631 and stored in petri-dish at room temperature before AFM imaging.

632

633 AFM Imaging and image analysis

634 AFM imaging was carried out on a Nanowizard III ULTRA Speed system (JPK, Germany).

635 Rectangular cantilevers with nominal spring constant of $0.3 \mathrm{~N} / \mathrm{m}$ and resonant frequency (in 636 liquid) of $\sim 150 \mathrm{kHz}$ (USC-F0.3-k0.3, NanoWorld, Switzerland) were used. The spring 
constant and deflection sensitivity of each cantilever was calibrated prior to each and $10 \mathrm{mM}$ Tris. Scans were driven at a line rate of $\sim 0.78 \mathrm{~Hz}$, with a typical $\mathrm{Z}$ length of 300

$641 \mathrm{~nm}$ and trigger force of $20 \mathrm{nN}$.

642 Resultant topographic images were processed using JPK Data Processing. No flattening or surface subtraction was applied. High pass filter (scale: 100\% to 500\%, degree of smoothing: $5 \mathrm{px}$, horizontal) was applied to the higher magnification images to enhance the contrast without modifying the morphological features. The morphological features of sacculi were summarised from images obtained on abundant technical repeats of 2 biological replicates.

\section{Recombinant protein production and purification}

E. coli BL21(DE3) cells containing plasmid pSA50 were grown in LB medium supplemented with $100 \mu \mathrm{g} \mathrm{ml}^{-1}$ ampicillin at $37^{\circ} \mathrm{C}$ to an $\mathrm{OD}_{578}$ of 0.5 . Protein overproduction was induced by addition of $0.5 \mathrm{mM}$ IPTG to the cell culture and further incubation for $4 \mathrm{~h}$ at $30^{\circ} \mathrm{C}$. Cells were harvested by centrifugation $\left(6,200 \mathrm{x} \mathrm{g}, 15 \mathrm{~min}, 4^{\circ} \mathrm{C}\right)$ and the pellet was resuspended in basic buffer (25 mM Tris-HCl, $100 \mathrm{mM} \mathrm{NaCl,} \mathrm{pH} \mathrm{7.5).} \mathrm{After} \mathrm{addition} \mathrm{of} 1 \mathrm{mM}$ PMSF, 1:1,000 dilution of protease inhibitor cocktail (Sigma-Aldrich) and DNase, the cells were disrupted by sonication (Branson Digital Sonifier). The cell lysate was centrifuged (130,000 $\mathrm{x} \mathrm{g}, 60 \mathrm{~min}, 4^{\circ} \mathrm{C}$ ) and the supernatant was recovered. The supernatant was incubated with NiNTA Superflow (Qiagen) for $2 \mathrm{~h}$ at $4^{\circ} \mathrm{C}$ with gentle stirring, which had been pre-equilibrated in basic buffer. The resin was poured into a gravity column and washed with 20 volumes of wash buffer (25 mM Tris- $\mathrm{HCl}, 150 \mathrm{mM} \mathrm{NaCl}, 10 \%$ (v/v) glycerol, $10 \mathrm{mM} \mathrm{MgCl} 2,20 \mathrm{mM}$

661 imidazole, $\mathrm{pH} 7.5$ ). Bound protein was eluted with elution buffer ( $25 \mathrm{mM}$ Tris-HCl, $150 \mathrm{mM}$ 
$662 \mathrm{NaCl}, 10 \%$ (v/v) glycerol, $10 \mathrm{mM} \mathrm{MgCl} 2,600 \mathrm{mM}$ imidazole, $\mathrm{pH}$ 7.5). $10 \mathrm{U} \mathrm{ml}-1$ of HRV-

663 3C protease (Takara) were added to the Ni-NTA eluted protein to remove the oligohistidine-

664 GST-tag during dialysis against $3 \mathrm{~L}$ of dialysis buffer I (25 mM Tris- $\mathrm{HCl}, 150 \mathrm{mM} \mathrm{NaCl}, 10$

$665 \mathrm{mM}$ EGTA, $10 \%(\mathrm{v} / \mathrm{v})$ glycerol, $\mathrm{pH} 7.5)$ for $20 \mathrm{~h}$ at $4^{\circ} \mathrm{C}$. Digested protein was dialysed

666 against $3 \mathrm{~L}$ of dialysis buffer II ( $25 \mathrm{mM}$ Tris- $\mathrm{HCl}, 150 \mathrm{mM} \mathrm{NaCl}, 10 \mathrm{mM} \mathrm{MgCl}, 10 \%$ (v/v)

667 glycerol, $\mathrm{pH} 7.5$ ), for $3 \mathrm{~h}$ at $4^{\circ} \mathrm{C}$. The protein was incubated in the same Ni-NTA beads (pre-

668 equilibrated in dialysis buffer II) for $2 \mathrm{~h}$ at $4^{\circ} \mathrm{C}$ to remove the contaminants and the His-GST

669 tag from the sample. The flow through and the washes (2 volume of wash buffer) were

670 pooled, dialysed against storage buffer (25 mM HEPES-NaOH, $150 \mathrm{mM} \mathrm{NaCl}, 10 \mathrm{mM}$

$671 \mathrm{MgCl}_{2}, 10 \%$ (v/v) glycerol, $\left.\mathrm{pH} 7.5\right)$ and concentrated using a Vivaspin Turbo 15 column

672 (MWCO $50000 \mathrm{Da})$.

673

674 SaPBP1, SaPBP1*, SaPBP1 ${ }_{\triangle \mathrm{PASTA}}$ and SaPASTAPBP1

675 All recombinant proteins were produced in E. coli Rosetta (DE3) cells at $37^{\circ} \mathrm{C}$ in $\mathrm{TB}$ medium supplemented with $50 \mu \mathrm{g} \mathrm{ml}^{-1}$ kanamycin and $30 \mu \mathrm{g} \mathrm{ml}^{-1}$ chloramphenicol. Once cultures had reached $\mathrm{OD}_{600} 0.9$, protein expression was induced with $1 \mathrm{mM}$ IPTG for $20 \mathrm{~h}$ at $20^{\circ} \mathrm{C}$. Cells were harvested by centrifugation $\left(4,000 \mathrm{x} \mathrm{g}\right.$ at $4^{\circ} \mathrm{C}$ for $\left.30 \mathrm{mins}\right)$ and the pellet was resuspended in a buffer of $50 \mathrm{mM}$ Tris- $\mathrm{HCl} \mathrm{pH} 8.0,500 \mathrm{mM} \mathrm{NaCl}, 20 \mathrm{mM}$ imidazole

680 supplemented with one EDTA-free protease inhibitor cocktail tablet (Roche) and DNAse (4 $681 \mu \mathrm{g} \mathrm{ml}^{-1}$ final concentration). Cells in this resuspension were lysed by two passes through a 682 One-Shot cell disruptor (Constant Systems) at $23 \mathrm{kpsi}$ and the cell debris was removed by centrifugation $\left(40,000 \mathrm{xg}\right.$ at $4^{\circ} \mathrm{C}$ for $\left.30 \mathrm{~min}\right)$. The first purification step was affinity

684 chromatography with a $5 \mathrm{~mL}$ HisTrap ${ }^{\mathrm{TM}} \mathrm{FF}$ column (GE Healthcare) precharged with $\mathrm{Ni}^{2+}$ 685 and equilibrated in buffer A (50 mM Tris-HCl, $\mathrm{pH} 8.0,500 \mathrm{mM} \mathrm{NaCl}, 20 \mathrm{mM}$ imidazole). A 
$\mathrm{mM}$ Tris- $\mathrm{HCl}, \mathrm{pH} 8.0,500 \mathrm{mM} \mathrm{NaCl}, 800 \mathrm{mM}$ imidazole). Further purification was carried out by size exclusion chromatography using a Superdex ${ }^{\mathrm{TM}} 200$ Hi Load 16/60 column (GE Healthcare). Proteins were eluted with SEC buffer (25 mM Tris-HCl, $\mathrm{pH} 8.0,150 \mathrm{mM} \mathrm{NaCl})$ and analysed by SDS-PAGE.

691

\section{Generation of anti-PBP1 antibody}

693 Serum against sPBP1A-BAP was produced from rabbits following a 28-day immunisation 694 program at Eurogentec (Belgium), and it was purified as previously described (Bertsche et 695 al., 2006).

\section{Immunoblot analysis}

698 S. aureus cultures were washed three times by resuspension and centrifugation $(5,000 \mathrm{x}$ g, 10 $\left.699 \mathrm{~min}, 4^{\circ} \mathrm{C}\right)$ in PBS. Cells were resuspended in TBSI (50 mM Tris, $100 \mathrm{mM} \mathrm{NaCl}, \mathrm{pH}$ 8, plus

700 Complete Protease Inhibitor Cocktail, Roche) and broken using $0.1 \mathrm{~mm}$ silica spheres

701 (Lysing Matrix B) and FastPrep Homogenizer (MP Biomedicals) in 12 cycles of $30 \mathrm{~s}$, at maximum speed $\left(6.5 \mathrm{~m} \mathrm{~s}^{-1}\right)$, with 5 min incubation on ice between cycles. Cell lysates were centrifuged $\left(5,000 \mathrm{x} \mathrm{g}, 10 \mathrm{~min}, 4^{\circ} \mathrm{C}\right)$ to remove unbroken cells. $\sim 60 \mu \mathrm{g}$ of total protein was separated on a $12 \%(\mathrm{w} / \mathrm{v})$ SDS-PAGE gel and electroblotted onto a nitrocellulose membrane and blocked in 5\% (w/v) skimmed-milk in TBST (20 mM Tris-HCl, $\mathrm{pH} 7.6 ; 17 \mathrm{mM} \mathrm{NaCl}$, $0.1 \%(\mathrm{v} / \mathrm{v})$ Tween-20). The membrane blocked in 5\% (w/v) skimmed-milk in TBST $(20 \mathrm{mM}$

707 Tris- $\mathrm{HCl}, \mathrm{pH} 7.6 ; 17 \mathrm{mM} \mathrm{NaCl}, 0.1 \%$ (v/v) Tween-20) was incubated with primary polyclonal anti-PBP1 $(1: 1,000)$ overnight with gentle agitation at $4{ }^{\circ} \mathrm{C}$. Primary antibodies were detected using horseradish peroxidase-conjugated goat anti-rabbit $\operatorname{IgG}(1: 10,000$,

710 BioRad) and Clarity Western ECL Substrate (BioRad) reagent according to the 

XX9.

\section{Crystallisation, data collection and structure determination}

715 Crystallisation of $\mathrm{SaPASTAPBP1}$ was carried out at $20^{\circ} \mathrm{C}$ by the sitting-drop vapour diffusion method in 96-well MRC plates (Molecular Dimensions) with a Mosquito crystallisation robot

717 (TTP LabTech) and commercial crystallisation screens (Hampton Research and Molecular

718 Dimensions). Orthorhombic crystals of diffraction quality, with a maximum dimension of approximately $500 \mu \mathrm{m}$, appeared overnight from a mixture of equal volumes of protein solution (42 mg ml-1 in $25 \mathrm{mM}$ Tris- $\mathrm{HCl}, \mathrm{pH} 8.0,150 \mathrm{mM} \mathrm{NaCl})$ and reservoir solution $(0.2$ $\mathrm{M} \mathrm{NaCl}, 0.1 \mathrm{M}$ sodium/potassium phosphate $\mathrm{pH}$ 6.2, $50 \%$ (v/v) PEG 200). Diffraction data were indexed and integrated using XDS (Kabsch, 2010) and scaled using AIMLESS (Evans \& Murshudov, 2013) from the CCP4 program suite (Winn et al., 2011). The crystals display space group $P 2{ }_{1}{ }_{1} 2_{1}$ with unit cell lengths $a=39.8 \AA, b=81.4 \AA$ and $c=89.6 \AA$. The asymmetric unit consists of two polypeptide chains with an estimated solvent content of $45 \%$ and a $V_{m}$ of $2.24 \AA^{3} / \mathrm{Da}$. The region corresponding to the two PASTA domains in the crystal structure of S. pneumoniae PBP2x (PBP 5OAU) was used as a molecular replacement search model, sharing approximately $26 \%$ sequence identity with $S a$ PASTAPBP1. The search model was generated using phenix.sculptor (Bunkóczi \& Read, 2011) to remove nonmacromolecular chains and prune sidechains. The structure was solved by molecular replacement using PHASER (McCoy et al., 2007) and the resultant electron density map was of high quality, allowing the tracing of the main chain. Model building and refinement were carried out with Coot (Emsley et al., 2010) and Phenix (Liebschner et al., 2019), respectively.

734 Assessments of the geometry and validation of the final model was carried out using

735 Molprobity (Chen et al., 2010). Analyses of surface areas and interactions were made using 
the PISA web service (Krissinel \& Henrick, 2007). The graphics program PyMOL

737 (Schrödinger, LLC, 2015) was used to generate all molecular figures presented.

738

\section{Cell wall binding assays}

740 Cell wall binding assays of recombinant PBP1 proteins fluorescently labelled with Cy2 bisreactive dye (GE Healthcare) were performed as previously described (Bottomley et al., 2014).

\section{Bacterial two-hybrid}

745 Competent BTH101 was co-transformed with pKT25 and pUT18 derivatives. Transformants were selected on LB agar plates containing $100 \mu \mathrm{g} \mathrm{ml}^{-1}$ ampicillin, $50 \mu \mathrm{g} \mathrm{ml}^{-1}$ kanamycin and $40 \mu \mathrm{g} \mathrm{ml}^{-1} \mathrm{X}-\mathrm{Gal}$ and incubated at $30^{\circ} \mathrm{C}$. Single colonies were grown in $150 \mu \mathrm{LB}$ with $100 \mu \mathrm{g} \mathrm{ml} \mathrm{l}^{-1}$ ampicillin, $50 \mu \mathrm{g} \mathrm{m} \mathrm{m}^{-1}$ kanamycin and $0.5 \mathrm{mM} \mathrm{IPTG}$ at $30^{\circ} \mathrm{C}$.

To qualitatively measure for pairwise interactions, $5 \mu 1$ of each overnight culture were spotted onto LB agar plates containing $100 \mu \mathrm{g} \mathrm{ml}^{-1}$ ampicillin, $50 \mu \mathrm{g} \mathrm{ml}^{-1}$ kanamycin, $0.5 \mathrm{mM}$ IPTG and $40 \mu \mathrm{g} \mathrm{ml} \mathrm{g}^{-1} \mathrm{X}-\mathrm{Gal}$. Plates were incubated at $30^{\circ} \mathrm{C} 24-48 \mathrm{~h}$ in an environment protected from light and imaged. To quantify interactions, overnight cultures were assayed for $\beta$ galactosidase activity against MUG (4-methylumbelliferyl- $\beta$-d-galactopyranoside) using an assay as previously described (Steele et al., 2011).

\section{Acknowledgements}

757 This work was funded by the Medical Research Council (MR/N002679/1; MR/K015753/1),

758 UKRI Strategic Priorities Fund (EP/T002778/1) and the Wellcome Trust (212197/Z/19/Z).

759 L.L. thanks The Florey Institute for her PhD studentship. We gratefully acknowledge the 760 Wolfson Light Microscopy facility for their support and assistance in this work. We thank 
761 Diamond Light Source for access to beamline I24 (mx18598) and Arnaud Baslé for data

762 collection, help with figure generation and support. We are grateful to Joshua Sutton, Grace

763 Pidwill, Victoria Lund, Laia Pasquina-Lemonche and Christopher Hill for help and advice.

764

765 Competing Interests

766 The authors declare no competing interests. 


\section{Figures and figure legends}

768

a

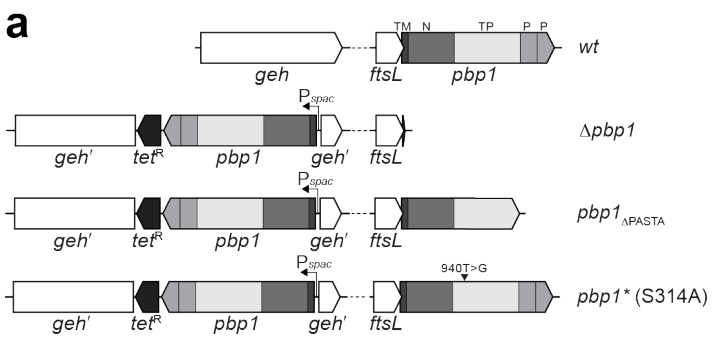

C

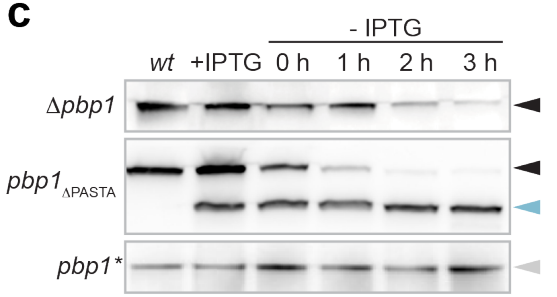

b
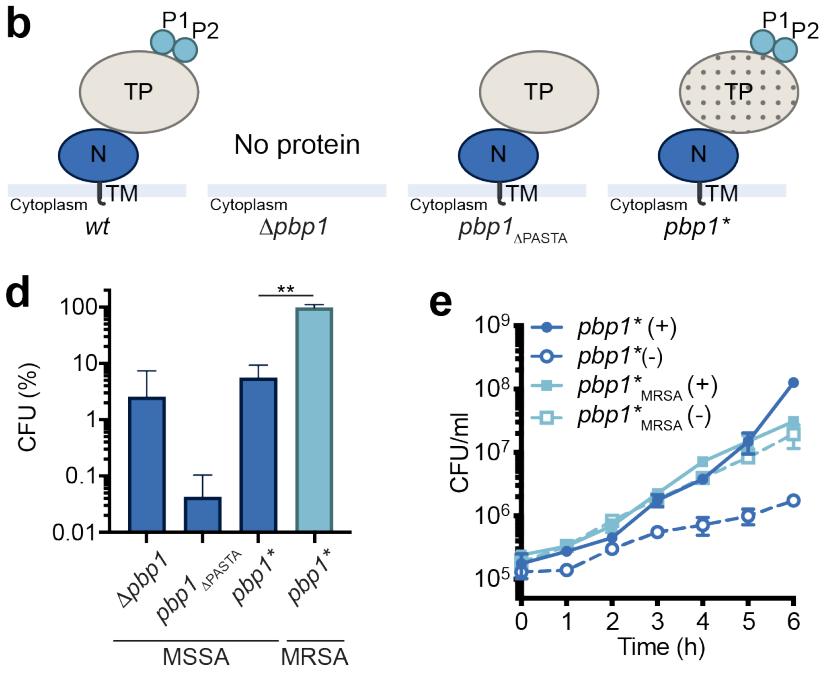

e

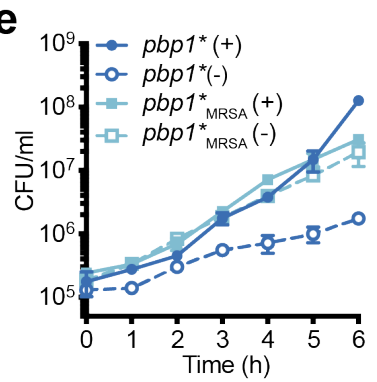

\section{Fig. 1 Essentiality of PBP1}

a, Schematic representation of genetic constructs used in this study. In S. aureus WT (wt) the

$5^{\prime}$ end of $p b p l$ overlaps with the $3^{\prime}$ of $f t s L$. The $p b p 1$ gene encodes a protein containing the

PASTA domains (P1 and P2). In the mutants, an ectopic copy of $p b p 1$ is placed under the control of the Pspac promoter at the lipase (geh) locus, whereas the gene in the native pbpl locus is either deleted ( $\Delta p b p 1)$, has $\mathrm{P} 1$ and $\mathrm{P} 2$ domains removed ( $\left.p b p 1_{\triangle \mathrm{PASTA}}\right)$, or has a point mutation which results in inactivation of the TP domain $\left(p b p 1^{*}\right)$.

b, Schematic representation of domain architecture of PBP1 in S. aureus WT (wt) and PBP1

779 forms produced by $\Delta p b p 1, p b p 1_{\triangle \mathrm{PASTA}}$ and $p b p 1^{*}$ mutants in the absence of inducer. The TP domain inactivation is shown by dotted shading.

c, Immunoblot showing PBP1 levels in SH1000 lacI (wt) and in $\Delta p b p 1, p b p 1_{\triangle \mathrm{PASTA}}$ and pbpl* grown with IPTG (+IPTG) and for $0,1,2$ and $3 \mathrm{~h}$ without inducer (-IPTG) analysed using anti-PBP1 antibody. Expected sizes: PBP1 and PBP1* $=83 \mathrm{kDa}$ (black and grey arrowheads, respectively) and $\mathrm{PBP} 1_{\triangle \mathrm{PASTA}}=67 \mathrm{kDa}$ (light blue arrowhead). 
$786\left(p b p 1^{*}{ }_{\mathrm{MRSA}}\right)$ cells upon inducer removal compared to the control groups grow in the presence

787 of inducer. $P$ value was determined by Mann-Whitney $U$ tests. $P=0.0043(* *, P<0.01)$.

788 Data represent mean $\pm \mathrm{SD}$.

789

e, Growth curves of $p b p 1^{*}(\mathrm{MSSA})$ and MRSA $p b p 1^{*}\left(p b p 1^{*}{ }_{\mathrm{MRSA}}\right)$ in the presence $(+)$ or

790 absence (-) of IPTG. Data represent mean \pm SD. Error bars that are smaller than the symbols

791 are not shown.

792

793 Data are representative of three (c, e) and at least four (d) independent experiments. 
a

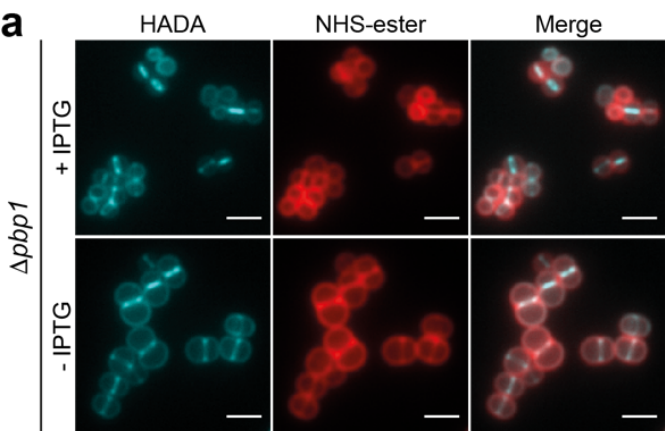

HADA
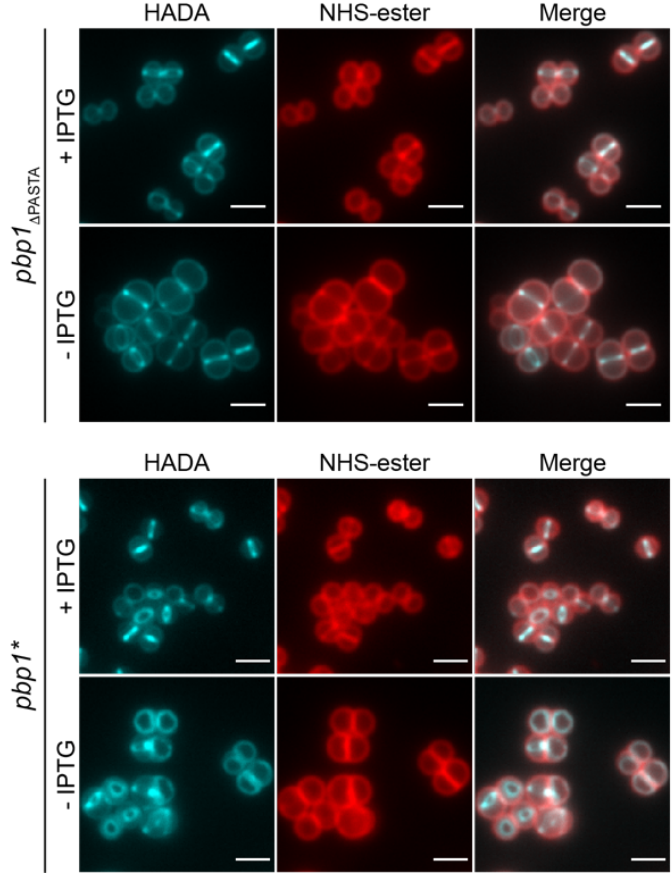

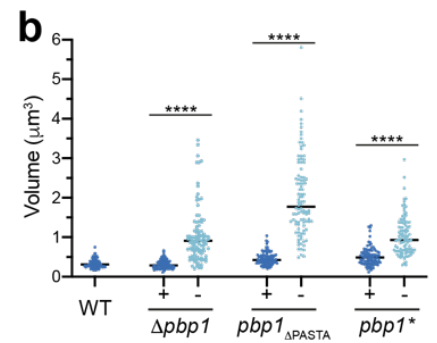

d
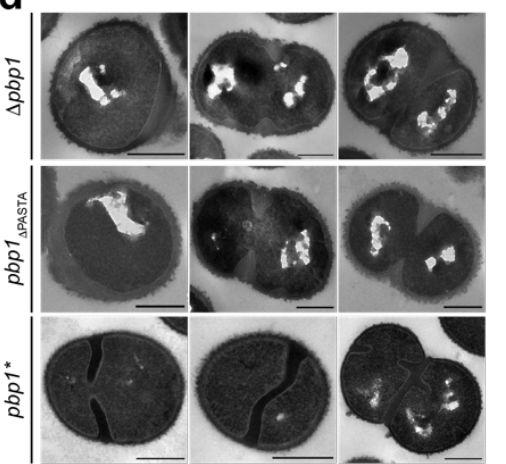

f

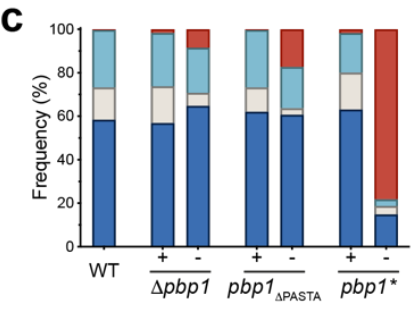

$\square$ Incomplete $\square$ Complete $\square$ No septum septum septum
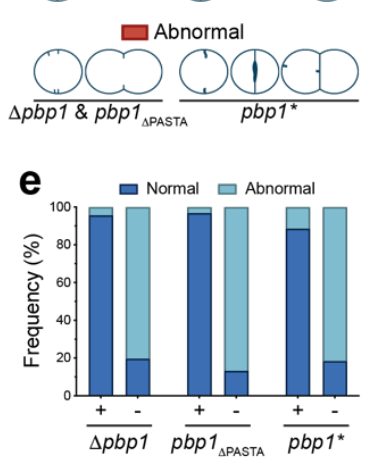

$p b p 1^{*}$

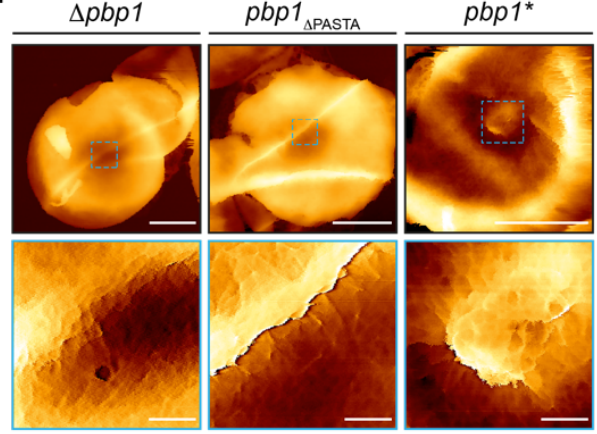

795 Fig. 2 The role of PBP1 in cell division and PG synthesis in S. aureus.

796 a, $\Delta p b p 1, p b p 1_{\triangle \mathrm{PASTA}}$ and $p b p 1^{*}$ grown with or without IPTG for $2 \mathrm{~h}$, incubated with HADA

797 for 5 min to show nascent PG, and counter-labelled with NHS-ester Alexa Fluor 555 to

798 image the cell wall. Images are average intensity projections of $z$ stacks. Scale bars $2 \mu \mathrm{m}$.

799 b, Cell volumes of WT (wt), $\Delta p b p 1, p b p 1_{\triangle \mathrm{PASTA}}$ and $p b p 1^{*}$ grown with $(+)$ or without (-)

800 IPTG for $2 \mathrm{~h}$ as measured by fluorescence microscopy after NHS-ester Alexa Fluor 555

801 labelling. Each dot represents a single cell. The median of each distribution is indicated by a

802 black line. The number of cells analysed for each mutant and condition was $n \geq 100$. $P$ value

803 was determined by Mann-Whitney $U$ tests $(* * * *, P<0.0001)$. From left to right: $P=3.033 \mathrm{e}-$

$804033,4.670 \mathrm{e}-049$ and 2.206e-022; $n=100,101,100,101,100,100$ and 101. 
c, Quantification of cellular phenotypes for WT (wt), $\Delta p b p 1, p b p 1_{\triangle \mathrm{PASTA}}$ and $p b p 1^{*}$ based on

806 HADA incorporation (Fig. 2a) after incubation with (+) or without (-) IPTG for 2 h. From left

807 to right $n=370,427,332,314,364,512$ and 331 .

808 d, TEM of $\Delta p b p 1, p b p 1_{\triangle \mathrm{PASTA}}$ and $p b p 1^{*}$ grown for $2 \mathrm{~h}$ in the absence of inducer. Scale bars

$809500 \mathrm{~nm}$.

$810 \mathbf{e}$, Quantification of cellular phenotypes based on TEM data of $\Delta p b p 1, p b p 1_{\triangle \mathrm{PASTA}}$ and $p b p 1^{*}$

811 grown for $2 \mathrm{~h}$ in the presence $(+)$ or absence (-) of IPTG. Examples of cells classified as

812 normal (blue) are shown in Fig. 2 - figure supplement 2b. Cells with abnormal phenotypes

813 (light blue) are shown in Fig. 2d and Fig. 2 - figure supplement 2c. From left to right $n=$

$814391,329,314,377,263$ and 302.

815 f, AFM topographic images of internal surface of purified sacculi from $\Delta p b p 1, p b p 1_{\triangle \mathrm{PASTA}}$

816 and $p b p l *$ grown in the absence of inducer for $2 \mathrm{~h}$. Sacculi (top images, scale bars $500 \mathrm{~nm}$,

817 data scales $(z): 450,300$ and $100 \mathrm{~nm}$ from left to right, respectively) and higher magnification

818 images (bottom images, scale bars $50 \mathrm{~nm}$, data scales $(z): 70,100$ and $50 \mathrm{~nm}$ from left to right

819 respectively) scanned within the boxed areas from the top images.

820

821 Data are representative of two (d-f) and (a-c) three independent experiments. 


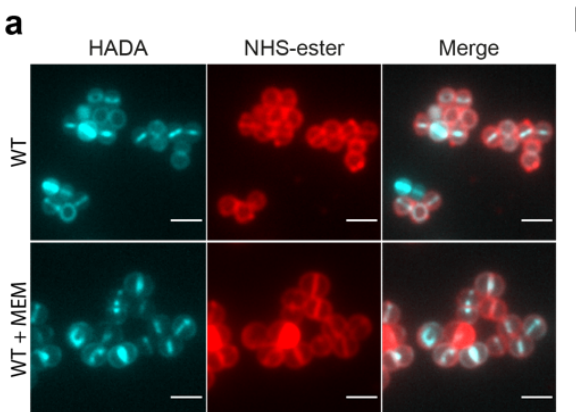

b

C

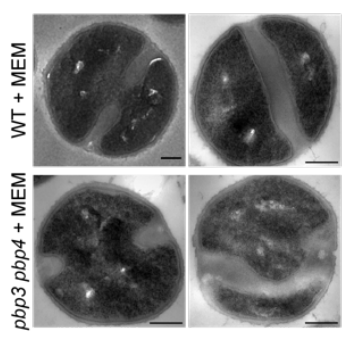

d

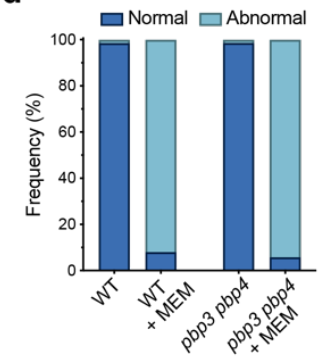

Fig. 3 Effect of meropenem (MEM), an antibiotic with high affinity for PBP1, on $S$.

aureus.

a, Fluorescence images of SH1000 WT treated with 1x MIC MEM for $1 \mathrm{~h}$, labelled with HADA for 5 min to show nascent PG and counter labelled with NHS-ester Alexa Fluor 555

827 (cell wall). Images are average intensity projections of $z$ stacks. Scale bars $2 \mu \mathrm{m}$.

b, Cell volumes of SH1000 WT and pbp3 pbp4 treated with 1x MIC MEM for $1 \mathrm{~h}$ as measured by fluorescence microscopy after NHS-ester Alexa Fluor 555 labelling (Fig. 3a).

830 Each dot represents a single cell. The median of each distribution is indicated by a black line.

831 The number of cells analysed for each condition was $n \geq 100$. $P$ value was determined by

832 Mann-Whitney $U$ tests $(* * * *, P<0.0001)$. From left to right: $P=1.276 \mathrm{e}-042$ and $1.421 \mathrm{e}-$ $024 ; n=102,100,101$ and 102 . nm.

836 d, Quantification of phenotypes of SH1000 WT and pbp3 pbp4 treated with MEM (1x MIC)

837 for $1 \mathrm{~h}$ based on TEM data (Fig. 3c and Fig. 3 - figure supplement 1e, f). Examples of cells classified as normal (blue) are shown in Fig. 3 - figure supplement 1e, f. Cells with abnormal 
839 phenotypes (light blue) are shown in Fig. 3c and Fig. 3 - figure supplement 1e, f. From left to

840 right $n=343,287,275$ and 172.

841

842 Data are representative of two ( $\mathrm{a}, \mathrm{b}$ (for WT) independent experiments. Experiments in b (for

$843 \quad$ pbp3 $p b p 4$ ) and d were performed once. 
a

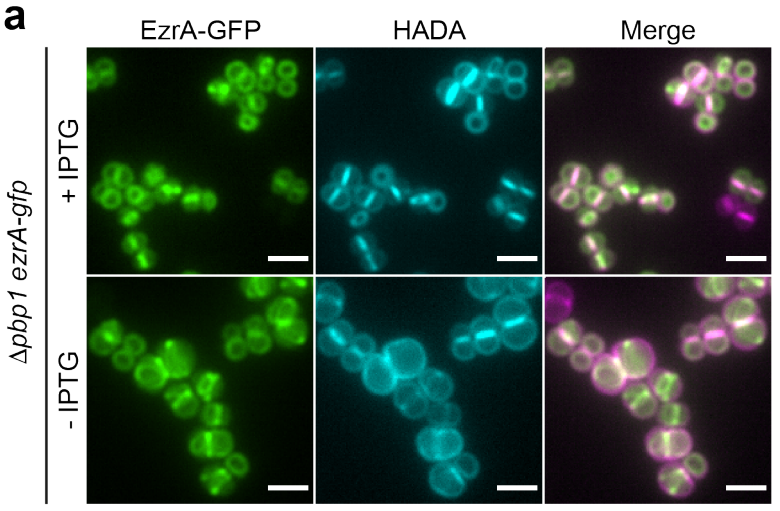

C

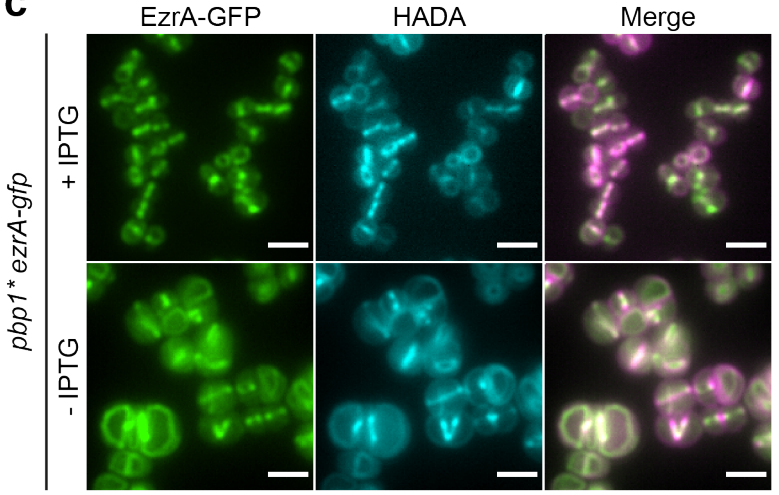

b

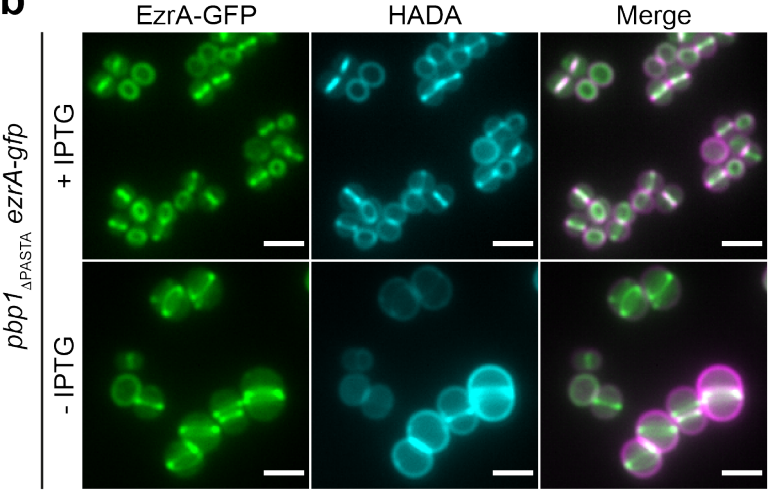

d
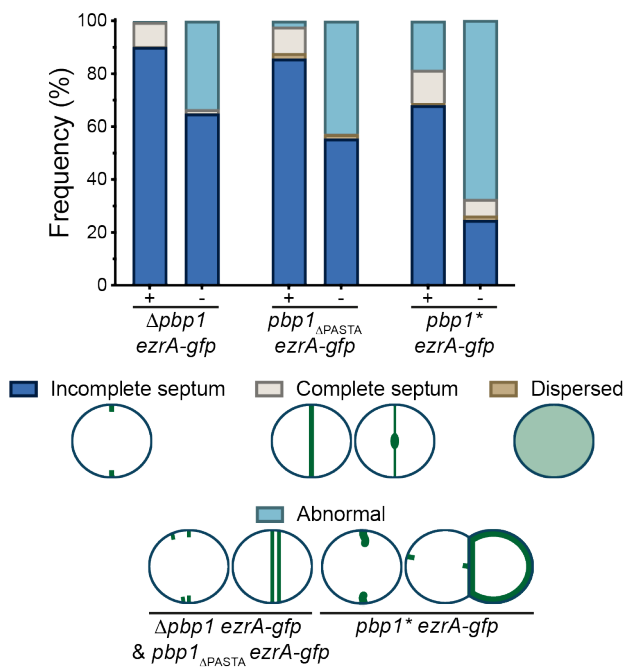

845

Fig. 4 The role of PBP1, PASTA and TP domains in EzrA localisation in S. aureus.

a-c, Localisation of EzrA-GFP in $\Delta p b p 1$ ezrA-gfp, $p b p 1_{\triangle \mathrm{PASTA}} \operatorname{ezr} A-g f p$ and $p b p 1^{*}$ ezrA-gfp

848 grown in the presence or absence of IPTG for $2 \mathrm{~h}$ and labelled with HADA for 5 min to stain

849 PG. Images are average intensity projections of $z$ stacks. Scale bars $5 \mu \mathrm{m}$.

850 d, Quantification of EzrA-GFP localisations in $\triangle p b p 1$ ezrA-gfp, $p b p 1_{\triangle \mathrm{PASTA}} e z r A-g f p$ and

$851 \quad p b p 1 *$ ezrA-gfp grown with or without IPTG. From left to right $n=395,499,481,438,360$

852 and 382 .

853

854 Data are representative of two independent experiments. 
a

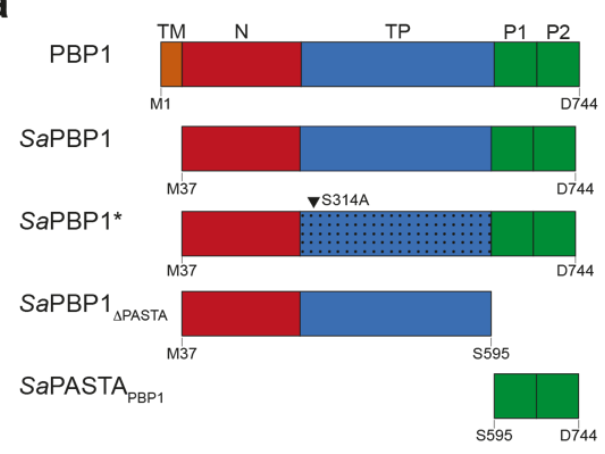

b
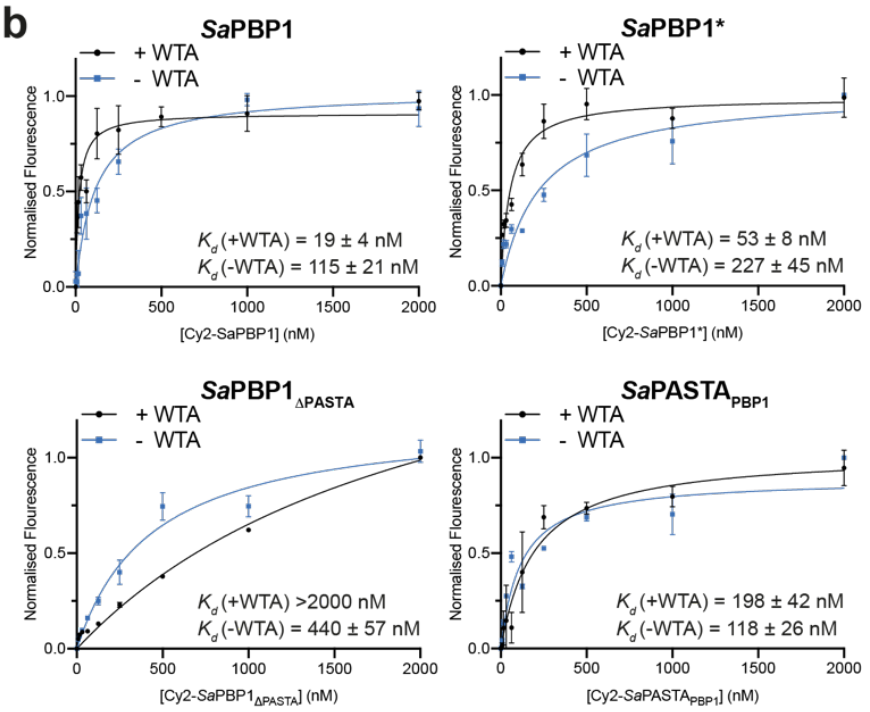

C

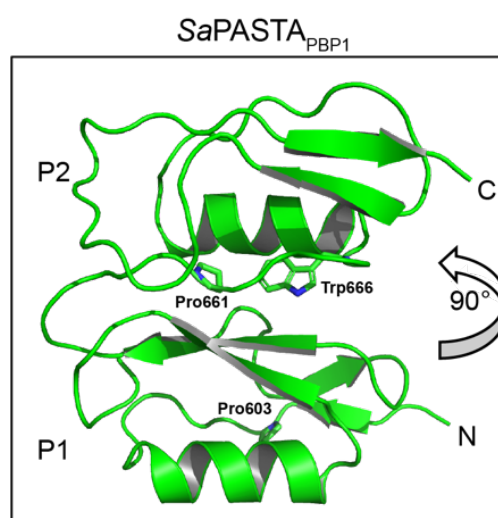

855

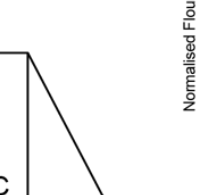

SaPBP1

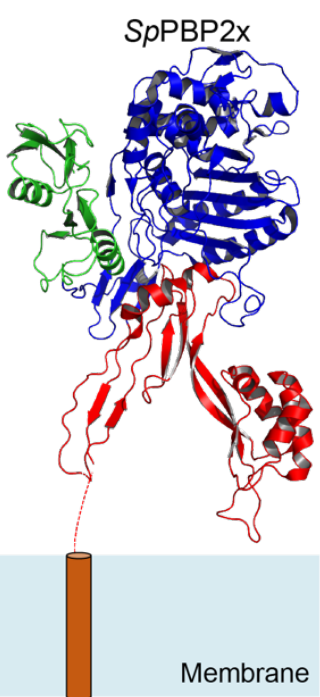

\section{Fig. 5 Role of PBP1 PASTA domains in cell wall binding}

a, Schematic representation of structural domain organization of $S$. aureus PBP1 (top) and recombinant proteins $\left(S a \mathrm{PBP} 1, S a \mathrm{PBP} 1_{\triangle \mathrm{PASTA}}, S a \mathrm{PBP} 1 *\right.$ and $\left.S a \mathrm{PAST} \mathrm{PPBP}_{1}\right)$ used in this study. TM, trans-membrane helix (orange); N, N-terminal dimerization domain (red); TP, transpeptidase domain (blue); P, PASTA domains (green). The arrowhead indicates the inactivation substitution in the TP domain of $S a \mathrm{PBP} 1 *$. The first and last amino acids of constructs are indicated.

b, Fluorescent cell wall sedimentation assay. A Wilcoxon signed rank test $(P<0.05)$ was carried out to assess the significance of difference in +WTA/-WTA PG binding: SaPBP1, $P=0.0273 ; S a \mathrm{PBP} 1^{*}, P=0.0078 ; S a \mathrm{PBP} 1_{\triangle \mathrm{PASTA}}, P=0.0195 ; S a \mathrm{PASTA}{ }_{\mathrm{PBP} 1}, P \geq 0.9999$, 
866 not significant. Data represent mean \pm SD. Error bars that are smaller than the symbols are

867 not shown.

868 c, Structure of $S a$ PASTAPBP1. The crystal structure of $S$. aureus PBP1 lacking the PASTA

869 domains ( $\mathrm{SaPBP1}$, PDB 5TRO) and our $S a$ PASTAPBP1 structure were superimposed on to $S$.

870 pneumoniae $\mathrm{PBP} 2 \mathrm{x}(\mathrm{SpPBP} 2 \mathrm{x}, \mathrm{PDB} 5 \mathrm{OAU})$ and displayed as cartoons. Their $\mathrm{N}$-termini are

871 orientated close to the representative cell membrane, as if anchored there by their respective

872 transmembrane helices (dashed red line/orange cylinder). Individual domains are coloured as

873 follows; N-terminal domain (red), transpeptidase domain (blue) and PASTA domain (green).

874 The individual PASTA domains are labelled P1 and P2, respectively. Residues Pro603,

875 Pro661 and Trp666 are displayed as sticks, with nitrogen atoms coloured blue. 
a
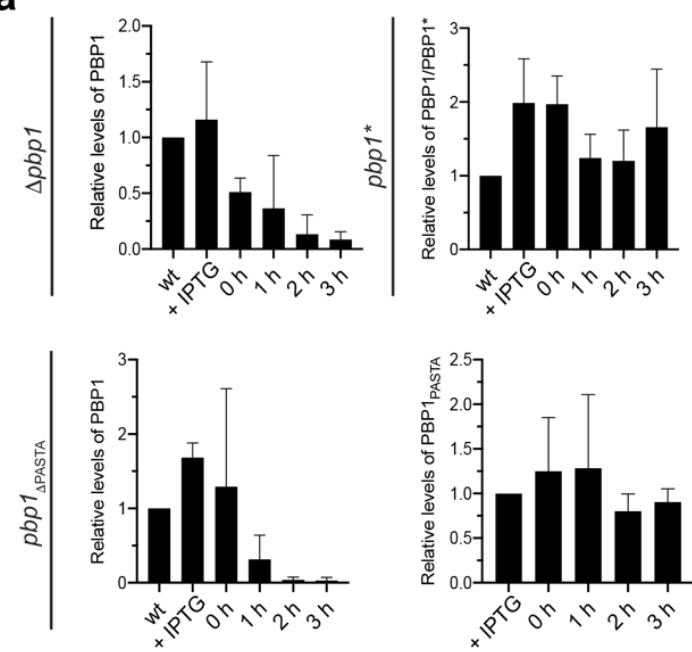

b
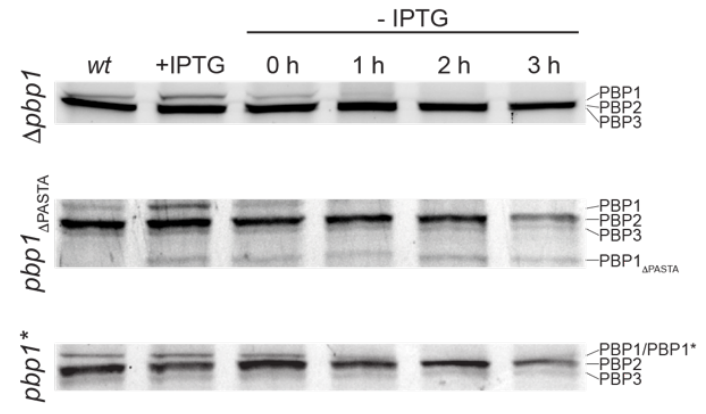

C
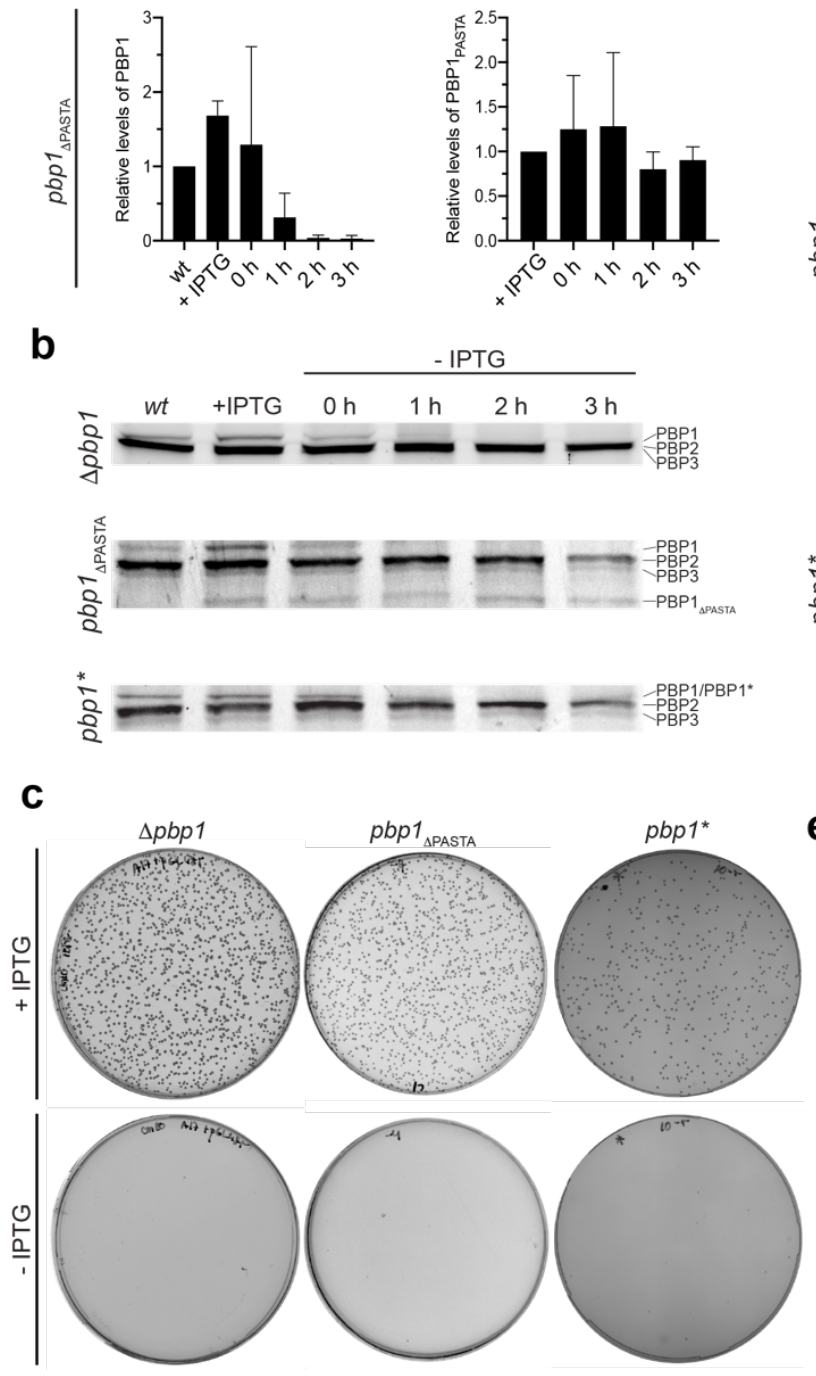

(2)
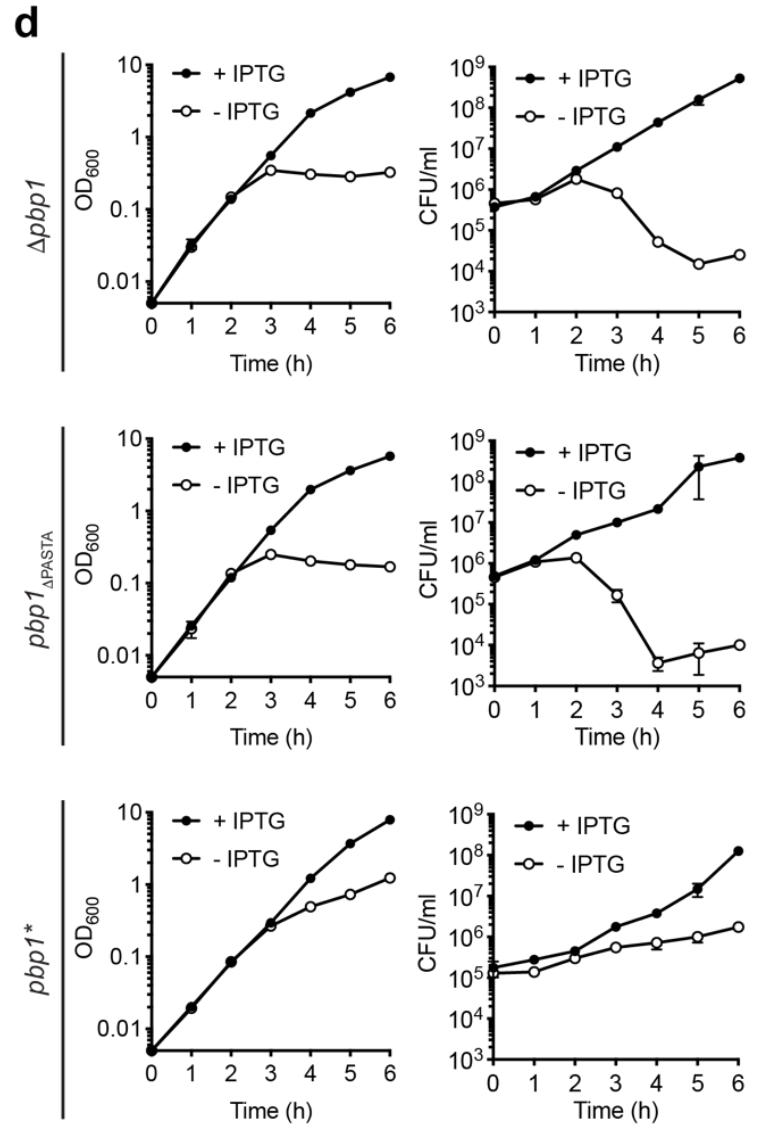

e

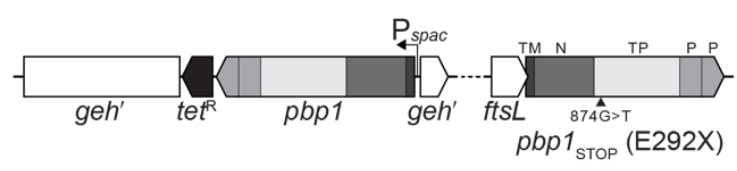

$\mathbf{f}$

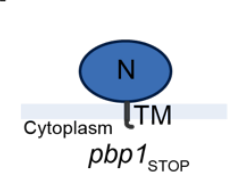

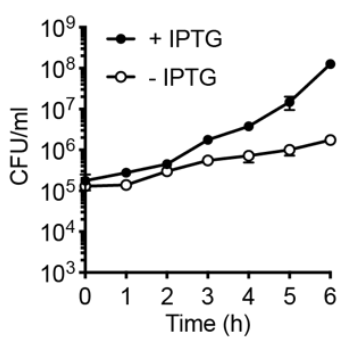

9

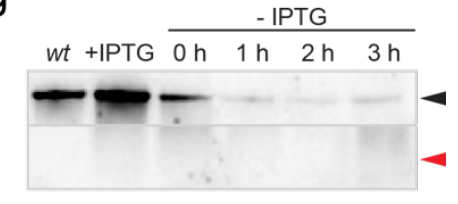

Fig. 1 - figure supplement 1. Essentiality of PBP1, PASTA and TP domains in S. aureus.

880 a, Relative levels of PBP1 in $\Delta p b p 1, p b p 1_{\triangle \mathrm{PASTA}}$ and $p b p 1^{*}$ grown with IPTG and for $0,1,2$

881 and $3 \mathrm{~h}$ after inducer removal. PBP1 levels were normalized to protein levels in SH1000 lacI 
$882(w t)$. PBP $1_{\triangle \mathrm{PASTA}}$ levels were normalized to PBP1 $1_{\triangle \mathrm{PASTA}}$ levels in the presence of inducer.

883 Quantifications are for the data shown in Fig. 1c. Data represent mean $\pm \mathrm{SD}$.

884 b, BocillinFL gel-based analysis of penicillin binding proteins in SH1000 lacI (wt) and

$885 \Delta p b p 1, p b p 1_{\triangle \mathrm{PASTA}}$ and $p b p 1^{*}$ grown with IPTG and $0,1,2$ and $3 \mathrm{~h}$ after inducer removal.

$886 \mathbf{c}$, Growth of $\Delta p b p 1$, $p b p 1_{\triangle \mathrm{PASTA}}$ and $p b p 1^{*}$ with or without IPTG. Quantifications for the 887 plate assay are shown in Fig. 1 d.

888 d, Growth curves of $\triangle p b p 1, p b p 1_{\triangle \mathrm{PASTA}}$ and $p b p 1 *$ in the presence or absence of IPTG. Data

889 represent mean $\pm \mathrm{SD}$. Error bars that are smaller than the data point symbols are not shown.

890 e, Schematic representation of the $p b p 1_{\text {STOP }}$ mutant. A SNP ( $874 \mathrm{G}$ for T) resulted in a

891 premature stop codon (E292X) and removal of the TP and PASTA domains.

892 f, Schematic representation of domain architecture of PBP $1_{\text {STOP }}$ encoded by the $p b p 1_{\text {STOP }}$

893 mutant.

894 g, Immunoblot showing PBP1 levels in SH1000 lacI (wt) and pbp $1_{\text {STOP }}$ grown with IPTG and

895 for 0, 1, 2 and $3 \mathrm{~h}$ without inducer analysed using anti-PBP1 antibody. Expected sizes: PBP1

$896=83 \mathrm{kDa}$ (black arrowhead) and PBP1 $1_{\mathrm{STOP}}=33 \mathrm{kDa}($ red arrowhead).

897

898 Data are representative of two $(\mathrm{g})$, three $(\mathrm{a}, \mathrm{b}, \mathrm{d})$ and at least four $(\mathrm{c})$ independent

899 experiments. 
a
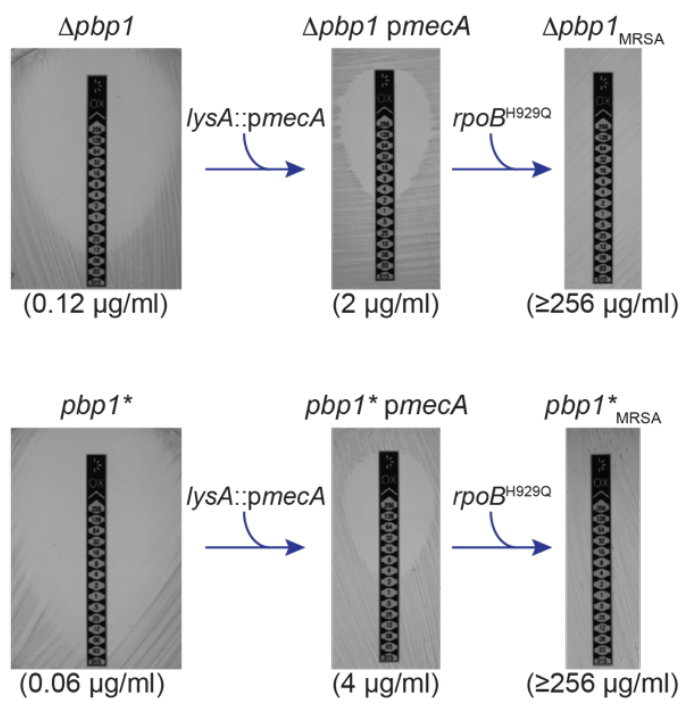

C
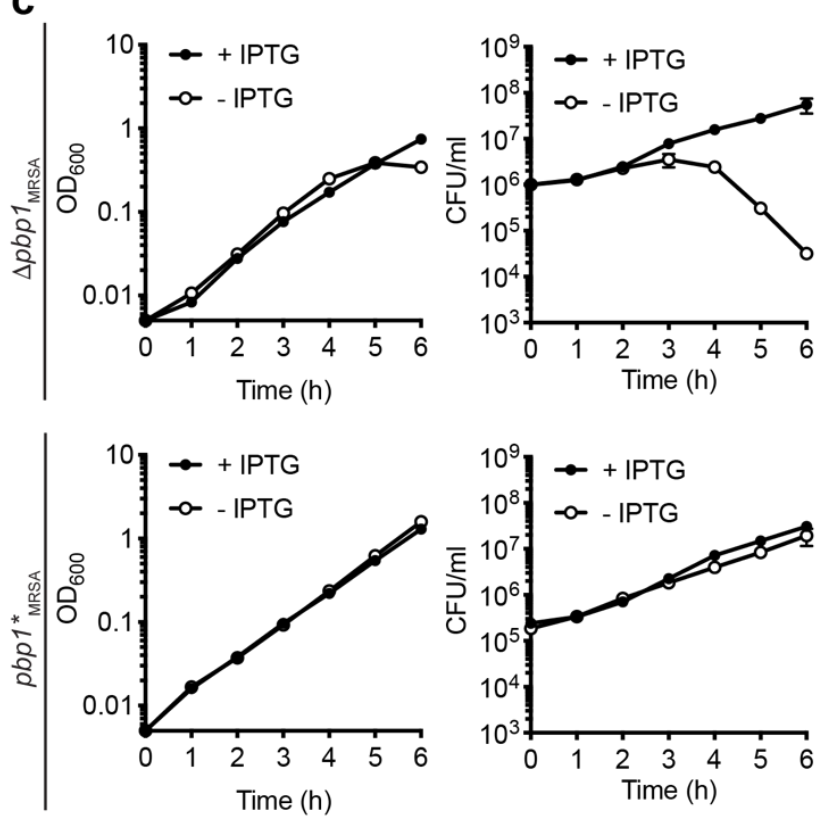

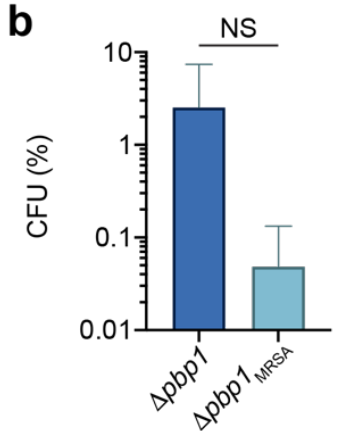

d

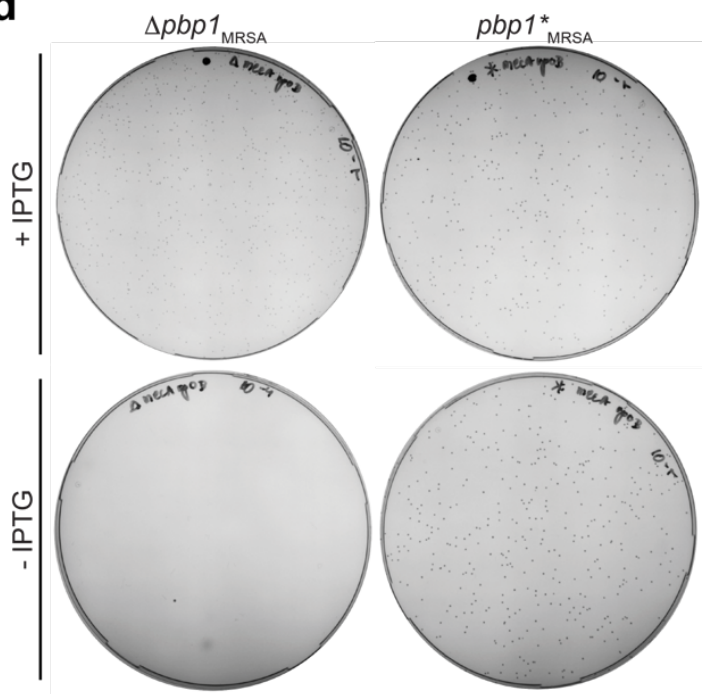

Fig. 1 - figure supplement 2. Essentiality of PBP1 and its TP activity in Methicillin-

\section{resistant $S$. aureus.}

a, Schematic representation of evolution of high-level $\beta$-lactam resistant $\Delta p b p 1$ and $p b p 1^{*}$. A single copy mec $A$ under its native promoter (pmecA) was introduced at the $\operatorname{lys} A$ locus, resulting in low-level oxacillin resistant $\triangle p b p 1 \mathrm{pmec} A$ and $p b p 1 * \mathrm{p} m e c A$. Subsequently,

906 addition of a point mutation in the $r p o B$ gene results in development of high-level resistant

$907 \Delta p b p 1_{\mathrm{MRSA}}$ and $p b p 1^{*}$. Oxacillin MICs shown in brackets were measured using the E-test

908 strips. 
909 b, Plating efficiency of $\Delta p b p$ (MSSA) and MRSA $\triangle p b p 1_{\text {MRSA }}$ cells upon the inducer removal

910 compared to the control groups grown in the presence of inducer. Data represent mean $\pm \mathrm{SD}$.

$911 P$ value was determined by Mann-Whitney $U$ tests. $P=0.5429$ (NS, not significant).

912 c, Growth curves of $\Delta p b p 1_{\text {MRSA }}$ and $p b p 1^{*}{ }_{\text {MRSA }}$ in the presence or absence of IPTG. Data

913 represent mean \pm SD. Error bars that are smaller than the data point symbols are not shown.

914 d, Growth of $\triangle p b p 1_{\text {MRSA }}$ and $p b p 1 *_{\text {MRSA }}$ with or without IPTG. Quantifications for

$915 \Delta p b p 1_{\text {MRSA }}$ are shown in Fig. 1 - figure supplement $2 \mathrm{c}$ and for $p b p 1^{*}$ MRSA are shown in Fig.

$9161 \mathrm{~b}$

917

918 Data are representative of at least three independent experiments. 
a

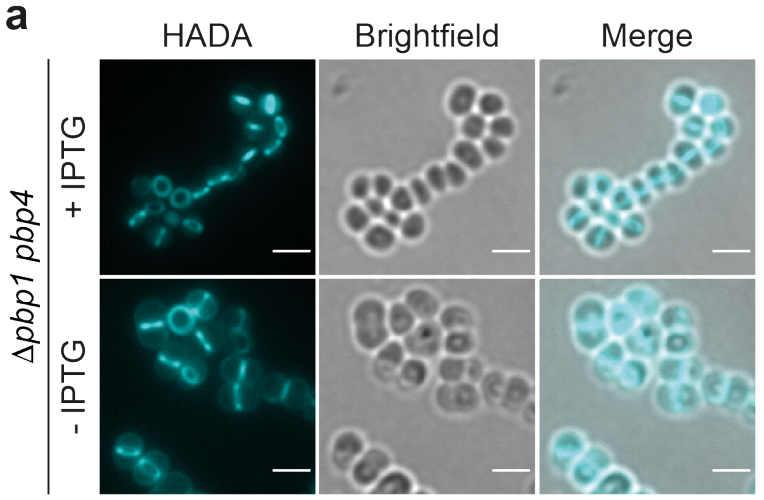

b

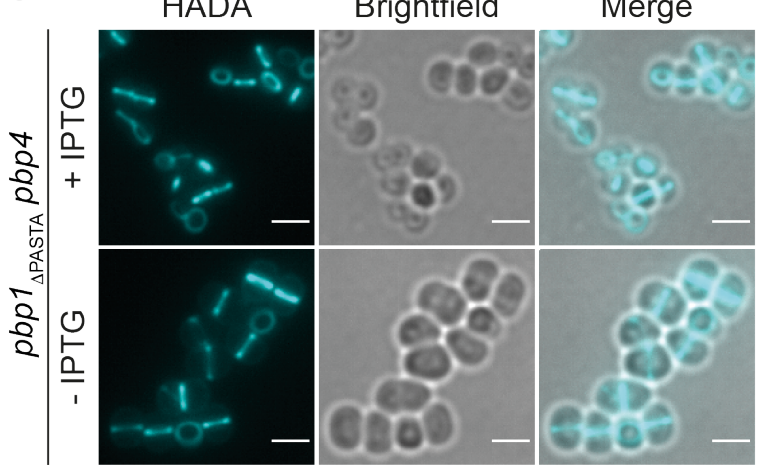

C

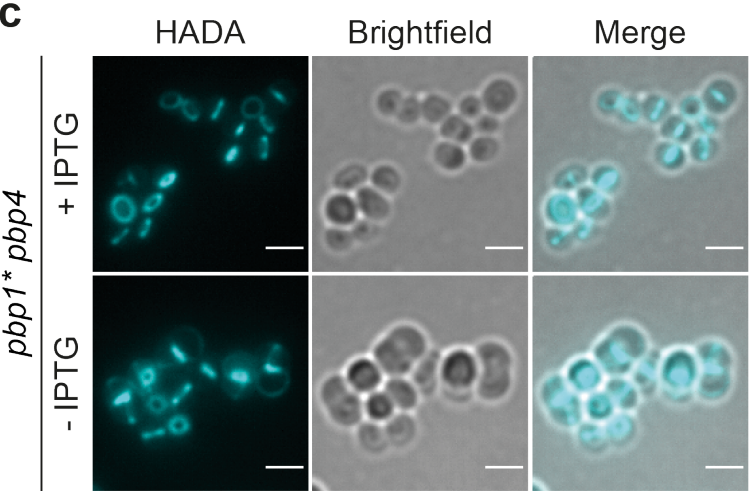

d

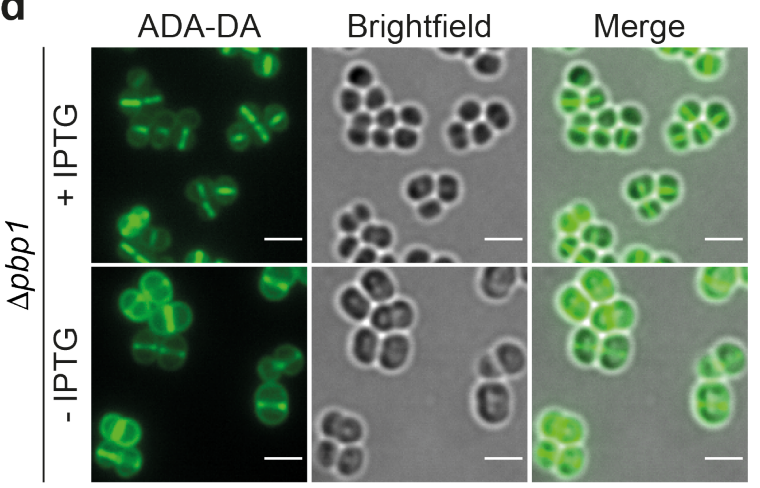

e

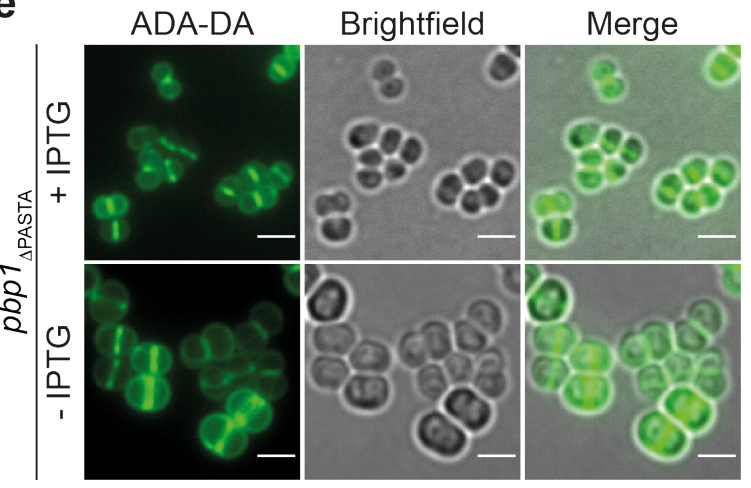

f

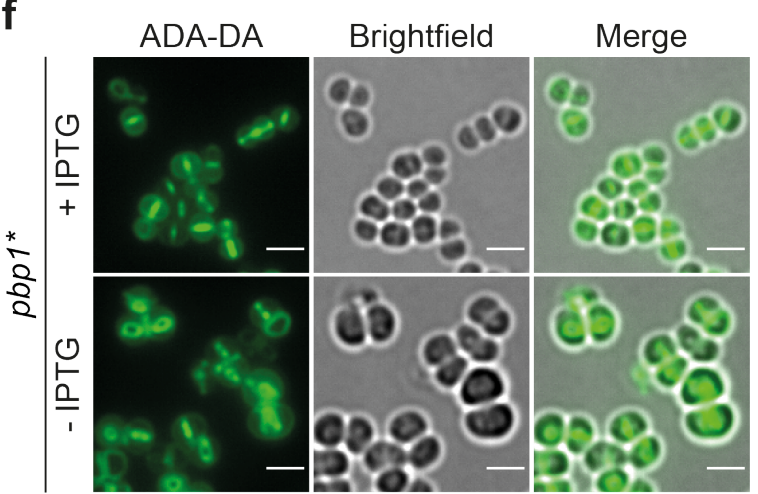

920 Fig. 2 - figure supplement 1. Loss of PBP1, PASTAs or TP activity of PBP1 does not prevent PG synthesis.

922 a-c, PG incorporation in $p b p 4$ mutants depleted of PBP1. $\Delta p b p 1 p b p 4, p b p 1_{\triangle \mathrm{PASTA}} p b p 4$ and

$923 p b p 1 * p b p 4$ grown with or without IPTG for $2 \mathrm{~h}$ and incubated with HADA for 5 min to

924 show nascent PG incorporation.

925 d-f, $\Delta p b p 1, p b p 1_{\triangle \mathrm{PASTA}}$ and $p b p 1^{*}$ grown with or without IPTG for $2 \mathrm{~h}$, incubated with

926 dipeptide (ADA-DA) for 5 min and clicked to Alexa Fluor 488 to show nascent PG

927 incorporation. 
bioRxiv preprint doi: https://doi.org/10.1101/2021.10.07.463504; this version posted October 7,2021 . The copyright holder for this preprint

(which was not certified by peer review) is the author/funder, who has granted bioRxiv a license to display the preprint in perpetuity. It is made available under aCC-BY-NC-ND 4.0 International license.

928 Fluorescence images are average intensity projections of $z$ stacks. Scale bars $2 \mu \mathrm{m}$.

929

930 Images are representatives of two independent experiments. 
bioRxiv preprint doi: https://doi.org/10.1101/2021.10.07.463504; this version posted October 7, 2021. The copyright holder for this preprint

(which was not certified by peer review) is the author/funder, who has granted bioRxiv a license to display the preprint in perpetuity. It is made available under aCC-BY-NC-ND 4.0 International license.

a

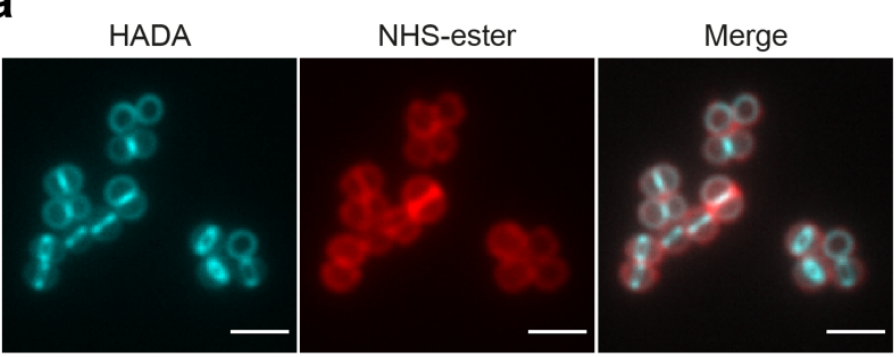

b

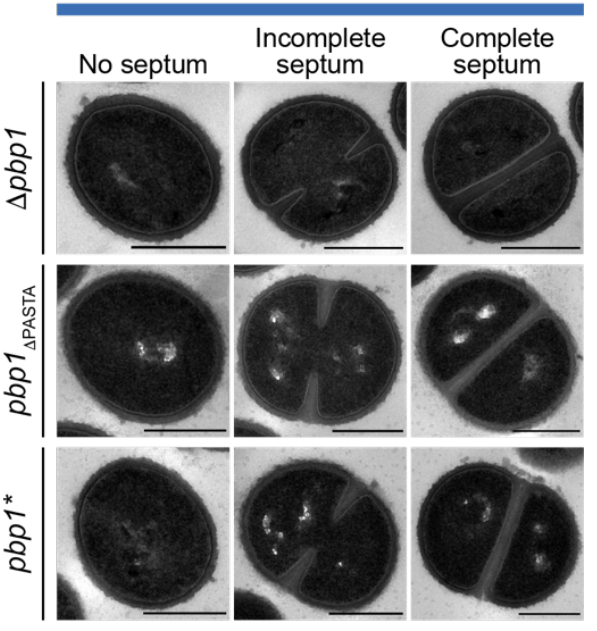

C

Abnormal
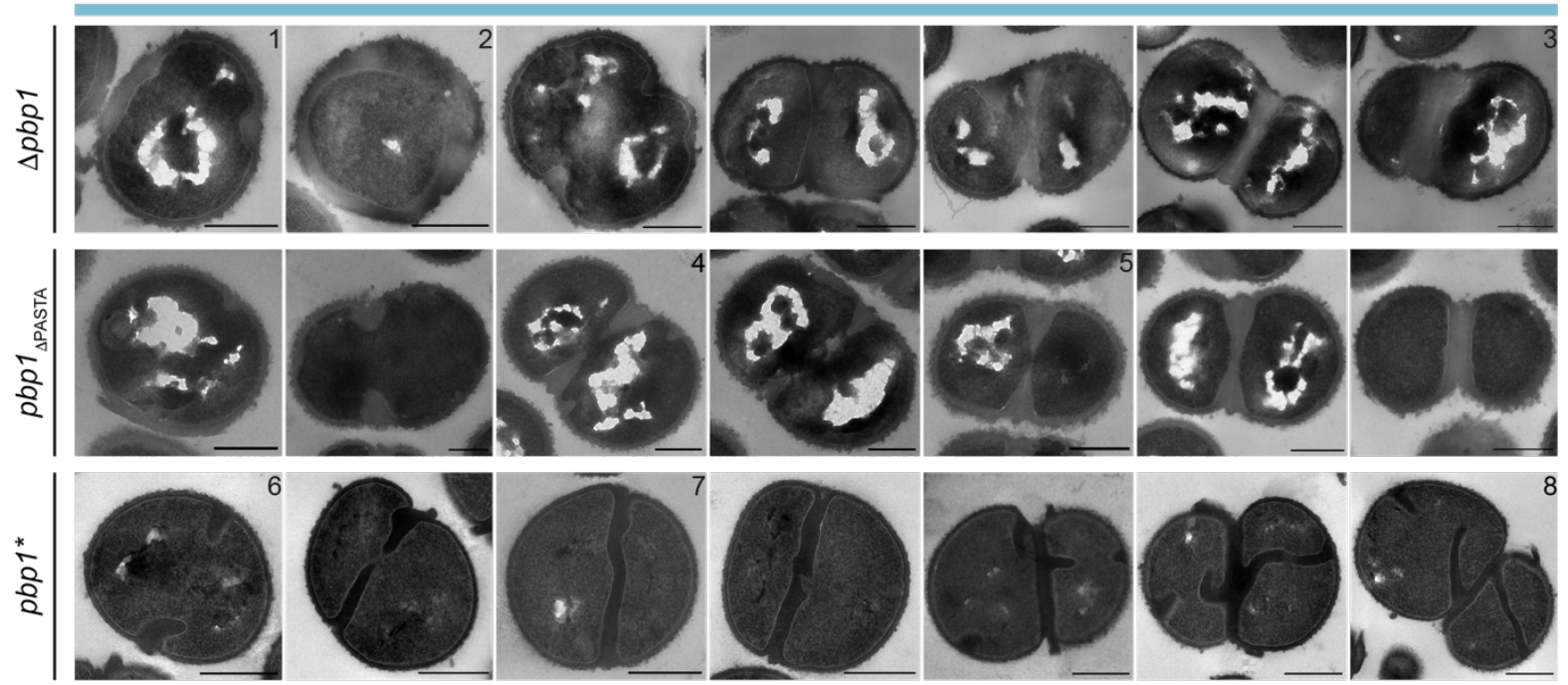

d

HADA

NHS-ester

Merge

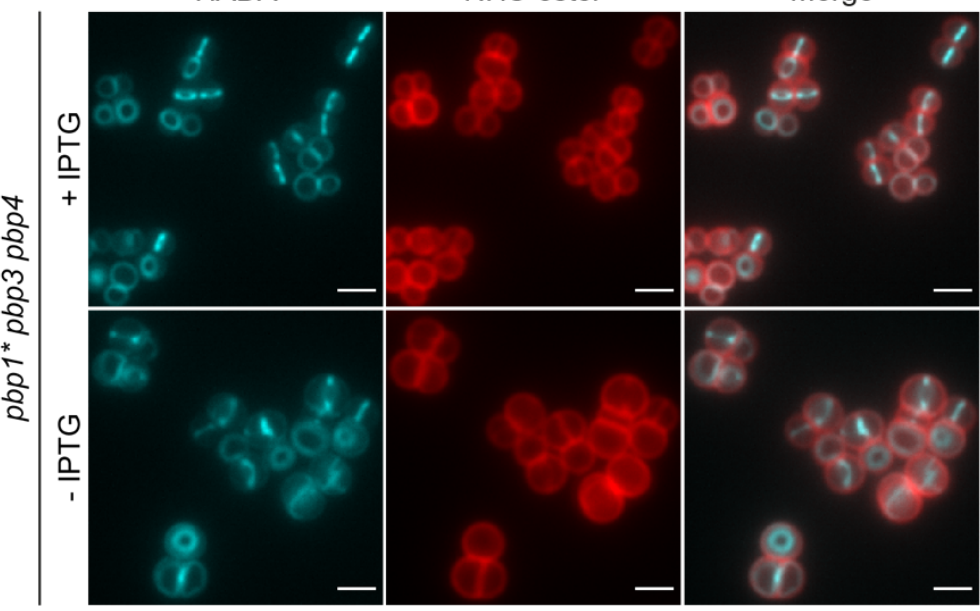


933 a, Fluorescence images of SH1000 WT labelled with HADA for 5 min (nascent PG) and

934 counter labelled with NHS-ester Alexa Fluor 555 (cell wall). Images are average intensity

935 projections of $z$ stacks. Scale bars $2 \mu \mathrm{m}$.

$936 \mathbf{b}$, TEM of $\triangle p b p 1, p b p 1_{\triangle \mathrm{PASTA}}$ and $p b p 1^{*}$ grown in the presence of IPTG categorised as

937 normal phenotype (blue). Scale bars $500 \mathrm{~nm}$.

938 c, TEM of $\triangle p b p 1, p b p 1_{\triangle \mathrm{PASTA}}$ and $p b p 1^{*}$ grown in the absence of IPTG for $2 \mathrm{~h}$ categorised

939 as abnormal phenotype (1, PG blebs; 2, thickened cell wall; 3, thickened complete septum; 4,

940 multiple septa; 5, misshapen incomplete septum; 6, thick incomplete septum with rounded

941 leading edge; 7, curved septum; 8, separation defect. Scale bars $500 \mathrm{~nm}$.

942 d, Fluorescence images of $p b p 1^{*} p b p 3 p b p 4$ grown with or without IPTG for $2 \mathrm{~h}$, labelled

943 with HADA for 5 min (nascent PG) and counter stained with NHS-ester Alexa Fluor 555

944 (cell wall). Images are average intensity projections of $z$ stacks. Scale bars $2 \mu \mathrm{m}$.

945

946 Data are representative of two independent experiments. 
a
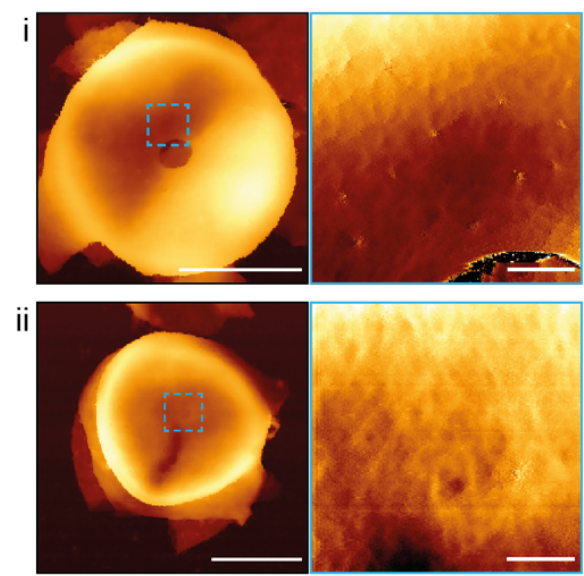

C
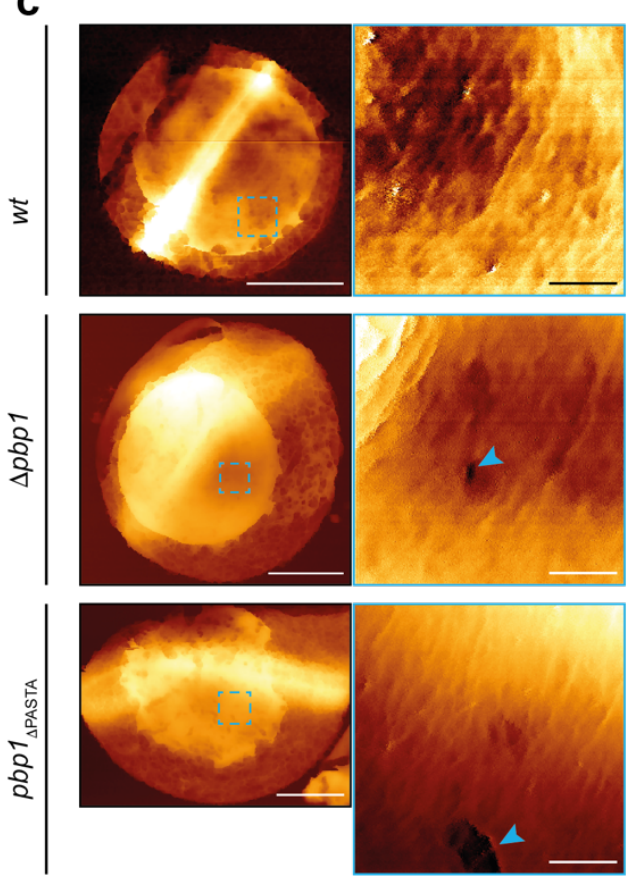
$\operatorname{pbp1*}$ b
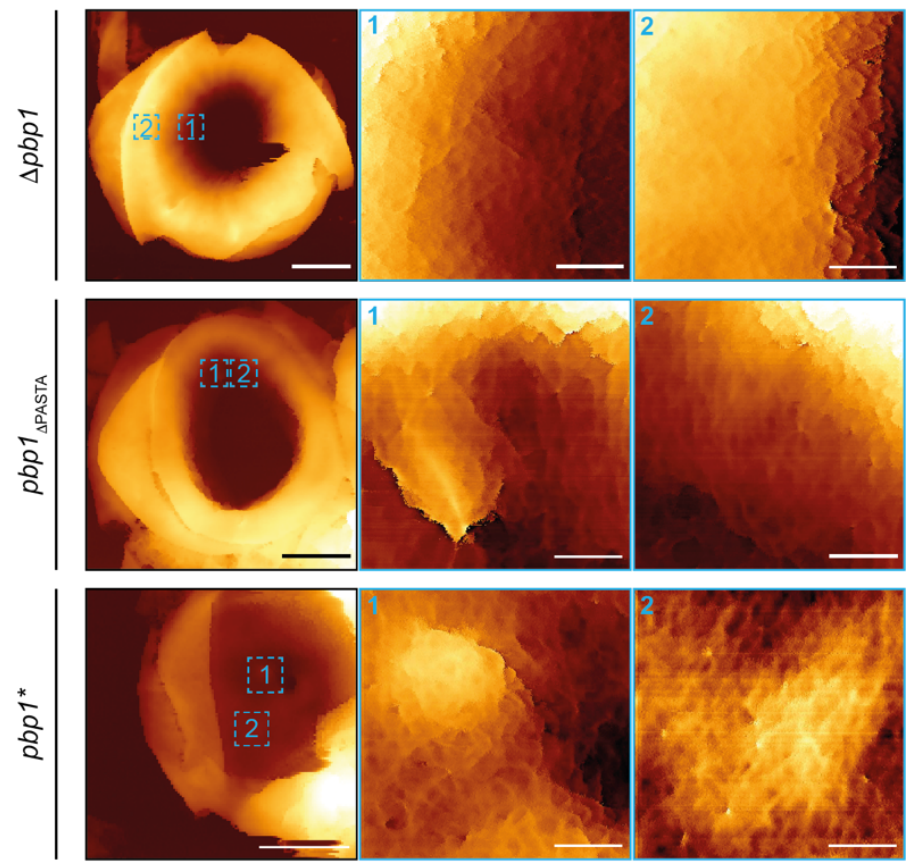

Fig. 2 - figure supplement 3. Gallery of AFM images of $S$. aureus $\Delta p b p 1, p b p 1_{\triangle \mathrm{PASTA}}$ and

a, AFM topographic images of unfinished (i) and closed (ii) septa in S. aureus SH1000.

Sacculi (images to the left, scale bars $500 \mathrm{~nm}$, data scales (z): 200 (top) and $250 \mathrm{~nm}$ (bottom)) and higher magnification scans (images to the right, scale bars $50 \mathrm{~nm}$, data scales (z): 80 (top) and $40 \mathrm{~nm}$ (bottom)) on the boxed areas from the images to the left.

b, AFM topographic images of unfinished septa in $\triangle p b p l$ (from left to right: scale bars 500, 50 and $50 \mathrm{~nm}$; data scales $(z) 500,120$ and $150 \mathrm{~nm}$ ), pbp $1_{\triangle \mathrm{PASTA}}$ (from left to right: scale bars 500, 50 and $50 \mathrm{~nm}$; data scales $(z)$ 693, 80 and $100 \mathrm{~nm}$ ) and $p b p 1^{*}$ (from left to right: scale 
957 bars 500, 50 and $50 \mathrm{~nm}$; data scales $(z) 500,80$ and $25 \mathrm{~nm}$ ) grown in the absence of inducer

958 for $2 \mathrm{~h}$. Images to the left are sacculi, while images in the centre (1) and to the right (2) are

959 higher magnification scans on the boxed areas of the images on the left.

960 c, AFM topographic images of external nascent ring architecture in SH1000 WT (wt; scale

961 bars: from left to right: scale bars 500 and $50 \mathrm{~nm}$; data scales $(z) 100$ and $20 \mathrm{~nm})$ and mutants

$962 \Delta p b p 1$ (scale bars: from left to right: scale bars 500 and $50 \mathrm{~nm}$; data scales $(z) 400$ and 60

$963 \mathrm{~nm}$ ) and $p b p 1_{\triangle \mathrm{PASTA}}$ (scale bars: from left to right: scale bars 500 and $50 \mathrm{~nm}$; data scales $(z)$

964350 and $100 \mathrm{~nm}$ ) grown in the absence of inducer for $2 \mathrm{~h}$. Images to the left are sacculi, while

965 images to the right are higher magnification scans on the boxed areas of the images on the

966 left. The arrowheads indicate abnormal features, holes.

967

968 Data are representative of two independent experiments. 

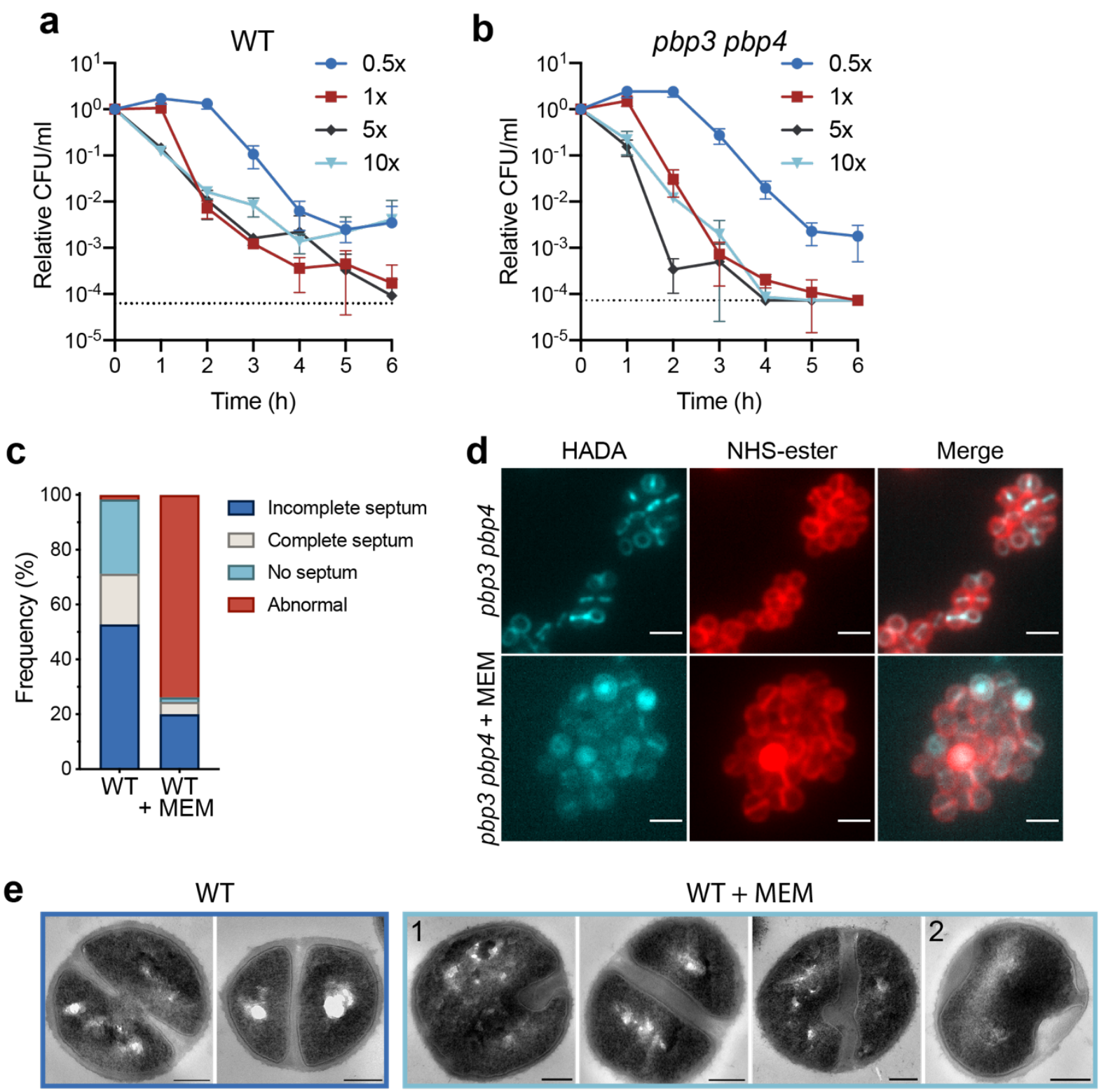

$\mathbf{f}$

pbp3 pbp4
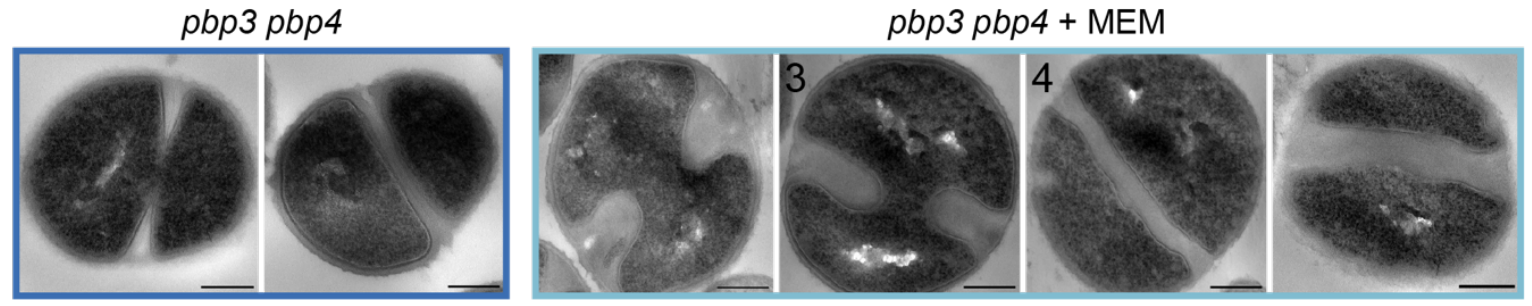

Fig. 3 - figure supplement 1. Effect of meropenem (MEM) on S. aureus.

971 a-b, Bactericidal effect of addition of 0.5x, 1x, 5x and 10x MIC MEM on (a) SH1000 WT

972 and (b) pbp3 pbp4 (b). MEM MIC is $0.4 \mu \mathrm{g} / \mathrm{ml}$ and $0.2 \mu \mathrm{g} / \mathrm{ml}$ for SH1000 WT and $p b p 3$

$973 p b p 4$, respectively Data represent mean \pm SD. Error bars that are symbols than the dots are

974 not shown. The dotted line is the detection limit. 
976 based on HADA incorporation (Fig 3a). Same phenotype classification was used as shown in

977 Fig. 2c. From left to right $n=309$ and 355.

978 d, Fluorescence images of pbp3 pbp4 treated with 1x MIC MEM for $1 \mathrm{~h}$, labelled with

979 HADA for 5 min to show nascent PG and counter labelled with NHS-ester Alexa Fluor 555

980 (cell wall). Images are average intensity projections of $z$ stacks. Scale bars $2 \mu \mathrm{m}$. Phenotype

981 classification of MEM treated $p b p 3 p b p 4$ was not possible due to low HADA fluorescence

982 signal.

983 e-f, TEM of SH1000 WT (e) and pbp3 pbp4 (f) grown with or without 1x MIC MEM for $1 \mathrm{~h}$.

984 Scale bars $200 \mathrm{~nm}$. Examples of cells categorised as normal phenotype are in blue, cells with

985 abnormal phenotype are in light blue (1, asymmetric septum ingrowth; 2, off-septal PG

986 thickening; 3, septum with rounded leading edge; 4, curved septum).

987

988 Data are representative of three (a and b) and two (c) independent experiments. Experiments 989 in $\mathrm{d}$, e and $\mathrm{f}$ were performed once. 
a

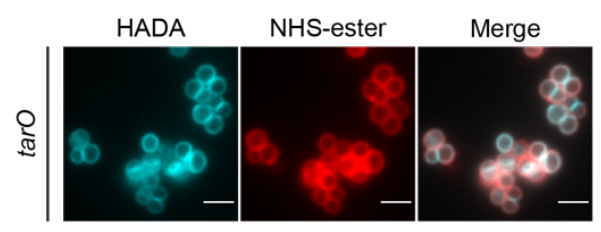

b

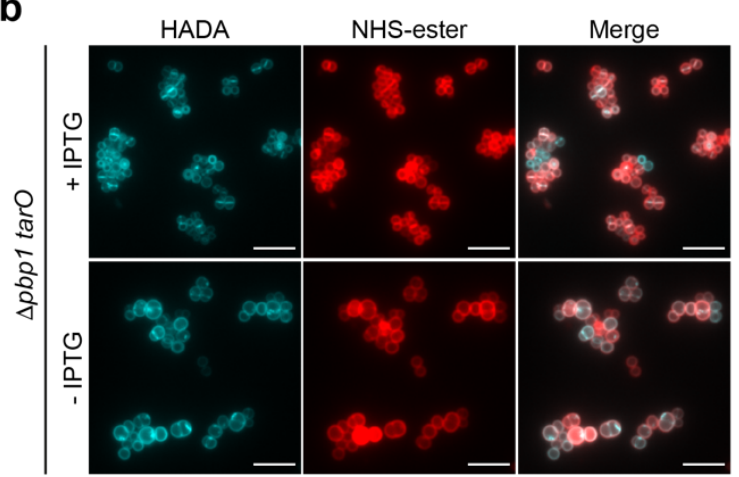

C

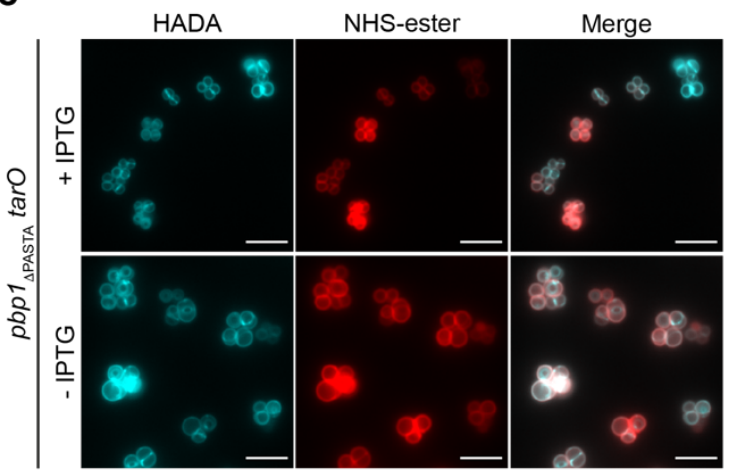

d

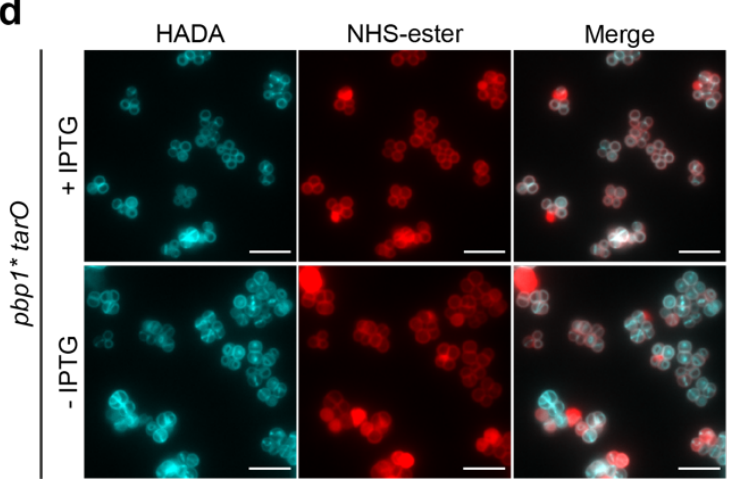

e

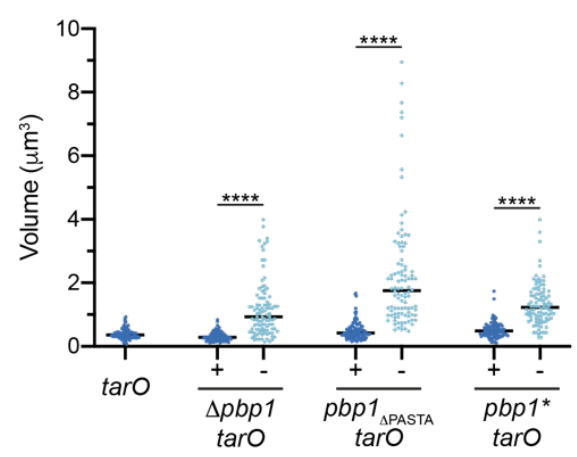

f

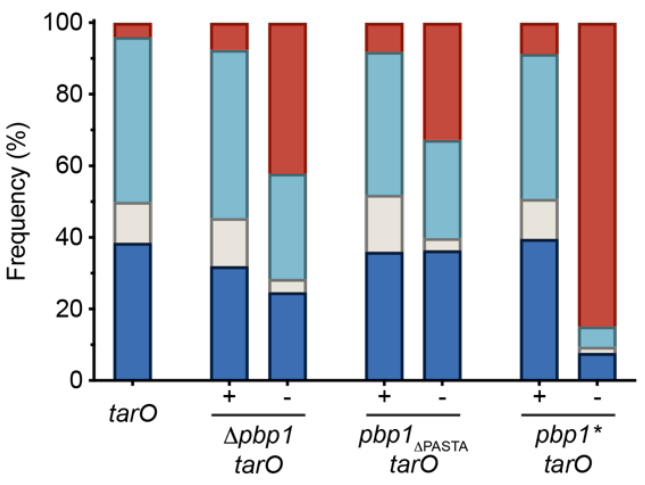

$\square$ Incomplete septum $\square$ Complete septum $\square$ No septum
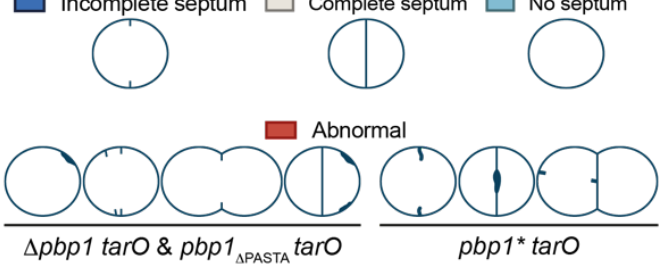

Fig. 4 - figure supplement 1. Functional association between PBP1 and WTA

992 a, Fluorescence images of the $\operatorname{tar} O$ mutant labelled with HADA for 5 min (nascent PG) and

993 counter stained with NHS-ester Alexa Fluor 555 (cell wall). Images are average intensity

994 projections of $z$ stacks. Scale bars $5 \mu \mathrm{m}$.

995 b-d, $\triangle p b p 1 \operatorname{tar} O, p_{p p 1} 1_{\triangle \mathrm{PASTA}} \operatorname{tar} O$ and $p b p 1^{*} \operatorname{tar} O$ grown with or without IPTG for $2 \mathrm{~h}$,

996 incubated with HADA for 5 min to show nascent PG and counter labelled with NHS-ester 
997 Alexa Fluor 555 (cell wall). Images are average intensity projections of $z$ stacks. Scale bars 5

$998 \mu \mathrm{m}$.

$999 \mathbf{e}$, Cell volumes of $\operatorname{tar} O$ and $\triangle p b p 1 \operatorname{tar} O, \operatorname{pbp}_{\triangle \mathrm{PASTA}} \operatorname{tar} O$ and $p b p 1 * \operatorname{tar} O$ grown with or

1000 without IPTG as measured by fluorescence microscopy after NHS-ester Alexa Fluor 555

1001 labelling. Each dot represents a single cell. The median of each distribution is indicated by a

1002 black line. The number of cells analysed for each mutant and condition was $n \geq 100 . P$ value

1003 was determined by Mann-Whitney $U$ tests $(* * *, P<0.0001)$. From left to right: $P=2.243 \mathrm{e}-$

$1004022,1.460 \mathrm{e}-037$ and 8.074e-029; $n=100,102,101,100,100,100$ and 100.

1005 f, Quantification of cellular phenotypes for $\operatorname{tar} O$ and $\triangle p b p 1 \operatorname{tar} O, p b p 1_{\triangle \mathrm{PASTA}} \operatorname{tar} O$ and

$1006 \mathrm{pbpl}^{*}$ tarO based on HADA incorporation (Fig. 4 - figure supplement 1a-d) after incubation

1007 with or without IPTG. From left to right $n=306,253,271,358,266,313$ and 336.

1008

1009 Data are representative of two independent experiments. 
a

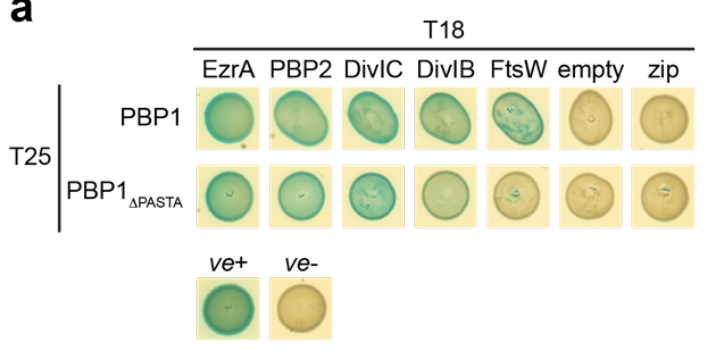

C

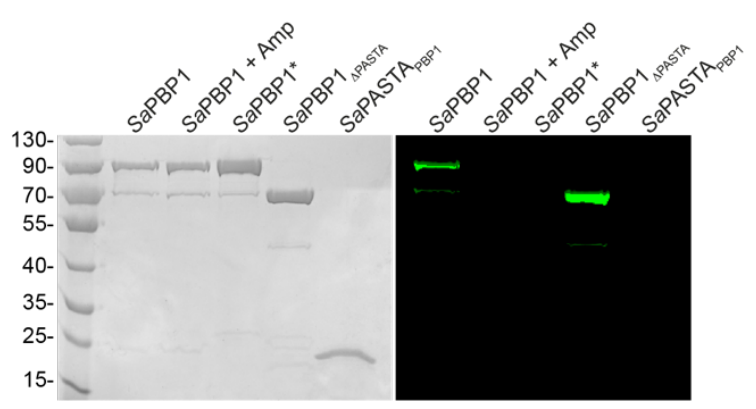

b

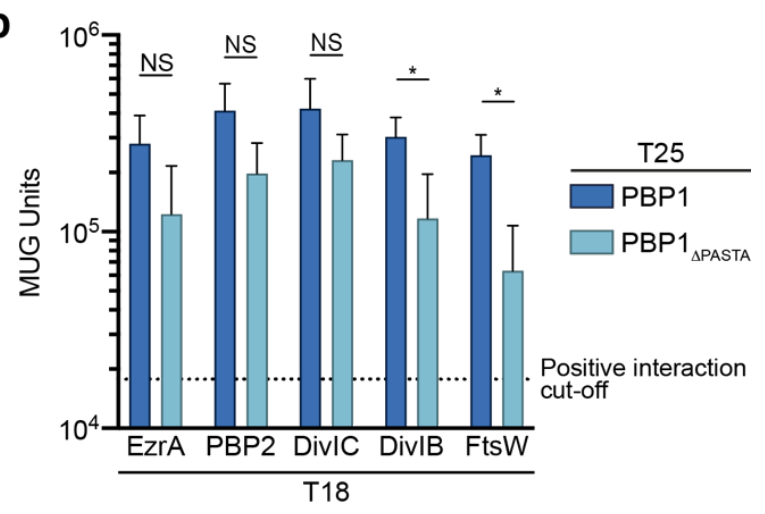

1011 Fig. 5 - figure supplement 1. The role of PBP1 PASTA domains in interactions with cell

1012 division components and PG.

1013 a, Bacterial two-hybrid analysis of the effect of PASTA domains truncation on PBP1

1014 interaction with its known interaction partners; empty, T18 with no insert; zip, T18 with a

1015 leucine zipper fragment; $v e^{+}$, positive control (T18-zip/T25-zip); ve-, negative control

1016 (T18/T25).

1017 b, Quantitative bacterial two-hybrid analysis of the effect of the PASTA domains truncation

1018 on PBP1 interaction with cell division components determined by analysis of the $\beta$ -

1019 galactosidase activities of E. coli BTH101 cells harbouring the corresponding plasmids.

1020 Dotted line, the positive interaction cut off value (4-fold greater than the pair of T18/T25).

1021 Data represent mean \pm SD. $P$ value was determined by Mann-Whitney $U$ tests $(*, P<0.05)$.

1022 DivIB (PBP1 vs PBP1 $\left.1_{\triangle \mathrm{PASTA}}\right) P=0.0424$, FtsW (PBP1 $\left.v s \mathrm{PBP} 1_{\triangle \mathrm{PASTA}}\right) P=0.0163$.

1023 c, Coomassie-stained SDS-PAGE gel (left) and BocillinFL gel-based analysis (right) of

1024 purified recombinant $S a \mathrm{PBP} 1, S a \mathrm{BPP} 1^{*}, S a \mathrm{PBP} 1_{\triangle \mathrm{PASTA}}$ and $S a \mathrm{PASTA} \mathrm{ABP}_{\mathrm{P} 1 .}$ Bands

1025 corresponding to $S a \mathrm{PBP} 1$ and $S a \mathrm{PBP} 1_{\triangle \mathrm{PASTA}}$ were fluorescent, indicating their covalent

1026 binding to BocillinFL. Bands corresponding to $S a \mathrm{PBP} 1^{*}$ and $S a \mathrm{PASTAPBP} 1$ were not

1027 fluorescent, and were therefore unable to bind BocillinFL. SaPBP1 incubated with ampicillin 
1028 prior to BocillinFL incubation failed to fluoresce, consistent with specific binding of

1029 BocillinFL to the TP domain. Expected sizes: SaPBP1 and SaPBP1*, 80.5kDa;

$1030 \quad S a P B P 11_{\triangle \mathrm{PASTA}}, 64.5 \mathrm{kDa} ;$ SaPASTAPBP1, $18.2 \mathrm{kDa}$.

1031

1032 Data are representative of two (c) and three (a-b) independent experiments. 


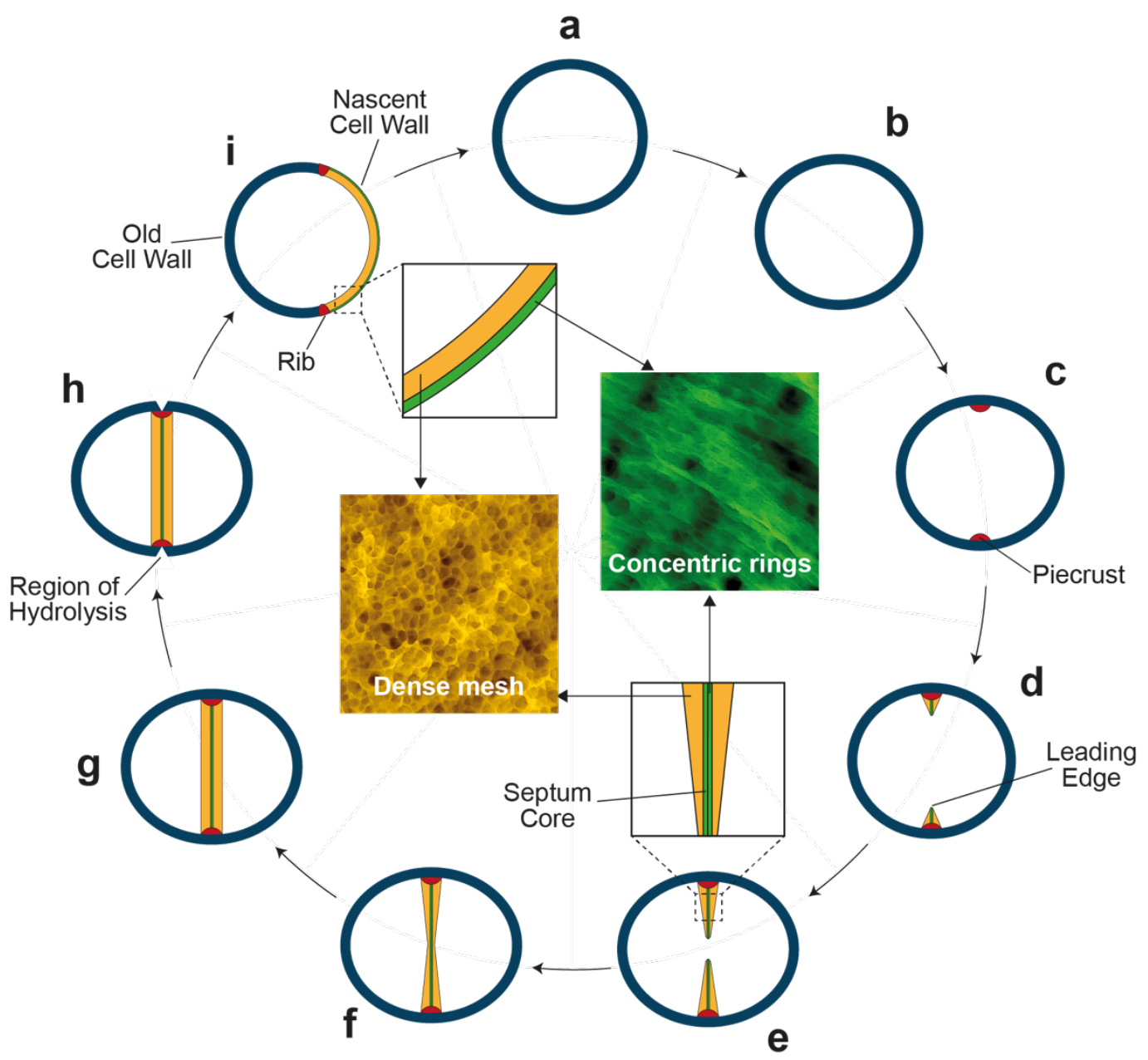

1034 Fig. 5 - figure supplement 2. Conceptual model of septum formation in S. aureus.

1035 (a, b) The growing S. aureus cell increases in volume (Zhou et al., 2015). (c) Septal synthesis 1036 starts by formation of the piecrust (red) (Turner et al., 2010). (d. e) 'V' shaped septum (Lund 1037 et al., 2018) progresses inwards by insertion of ring like structured PG synthesised by PBP1-

1038 FtsW at the septum core and mesh structured PG produced by PBP2. (f) The annulus closes resulting in a bowed septum. (g) Septum is filled out by peptidoglycan insertion executed by

1040 PBP2 and this continues until the cross wall is of uniform thickness (Lund et al., 2018). (h)

1041 Cell wall is hydrolysed at the plane of septation. (i) Daughter cells separate. The cell wall of

1042 the daughter cell (coloured insets) is a chimera of the old cell wall with both internally and externally mesh structured PG and a nascent cell wall with the external ring structured PG and the mesh-like cytoplasmic facing PG (Pasquina-Lemonche et al., 2020). 


\section{References}

1046 Arnaud, M., Chastanet, A., \& Débarbouillé, M. (2004). New vector for efficient allelic replacement in naturally nontransformable, low-GC-content, gram-positive bacteria. Applied and Environmental Microbiology, 70(11), 6887-6891. https://doi.org/10.1128/AEM.70.11.6887-6891.2004

Atilano, M. L., Pereira, P. M., Yates, J., Reed, P., Veiga, H., Pinho, M. G., \& Filipe, S. R. (2010). Teichoic acids are temporal and spatial regulators of peptidoglycan crosslinking in Staphylococcus aureus. Proceedings of the National Academy of Sciences of the United States of America, 107(44), 18991-18996.

Bernardo-García, N., Mahasenan, K. V., Batuecas, M. T., Lee, M., Hesek, D., Petráčková, D., https://doi.org/10.1073/pnas.1004304107

Barthe, P., Mukamolova, G. V., Roumestand, C., \& Cohen-Gonsaud, M. (2010). The Structure of PknB Extracellular PASTA Domain from Mycobacterium tuberculosis Suggests a Ligand-Dependent Kinase Activation. Structure, 18(5), 606-615. Doubravová, L., Branny, P., Mobashery, S., \& Hermoso, J. A. (2018). Allostery, Recognition of Nascent Peptidoglycan, and Cross-linking of the Cell Wall by the

1064 Berrow, N. S., Alderton, D., \& Owens, R. J. (2009). The precise engineering of expression vectors using high-throughput In-Fusion PCR cloning. Methods in Molecular Biology

1067 Berti, A. D., Sakoulas, G., Nizet, V., Tewhey, R., \& Rose, W. E. (2013). $\beta$-Lactam 
1071 Bertsche, U., Kast, T., Wolf, B., Fraipont, C., Aarsman, M. E. G., Kannenberg, K., von Rechenberg, M., Nguyen-Distèche, M., den Blaauwen, T., Höltje, J.-V., \& Vollmer,

Bottomley, A. L., Kabli, A. F., Hurd, A. F., Turner, R. D., Garcia-Lara, J., \& Foster, S. J.

Bunkóczi, G., \& Read, R. J. (2011). Improvement of molecular-replacement models with required for a morphological checkpoint in cell division. Molecular Microbiology. Sculptor. Acta Crystallographica. Section D, Biological Crystallography, 67(Pt 4), 303-312. https://doi.org/10.1107/S0907444910051218

1087 Campbell, J., Singh, A. K., Santa Maria, J. P., Kim, Y., Brown, S., Swoboda, J. G., Mylonakis, E., Wilkinson, B. J., \& Walker, S. (2011). Synthetic lethal compound combinations reveal a fundamental connection between wall teichoic acid and

1092 Chen, V. B., Arendall, W. B., Headd, J. J., Keedy, D. A., Immormino, R. M., Kapral, G. J., 
structure validation for macromolecular crystallography. Acta Crystallographica. Section D, Biological Crystallography, 66(Pt 1), 12-21. https://doi.org/10.1107/S0907444909042073

1097 Cho, H., Wivagg, C. N., Kapoor, M., Barry, Z., Rohs, P. D. A., Suh, H., Marto, J. A., Garner, 1(10), 1-8. https://doi.org/10.1038/nmicrobiol.2016.172

Cooper, E. L., García-Lara, J., \& Foster, S. J. (2009). YsxC, an essential protein in Staphylococcus aureus crucial for ribosome assembly/stability. BMC Microbiology, 9,

1104 Emsley, P., Lohkamp, B., Scott, W. G., \& Cowtan, K. (2010). Features and development of Coot. Acta Crystallographica. Section D, Biological Crystallography, 66(Pt 4), 486501. https://doi.org/10.1107/S0907444910007493

1107 Erster, O., \& Liscovitch, M. (2010). A modified inverse PCR procedure for insertion, Methods in Molecular Biology (Clifton, N.J.), 634, 157-174. https://doi.org/10.1007/978-1-60761-652-8_12

1112 Evans, P. R., \& Murshudov, G. N. (2013). How good are my data and what is the resolution? Acta Crystallographica. Section D, Biological Crystallography, 69(Pt 7), 1204-1214.

1115 Farha, M. A., Leung, A., Sewell, E. W., D’Elia, M. A., Allison, S. E., Ejim, L., Pereira, P. M., Pinho, M. G., Wright, G. D., \& Brown, E. D. (2013). Inhibition of WTA synthesis blocks the cooperative action of PBPs and sensitizes MRSA to $\beta$-lactams. ACS 
1119 Fey, P. D., Endres, J. L., Yajjala, V. K., Widhelm, T. J., Boissy, R. J., Bose, J. L., \& Bayles, K. W. (2013). A genetic resource for rapid and comprehensive phenotype screening of nonessential Staphylococcus aureus genes. MBio, 4(1), e00537-00512. https://doi.org/10.1128/mBio.00537-12

1123 García-Lara, J., Weihs, F., Ma, X., Walker, L., Chaudhuri, R. R., Kasturiarachchi, J., Crossley, H., Golestanian, R., \& Foster, S. J. (2015). Supramolecular structure in the membrane of Staphylococcus aureus. Proceedings of the National Academy of Sciences, 112(51), 15725-15730. https://doi.org/10.1073/pnas.1509557112

Gibson, D. G., Young, L., Chuang, R.-Y., Venter, J. C., Hutchison, C. A., \& Smith, H. O. (2009). Enzymatic assembly of DNA molecules up to several hundred kilobases. Nature Methods, 6(5), 343-345. https://doi.org/10.1038/nmeth.1318

1130 Holm, L. (2020). DALI and the persistence of protein shape. Protein Science: A Publication of the Protein Society, 29(1), 128-140. https://doi.org/10.1002/pro.3749

1132 Horsburgh, M. J., Aish, J. L., White, I. J., Shaw, L., Lithgow, J. K., \& Foster, S. J. (2002). $\sigma B$ Modulates Virulence Determinant Expression and Stress Resistance: Characterization of a Functional rsbU Strain Derived from Staphylococcus aureus 8325-4. Journal of Bacteriology, 184(19), 5457-5467. https://doi.org/10.1128/JB.184.19.54575467.2002

1137 Hudson, K. L., Bartlett, G. J., Diehl, R. C., Agirre, J., Gallagher, T., Kiessling, L. L., \& Woolfson, D. N. (2015). Carbohydrate-Aromatic Interactions in Proteins. Journal of the American Chemical Society, 137(48), 15152-15160.

1141 Hutter, J. L., \& Bechhoefer, J. (1993). Calibration of atomic-force microscope tips. Review of Scientific Instruments, 64(7), 1868-1873. https://doi.org/10.1063/1.1143970 
1143 Kabsch, W. (2010). XDS. Acta Crystallographica. Section D, Biological Crystallography, 66(Pt 2), 125-132. https://doi.org/10.1107/S0907444909047337

1145 Karimova, G., Ullmann, A., \& Ladant, D. (2001). Protein-protein interaction between Bacillus stearothermophilus tyrosyl-tRNA synthetase subdomains revealed by a

Kreiswirth, B. N., Löfdahl, S., Betley, M. J., O’Reilly, M., Schlievert, P. M., Bergdoll, M. S., bacterial two-hybrid system. Journal of Molecular Microbiology and Biotechnology,

Krissinel, E., \& Henrick, K. (2007). Inference of macromolecular assemblies from crystalline state. Journal of Molecular Biology, 372(3), 774-797. https://doi.org/10.1016/j.jmb.2007.05.022

Kuru, E., Radkov, A., Meng, X., Egan, A., Alvarez, L., Dowson, A., Booher, G., Breukink, E., Roper, D. I., Cava, F., Vollmer, W., Brun, Y., \& VanNieuwenhze, M. S. (2019). Mechanisms of Incorporation for D-Amino Acid Probes That Target Peptidoglycan

1161 Lee, C. Y., Buranen, S. L., \& Ye, Z. H. (1991). Construction of single-copy integration Biosynthesis. ACS Chemical Biology, 14(12), 2745-2756.

1164 Liebschner, D., Afonine, P. V., Baker, M. L., Bunkóczi, G., Chen, V. B., Croll, T. I., Hintze, B., Hung, L. W., Jain, S., McCoy, A. J., Moriarty, N. W., Oeffner, R. D., Poon, B. K., Prisant, M. G., Read, R. J., Richardson, J. S., Richardson, D. C., Sammito, M. D., Sobolev, O. V., ... Adams, P. D. (2019). Macromolecular structure determination 
1171 Loskill, P., Pereira, P. M., Jung, P., Bischoff, M., Herrmann, M., Pinho, M. G., \& Jacobs, K. (2014). Reduction of the peptidoglycan crosslinking causes a decrease in stiffness of the Staphylococcus aureus cell envelope. Biophysical Journal, 107(5), 1082-1089. https://doi.org/10.1016/j.bpj.2014.07.029

Lund, V. A., Wacnik, K., Turner, R. D., Cotterell, B. E., Walther, C. G., Fenn, S. J., Grein, Foster, S. J. (2018). Molecular coordination of Staphylococcus aureus cell division.

Maurer, P., Todorova, K., Sauerbier, J., \& Hakenbeck, R. (2012). Mutations in Streptococcus pneumoniae penicillin-binding protein $2 x$ : Importance of the C-terminal penicillin-

McCoy, A. J., Grosse-Kunstleve, R. W., Adams, P. D., Winn, M. D., Storoni, L. C., \& Read, binding protein and serine/threonine kinase-associated domains for beta-lactam R. J. (2007). Phaser crystallographic software. Journal of Applied Crystallography,

1187 Meeske, A. J., Riley, E. P., Robins, W. P., Uehara, T., Mekalanos, J. J., Kahne, D., Walker, binding. Microbial Drug Resistance (Larchmont, N.Y.), 18(3), 314-321. 40(Pt 4), 658-674. https://doi.org/10.1107/S0021889807021206 

PASTA domains of Bacillus subtilis PBP2B strengthen the interaction of PBP2B with DivIB. Microbiology (Reading, England), 166(9), 826-836. https://doi.org/10.1099/mic.0.000957

1199 Neuhaus, F. C., \& Baddiley, J. (2003). A continuum of anionic charge: Structures and

Novick, R. P., \& Morse, S. I. (1967). In vivo transmission of drug resistance factors between strains of Staphylococcus aureus. The Journal of Experimental Medicine, 125(1), 4559. https://doi.org/10.1084/jem.125.1.45

Panchal, V. V., Griffiths, C., Mosaei, H., Bilyk, B., Sutton, J. A. F., Carnell, O. T., Hornby, D. P., Green, J., Hobbs, J. K., Kelley, W. L., Zenkin, N., \& Foster, S. J. (2020). Evolving MRSA: High-level $\beta$-lactam resistance in Staphylococcus aureus is associated with RNA Polymerase alterations and fine tuning of gene expression. PLoS

1215 Pereira, S. F. F., Henriques, A. O., Pinho, M. G., de Lencastre, H., \& Tomasz, A. (2007). Role of PBP1 in cell division of Staphylococcus aureus. Journal of Bacteriology, 189(9), 3525-3531. https://doi.org/10.1128/JB.00044-07 
1218 Pereira, S. F. F., Henriques, A. O., Pinho, M. G., de Lencastre, H., \& Tomasz, A. (2009).

1219 Evidence for a dual role of PBP1 in the cell division and cell separation of Staphylococcus aureus. Molecular Microbiology, 72(4), 895-904. https://doi.org/10.1111/j.1365-2958.2009.06687.x

Pinho, M. G., de Lencastre, H., \& Tomasz, A. (2001). An acquired and a native penicillinbinding protein cooperate in building the cell wall of drug-resistant staphylococci. Proceedings of the National Academy of Sciences of the United States of America, 98(19), 10886-10891. https://doi.org/10.1073/pnas.191260798

Pinho, M. G., \& Errington, J. (2005). Recruitment of penicillin-binding protein PBP2 to the division site of Staphylococcus aureus is dependent on its transpeptidation substrates.

Pinho, M. G., Filipe, S. R., de Lencastre, H., \& Tomasz, A. (2001). Complementation of the Molecular Microbiology, 55(3), 799-807. https://doi.org/10.1111/j.1365essential peptidoglycan transpeptidase function of penicillin-binding protein 2 (PBP2)

Pinho, M. G., Kjos, M., \& Veening, J.-W. (2013). How to get (a)round: Mechanisms by the drug resistance protein PBP2A in Staphylococcus aureus. Journal of Bacteriology, 183(22), 6525-6531. https://doi.org/10.1128/JB.183.22.6525-

Reed, P., Atilano, M. L., Alves, R., Hoiczyk, E., Sher, X., Reichmann, N. T., Pereira, P. M., Roemer, T., Filipe, S. R., Pereira-Leal, J. B., Ligoxygakis, P., \& Pinho, M. G. (2015). Staphylococcus aureus Survives with a Minimal Peptidoglycan Synthesis Machine but Sacrifices Virulence and Antibiotic Resistance. PLoS Pathogens, 11(5), e1004891. https://doi.org/10.1371/journal.ppat.1004891 
1243 Reichmann, N. T., Tavares, A. C., Saraiva, B. M., Jousselin, A., Reed, P., Pereira, A. R., https://doi.org/10.1038/s41564-019-0437-2

Ruggiero, A., Squeglia, F., Marasco, D., Marchetti, R., Molinaro, A., \& Berisio, R. (2011).

Sader, J. E., Borgani, R., Gibson, C. T., Haviland, D. B., Higgins, M. J., Kilpatrick, J. I., Lu, Pinho, M. G. (2020). Reassessment of the distinctive geometry of Staphylococcus

1264 Schenk, S., \& Laddaga, R. A. (1992). Improved method for electroporation of Staphylococcus aureus. FEMS Microbiology Letters, 73(1-2), 133-138. https://doi.org/10.1016/0378-1097(92)90596-g 
1267 Schneider, T., \& Sahl, H.-G. (2010). An oldie but a goodie-Cell wall biosynthesis as antibiotic target pathway. International Journal of Medical Microbiology: IJMM, 300(2-3), 161-169. https://doi.org/10.1016/j.ijmm.2009.10.005

Shah, I. M., Laaberki, M.-H., Popham, D. L., \& Dworkin, J. (2008). A Eukaryotic-like Ser/Thr Kinase Signals Bacteria to Exit Dormancy in Response to Peptidoglycan Fragments. Cell, 135(3), 486-496. https://doi.org/10.1016/j.cell.2008.08.039

Silhavy, T. J., Kahne, D., \& Walker, S. (2010). The bacterial cell envelope. Cold Spring Harbor Perspectives in Biology, 2(5), a000414. https://doi.org/10.1101/cshperspect.a000414

Squeglia, F., Marchetti, R., Ruggiero, A., Lanzetta, R., Marasco, D., Dworkin, J., Petoukhov, M., Molinaro, A., Berisio, R., \& Silipo, A. (2011). Chemical Basis of Peptidoglycan

Steele, V. R., Bottomley, A. L., Garcia-Lara, J., Kasturiarachchi, J., \& Foster, S. J. (2011). Discrimination by PrkC, a Key Kinase Involved in Bacterial Resuscitation from Dormancy. Journal of the American Chemical Society, 133(51), 20676-20679. https://doi.org/10.1021/ja208080r

Srisuknimit, V., Qiao, Y., Schaefer, K., Kahne, D., \& Walker, S. (2017). Peptidoglycan Cross-Linking Preferences of Staphylococcus aureus Penicillin-Binding Proteins Have Implications for Treating MRSA Infections. Journal of the American Chemical 
wall. Proceedings of the National Academy of Sciences of the United States of America, 117(11), 6129-6138. https://doi.org/10.1073/pnas.1917820117

1293 Studier, F. W., \& Moffatt, B. A. (1986). Use of bacteriophage T7 RNA polymerase to direct selective high-level expression of cloned genes. Journal of Molecular Biology, 189(1), 113-130. https://doi.org/10.1016/0022-2836(86)90385-2

Su, H.-N., Li, K., Zhao, L.-S., Yuan, X.-X., Zhang, M.-Y., Liu, S.-M., Chen, X.-L., Liu, L.N., \& Zhang, Y.-Z. (2020). Structural Visualization of Septum Formation in Staphylococcus warneri Using Atomic Force Microscopy. Journal of Bacteriology, 202(19). https://doi.org/10.1128/JB.00294-20

Sutton, J. A. F., Carnell, O. T., Lafage, L., Gray, J., Biboy, J., Gibson, J. F., Pollitt, E. J. G., Tazoll, S. C., Turnbull, W., Hajdamowicz, N. H., Salamaga, B., Pidwill, G. R., Condliffe, A. M., Renshaw, S. A., Vollmer, W., \& Foster, S. J. (2021).

Swoboda, J. G., Campbell, J., Meredith, T. C., \& Walker, S. (2010). Wall teichoic acid function, biosynthesis, and inhibition. Chembiochem: A European Journal of Staphylococcus aureus cell wall structure and dynamics during host-pathogen Chemical Biology, 11(1), 35-45. https://doi.org/10.1002/cbic.200900557 Bernhardt, T. G., \& Walker, S. (2019). FtsW is a peptidoglycan polymerase that is functional only in complex with its cognate penicillin-binding protein. Nature Microbiology, 4(4), 587-594. https://doi.org/10.1038/s41564-018-0345-х

Turner, R. D., Ratcliffe, E. C., Wheeler, R., Golestanian, R., Hobbs, J. K., \& Foster, S. J. (2010). Peptidoglycan architecture can specify division planes in Staphylococcus aureus. Nature Communications, 1, 26. https://doi.org/10.1038/ncomms1025 
1316 Turner, R. D., Vollmer, W., \& Foster, S. J. (2014). Different walls for rods and balls: The diversity of peptidoglycan. Molecular Microbiology, 91(5), 862-874. https://doi.org/10.1111/mmi.12513

Typas, A., Banzhaf, M., Gross, C. A., \& Vollmer, W. (2011). From the regulation of peptidoglycan synthesis to bacterial growth and morphology. Nature Reviews.

Vollmer, W., Blanot, D., \& de Pedro, M. A. (2008). Peptidoglycan structure and architecture. FEMS Microbiology Reviews, 32(2), 149-167. https://doi.org/10.1111/j.15746976.2007.00094.x

Weidenmaier, C., Peschel, A., Xiong, Y.-Q., Kristian, S. A., Dietz, K., Yeaman, M. R., \& Bayer, A. S. (2005). Lack of wall teichoic acids in Staphylococcus aureus leads to reduced interactions with endothelial cells and to attenuated virulence in a rabbit model of endocarditis. The Journal of Infectious Diseases, 191(10), 1771-1777. https://doi.org/10.1086/429692

Winn, M. D., Ballard, C. C., Cowtan, K. D., Dodson, E. J., Emsley, P., Evans, P. R., Keegan,

1336 Yang, Y., Bhachech, N., \& Bush, K. (1995). Biochemical comparison of imipenem, meropenem and biapenem: Permeability, binding to penicillin-binding proteins, and stability to hydrolysis by beta-lactamases. The Journal of Antimicrobial 
1340 Yeats, C., Finn, R. D., \& Bateman, A. (2002). The PASTA domain: A beta-lactam-binding domain. Trends in Biochemical Sciences, 27(9), 438. https://doi.org/10.1016/s09680004(02)02164-3

1343 Zapun, A., Contreras-Martel, C., \& Vernet, T. (2008). Penicillin-binding proteins and betalactam resistance. FEMS Microbiology Reviews, 32(2), 361-385. https://doi.org/10.1111/j.1574-6976.2007.00095.x

Zhao, G., Meier, T. I., Kahl, S. D., Gee, K. R., \& Blaszczak, L. C. (1999). BOCILLIN FL, a Sensitive and Commercially Available Reagent for Detection of Penicillin-Binding Proteins. Antimicrobial Agents and Chemotherapy, 43(5), 1124-1128.

1349 Zhou, X., Halladin, D. K., Rojas, E. R., Koslover, E. F., Lee, T. K., Huang, K. C., \& Theriot, J. A. (2015). Bacterial division. Mechanical crack propagation drives millisecond daughter cell separation in Staphylococcus aureus. Science (New York, N.Y.), 348(6234), 574-578. https://doi.org/10.1126/science.aaa1511 
Appendix Tables

Appendix Table 1. Strains used in this study

\begin{tabular}{|c|c|c|}
\hline Name & Relevant genotype/Markers & Source \\
\hline \multicolumn{3}{|l|}{ Staphylococcus aureus } \\
\hline SH1000 & $\begin{array}{l}\text { Functional } r s b U^{+} \text {derivative of } S \text {. aureus } \\
8325-4\end{array}$ & $\begin{array}{l}\text { (Horsburgh et al., } \\
\text { 2002) }\end{array}$ \\
\hline VF17 & SH1000 pGL485 (lacl); Cm $^{\mathrm{R}}$ & (Steele et al., 2011) \\
\hline RN4220 & $\begin{array}{l}\text { Restriction deficient transformation } \\
\text { recipient }\end{array}$ & $\begin{array}{l}\text { (Kreiswirth et al., } \\
\text { 1983) }\end{array}$ \\
\hline CYL316 & RN4220 pCL112 119 & (Lee et al., 1991) \\
\hline SJF4588 & SH1000 geh::Pspac-pbp1; Tet $^{\mathrm{R}}$ & This study \\
\hline SJF5116 & SH1000 geh::Pspac -pbpl $\Delta p b p 1 ;$ Tet $^{\mathrm{R}}$ & This study \\
\hline SJF5275 & SH1000 geh::Pspac -pbpl pbpl $1_{\triangle \mathrm{PASTA}} ; \mathrm{Tet}^{\mathrm{R}}$ & This study \\
\hline SJF4590 & SH1000 geh::Pspac -pbpl pbpl ${ }^{*} \mathrm{Tet}^{\mathrm{R}}, \mathrm{Cm}^{\mathrm{R}}$ & This study \\
\hline$\Delta p b p l$ & SH1000 geh::Pspac -pbpl spbpl lacI; Tet $^{\mathrm{R}}$ & This study \\
\hline$p b p 1_{\triangle \mathrm{PASTA}}$ & $\begin{array}{l}\text { SH1000 geh::Pspac -pbpl pbpl } 1_{\text {PASTA }} \text { lacI; } \\
\text { Tet }^{\mathrm{R}}, \mathrm{Cm}^{\mathrm{R}}\end{array}$ & This study \\
\hline$p b p 1^{*}$ & $\begin{array}{l}\text { SH1000 geh::Pspac -pbpl pbpl *lacI; Tet }{ }^{\mathrm{R}} \text {, } \\
\mathrm{Cm}^{\mathrm{R}}\end{array}$ & This study \\
\hline SJF5046 & SH1000 lysA::pmecA rpoB ${ }^{\mathrm{H} 929 \mathrm{Q}} ;$ Ery $^{\mathrm{R}}, \mathrm{Kan}^{\mathrm{R}}$ & $\begin{array}{l}\text { (Panchal et al., } \\
\text { 2020) }\end{array}$ \\
\hline$\Delta p b p 1 \mathrm{pmec} A$ & 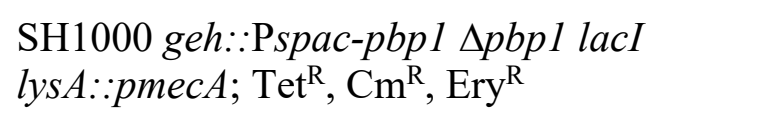 & This study \\
\hline$p b p 1^{*}$ pmecA & 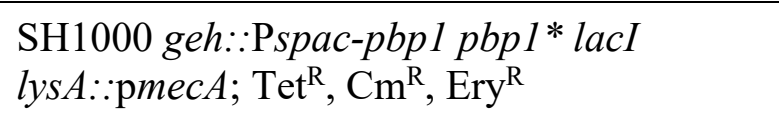 & This study \\
\hline MRSA $\Delta p b p l$ & $\begin{array}{l}\mathrm{SH} 1000 \text { geh }: \text { Pspac-pbpl } \Delta \text { pbpl lacI } \\
\text { lys } A:: \text { pmecA }_{\text {rpo }}{ }^{\mathrm{H} 929 \mathrm{Q}} ; \mathrm{Tet}^{\mathrm{R}}, \mathrm{Cm}^{\mathrm{R}}, \mathrm{Ery}^{\mathrm{R}}, \\
\operatorname{Kan}^{\mathrm{R}}\end{array}$ & This study \\
\hline MRSA $p b p 1^{*}$ & $\begin{array}{l}\mathrm{SH} 1000 \text { geh::Pspac-pbpl pbp }{ }^{*} \text { lacI } \\
\text { lysA::pmecA rpoB }{ }^{\mathrm{H} 929 \mathrm{Q}} ; \mathrm{Tet}^{\mathrm{R}}, \mathrm{Cm}^{\mathrm{R}}, \operatorname{Ery}^{\mathrm{R}} \text {, } \\
\operatorname{Kan}^{\mathrm{R}}\end{array}$ & This study \\
\hline JGL227 & SH1000 ezrA-gfp+; Ery ${ }^{\mathrm{R}}$ & (Steele et al., 2011) \\
\hline$\Delta p b p 1$ ezrA-gfp & $\begin{array}{l}\text { SH1000 geh::Pspac-pbpl } \Delta p b p 1 \text { lacI ezrA- } \\
g f p ; \text { Tet }^{\mathrm{R}}, \mathrm{Cm}^{\mathrm{R}}, \text { Ery }^{\mathrm{R}}\end{array}$ & This study \\
\hline$p b p 1_{\triangle \mathrm{PASTA}} e z r A-g f p$ & $\begin{array}{l}\text { SH1000 geh::Pspac-pbpl pbpl } 1_{\triangle \mathrm{PASTA}} \text { lacI } \\
\text { ezrA-gfp; } \mathrm{Tet}^{\mathrm{R}}, \mathrm{Cm}^{\mathrm{R}}, \mathrm{Ery}^{\mathrm{R}}\end{array}$ & This study \\
\hline
\end{tabular}




\begin{tabular}{|c|c|c|}
\hline$p b p 1 * e z r A-g f p$ & $\begin{array}{l}\text { SH1000 geh::Pspac-pbpl pbpl* lacI ezrA- } \\
g f p ; \text { Tet }^{\mathrm{R}}, \mathrm{Cm}^{\mathrm{R}}, \text { Ery }^{\mathrm{R}}\end{array}$ & This study \\
\hline NE420 & JE2 pbp3::Tn; Ery ${ }^{\mathrm{R}}$ & (Fey et al., 2013) \\
\hline SH4421 & SH1000 pbp3::Tn; Ery ${ }^{\mathrm{R}}$ & This study \\
\hline NE3004 & RN4220 pKAN; Cm ${ }^{\mathrm{R}}$ Ery ${ }^{\mathrm{R}}$ & (Fey et al., 2013) \\
\hline SH4425 & pbp 4::Tn; Ery ${ }^{\mathrm{R}}$ & (Lund et al., 2018) \\
\hline SH5115 & SH1000 pbp $4: \because k a n ; \operatorname{Kan}^{\mathrm{R}}$ & This study \\
\hline pbp3 pbp4 (SH5483) & pbp3::Tn pbp $4:: k a n ; \operatorname{Ery}^{\mathrm{R}}, \operatorname{Kan}^{\mathrm{R}}$, & This study \\
\hline$\Delta p b p 1 p b p 4$ & $\begin{array}{l}\text { SH1000 geh::Pspac-pbpl } \Delta p b p 1 \text { lacI } \\
\text { pbp } 4:: T n ; \mathrm{Tet}^{\mathrm{R}}, \mathrm{Cm}^{\mathrm{R}}, \mathrm{Kan}^{\mathrm{R}}\end{array}$ & This study \\
\hline$p b p 1_{\triangle \mathrm{PASTA}} p b p 4$ & $\begin{array}{l}\text { SH1000 geh::Pspac-pbpl pbp } 1_{\Delta \mathrm{PASTA}} l a c I \\
\text { pbp } 4: \because \operatorname{Tn} ; \mathrm{Tet}^{\mathrm{R}}, \mathrm{Cm}^{\mathrm{R}}, \mathrm{Kan}^{\mathrm{R}}\end{array}$ & This study \\
\hline$p b p 1^{*} p b p 4$ & $\begin{array}{l}\text { SH1000 geh }:: \text { Pspac-pbpl pbpl*lacI } \\
\text { pbp } 4: \because T n ; \mathrm{Tet}^{\mathrm{R}}, \mathrm{Cm}^{\mathrm{R}}, \mathrm{Kan}^{\mathrm{R}}\end{array}$ & This study \\
\hline $\operatorname{tarO}$ & SH1000 $\Delta$ tarO::ery; Ery ${ }^{\mathrm{R}}$ & $\begin{array}{l}\text { Constructed by Dr } \\
\text { B. Salamaga } \\
\text { (University of } \\
\text { Sheffield) }\end{array}$ \\
\hline $\operatorname{tarO} \operatorname{tarO}+$ & $\mathrm{SA} 113 \Delta$ tarO::ery $\mathrm{pUC1}$-tarO; $\mathrm{Ery}^{\mathrm{R}}, \mathrm{Cm}^{\mathrm{R}}$ & $\begin{array}{l}\text { Constructed by Dr } \\
\text { B. Salamaga } \\
\text { (University of } \\
\text { Sheffield) }\end{array}$ \\
\hline$\Delta p b p 1 \operatorname{tarO}$ & $\begin{array}{l}\text { SH1000 geh::Pspac-pbpl } \Delta \text { pbpl lacI } \\
\Delta \text { tarO::ery; } \text { Tet }^{\mathrm{R}}, \mathrm{Cm}^{\mathrm{R}}, \text { Ery }^{\mathrm{R}}\end{array}$ & This study \\
\hline$p b p 1_{\triangle \mathrm{PASTA}} \operatorname{tar} O$ & 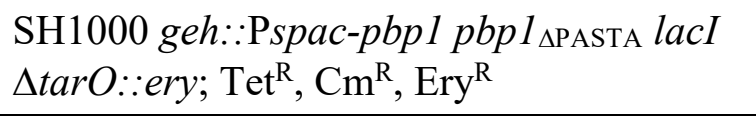 & This study \\
\hline$p b p 1 * \operatorname{tarO}$ & $\begin{array}{l}\text { SH1000 geh }:: \text { Pspac-pbpl pbpl*lacI } \\
\Delta \text { tarO::ery; } \text { Tet }^{\mathrm{R}}, \mathrm{Cm}^{\mathrm{R}}, \text { Ery }^{\mathrm{R}}\end{array}$ & This study \\
\hline \multicolumn{3}{|l|}{ Escherichia coli } \\
\hline NEB $5 \alpha$ & $\begin{array}{l}\text { fhuA2 (argF-lacZ)U169 phoA glnV44 } 80 \\
\text { (lacZ)M15 gyrA96 recA1 relA1 endA1 thi-1 } \\
\text { hsdR17 }\end{array}$ & $\begin{array}{l}\text { New England } \\
\text { Biolabs }\end{array}$ \\
\hline BTH101 & 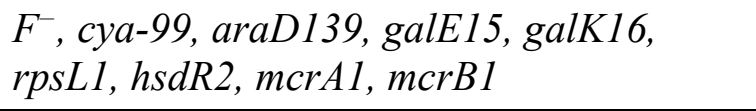 & $\begin{array}{l}\text { (Karimova et al., } \\
\text { 2001) }\end{array}$ \\
\hline Rosetta (DE3) & $\begin{array}{l}F^{-} \text {ompT } h s d S_{\mathrm{B}}\left(\mathrm{r}_{\mathrm{B}}^{-} \mathrm{m}_{\mathrm{B}}^{-}\right) \text {gal dcm }(\mathrm{DE} 3) \\
\operatorname{pRARE}\left(\mathrm{Cm}^{\mathrm{R}}\right)\end{array}$ & Novagen \\
\hline BL21(DE3) & $\mathrm{F}^{-}$omp $\mathrm{T} h s d \mathrm{~S}_{\mathrm{B}}\left(\mathrm{r}_{\mathrm{B}}^{-}, \mathrm{m}_{\mathrm{B}}^{-}\right)$gal dcm (DE3) & $\begin{array}{l}\text { (Studier \& Moffatt, } \\
\text { 1986) }\end{array}$ \\
\hline
\end{tabular}


Appendix Table 2. Plasmids used in this study

\begin{tabular}{|c|c|c|}
\hline Name & Characteristics & Source \\
\hline pCQ11-FtsZ-SNAP & $\begin{array}{l}\text { pCQ11 derivative containing ftsZ-snap under } \\
\text { Pspac; } \text { Amp }^{\mathrm{R}}, \text { Ery }^{\mathrm{R}}\end{array}$ & $\begin{array}{l}\text { (Lund et al., } \\
\text { 2018) }\end{array}$ \\
\hline pKASBAR & $\begin{array}{l}\text { pUC18 containing attP and tetracycline cassette; } \\
\mathrm{Amp}^{\mathrm{R}}, \mathrm{Tet}^{\mathrm{R}}\end{array}$ & $\begin{array}{l}\text { (Bottomley et } \\
\text { al., 2014) }\end{array}$ \\
\hline pKB-Pspac-pbpl & $\begin{array}{l}\text { pKASBAR containing } S \text {. aureus pbpl under } \\
\text { Pspac; } \text { Amp }^{\mathrm{R}}, \text { Tet }^{\mathrm{R}}\end{array}$ & This study \\
\hline pMAD & $\begin{array}{l}\text { E. coli-S. aureus shuttle vector with temperature- } \\
\text { sensitive origin of replication in } S \text {. aureus and } \\
\text { constitutively produced thermostable } \beta \text { - } \\
\text { galactosidase encoded by bgaB; Amp } \text { Ery }^{\mathrm{R}}\end{array}$ & $\begin{array}{l}\text { (Arnaud et al., } \\
\text { 2004) }\end{array}$ \\
\hline pMAD- $\Delta p b p 1$ & $\begin{array}{l}\text { pMAD containing a deletion cassette for } S . \\
\text { aureus pbpl; Amp }{ }^{\mathrm{R}}, \mathrm{Ery}^{\mathrm{R}}\end{array}$ & This study \\
\hline pMAD- $p b p 1_{\triangle \mathrm{PASTA}}$ & $\begin{array}{l}\text { pMAD containing a deletion cassette for } S \text {. } \\
\text { aureus pbpl PASTA domains; } \text { Amp }^{\mathrm{R}}, \text { Ery }^{\mathrm{R}}\end{array}$ & This study \\
\hline pMAD-pbpl* & $\begin{array}{l}\text { pMAD containing a cassette for introduction of a } \\
\text { point mutation }(\mathrm{S} 314 \mathrm{~A}) \text { in the active site } S . \\
\text { aureus pbpl; } \mathrm{Amp}^{\mathrm{R}}, \text { Ery }^{\mathrm{R}}\end{array}$ & This study \\
\hline pGL485 & $\begin{array}{l}\text { E. coli-S. aureus shuttle vector carrying } E \text {. coli } \\
\text { lacI gene under the control of a constitutive } \\
\text { promoter; } \mathrm{Spec}^{\mathrm{R}}, \mathrm{Cam}^{\mathrm{R}}\end{array}$ & $\begin{array}{l}\text { (Cooper et al., } \\
\text { 2009) }\end{array}$ \\
\hline T18 (pUT18C) & $\begin{array}{l}\text { Derivative of high copy-number pUC19, } \\
\text { carrying gene encoding amino acids } 225 \text { to } 399 \\
\text { of CyaA (T18 fragment); Amp }{ }^{\mathrm{R}}\end{array}$ & $\begin{array}{l}\text { (Karimova et } \\
\text { al., 2001) }\end{array}$ \\
\hline $\begin{array}{l}\text { T18-zip (pUT18C- } \\
\text { zip) }\end{array}$ & $\begin{array}{l}\text { pUT18C coding for the leucine zipper region of } \\
\text { the GCN4 yeast protein. Positive control; } \mathrm{Amp}^{\mathrm{R}}\end{array}$ & $\begin{array}{l}\text { (Karimova et } \\
\text { al., 2001) }\end{array}$ \\
\hline EzrA-T18 (pVF32) & $\begin{array}{l}\text { pUT18(Karimova et al., 2001) containing T18 } \\
\text { fused in frame to the } 3^{\prime} \text { end of } S \text {. aureus ezrA; } \\
\mathrm{Amp}^{\mathrm{R}}\end{array}$ & $\begin{array}{l}\text { (Steele et al., } \\
\text { 2011) }\end{array}$ \\
\hline T18-PBP2 (pGL547) & $\begin{array}{l}\text { pUT18C containing T18 fused in frame to the } 5^{\prime} \\
\text { end of } S . \text { aureus pbp } 2 ; \mathrm{Amp}^{\mathrm{R}}\end{array}$ & $\begin{array}{l}\text { (Steele et al., } \\
\text { 2011) }\end{array}$ \\
\hline T18-DivIC (pGL564) & $\begin{array}{l}\text { pUT18C containing T18 fused in frame to the } 5^{\prime} \\
\text { end of } S . \text { aureus divIC; } \mathrm{Amp}^{\mathrm{R}}\end{array}$ & $\begin{array}{l}\text { (Steele et al., } \\
\text { 2011) }\end{array}$ \\
\hline T18-DivIB (pGL544) & $\begin{array}{l}\text { pUT18C containing T18 fused in frame to the } 5^{\prime} \\
\text { end of } S . \text { aureus divIB;Amp }\end{array}$ & $\begin{array}{l}\text { (Steele et al., } \\
\text { 2011) }\end{array}$ \\
\hline T18-FtsW (pALB6) & $\begin{array}{l}\text { pUT18C containing T18 fused in frame to the } 5^{\prime} \\
\text { end of } S . \text { aureus fts } W ; \mathrm{Amp}^{\mathrm{R}}\end{array}$ & $\begin{array}{l}\text { (Steele et al., } \\
\text { 2011) }\end{array}$ \\
\hline $\mathrm{T} 25(\mathrm{pKT} 25)$ & $\begin{array}{l}\text { Derivative of low copy-number pSU40, carrying } \\
\text { the first } 224 \text { amino acids of } B \text {. subtilis CyaA } \\
\text { (T25 fragment); Kan }{ }^{\mathrm{R}}\end{array}$ & $\begin{array}{l}\text { (Karimova et } \\
\text { al., 2001) }\end{array}$ \\
\hline
\end{tabular}




\begin{tabular}{|c|c|c|}
\hline T25-zip (pKT25-zip) & $\begin{array}{l}\text { pKT } 25 \text { coding for the leucine zipper region of } \\
\text { the GCN4 yeast protein. Positive control; } \operatorname{Kan}^{\mathrm{R}}\end{array}$ & $\begin{array}{l}\text { (Karimova et } \\
\text { al., 2001) }\end{array}$ \\
\hline T25-PBP1 (pGL550) & $\begin{array}{l}\text { pKT } 25 \text { containing } \mathrm{T} 25 \text { fused in frame to the } 5^{\prime} \\
\text { end of } S \text {. aureus pbp } 1 ; \mathrm{Kan}^{\mathrm{R}}\end{array}$ & $\begin{array}{l}\text { (Steele et al., } \\
\text { 2011) }\end{array}$ \\
\hline $\mathrm{T} 25-\mathrm{PBP} 1_{\triangle \mathrm{PASTA}}$ & $\begin{array}{l}\text { pKT } 25 \text { containing T } 25 \text { fused in frame to the } 5^{\prime} \\
\text { end of } S \text {. aureus pbp } 1_{\triangle \mathrm{PASTA}}(\mathrm{M} 1-\mathrm{S} 595) ; \mathrm{Kan}^{\mathrm{R}}\end{array}$ & This study \\
\hline pOPINRSF & kan $\mathrm{P}_{T 7}$ lacI; $\operatorname{Kan}^{\mathrm{R}}$ & $\begin{array}{l}\text { (Berrow et al., } \\
\text { 2009) }\end{array}$ \\
\hline pVR01 & $\begin{array}{l}\text { kan } \mathrm{P}_{T 7} \text { pbpl lacI; pOPINRSF derivative for } \\
\text { overexpression of full length } S \text {. aureus PBP1 (1- } \\
744) ; \mathrm{Kan}^{\mathrm{R}}\end{array}$ & This study \\
\hline pVR02 & $\begin{array}{l}\text { kan } \mathrm{P}_{T 7} \text { pbpl(37-744) lacI; pOPINRSF } \\
\text { derivative for overexpression of } S a \mathrm{PBP} 1 \text { (37- } \\
\text { 744); } \operatorname{Kan}^{\mathrm{R}}\end{array}$ & This study. \\
\hline pVR03 & $\begin{array}{l}\text { kan } \mathrm{P}_{T 7} p b p 1^{*}(37-744: \mathrm{S} 314 \mathrm{~A}) \text { lacI; } \mathrm{pOPINRSF} \\
\text { derivative for overexpression of } S a \mathrm{PBP} 1 *(37- \\
744) ; \mathrm{Kan}^{\mathrm{R}}\end{array}$ & This study \\
\hline pVR04 & $\begin{array}{l}\text { kan } \mathrm{P}_{T 7} \text { pbp 1(37-595) lacI; pOPINRSF } \\
\text { derivative for overexpression of } \\
\text { SaPBP1 } 1_{\triangle \mathrm{PASTA}}(37-595) ; \mathrm{Kan}^{\mathrm{R}}\end{array}$ & This study \\
\hline pVR06 & $\begin{array}{l}\text { kan } \mathrm{P}_{T 7} \text { pbp l(595-744) lacI; pOPINRSF } \\
\text { derivative for overexpression of SaPASTAPBP1 } \\
(595-744) ; \operatorname{Kan}^{\mathrm{R}}\end{array}$ & This study \\
\hline pOPINJB & bla $\mathrm{P}_{T 7}$ lacI; $\mathrm{Amp}^{\mathrm{R}}$ & $\begin{array}{l}\text { (Berrow et al., } \\
\text { 2009) }\end{array}$ \\
\hline pSA50 & $\begin{array}{l}\text { pOPINJB derivative for overexpression of } \\
\text { sPBP1A-BAP; Amp }\end{array}$ & This study \\
\hline
\end{tabular}


Appendix Table 3. Oligonucleotides used in this study

\begin{tabular}{|c|c|}
\hline Name & 5'-3' oligonucleotide sequence \\
\hline pCQ-pbp1-F & $\begin{array}{l}\text { AGAAGGAGATATACATATGGCTTGAGAACGATAATGTAAA } \\
\text { G }\end{array}$ \\
\hline pCQ-pbp1-F & TATTATGCATTTAGAATAGGTTAGTCCGACTTATCCTTG \\
\hline pKB-Pspac-pbp1-F & $\begin{array}{l}\text { CCTTTTTTTGCCCCGGGATCCGCAAAAAGTTGTTGACTTTA } \\
\text { TC }\end{array}$ \\
\hline pKB-Pspac-pbp1-R & CTATGACCATGATTACGAATTCTTAGTCCGACTTATCCTTG \\
\hline $\mathrm{pbp} 1-\mathrm{A}$ & CCATGGTACCCGGGAGCTCGCACCATGACGCAACATTAG \\
\hline $\mathrm{pbp} 1-\mathrm{B}$ & ATCCTTGTCATTAATTTTTTGCTTCGCC \\
\hline pbp1-C & CAAAAAATTAATGACAAGGATAAGTCGGAC \\
\hline pbp1-D & CCTCGCGTCGGGCGATATCGATCTCCCATAAACACTTTAGC \\
\hline $\mathrm{pbp} 1-\mathrm{E}$ & $\begin{array}{l}\text { CCATGGTACCCGGGAGCTCGAATTCTAAAAAACCTAGGCA } \\
\text { TG }\end{array}$ \\
\hline pbp1-F & TATCCTTGTCAGATGTGTCATCTTTTGATTTAC \\
\hline $\mathrm{pbp} 1-\mathrm{G}$ & TGACACATCTGACAAGGATAAGTCGGACTAAC \\
\hline pbp1-H & $\begin{array}{l}\text { GCGTCTGCAGAAGCTTCTAGTTAATGCACTCCAATCCATAA } \\
\text { AC }\end{array}$ \\
\hline $\mathrm{pbp} 1 * 5^{\prime}-\mathrm{F}$ & $\begin{array}{l}\text { CCATGGTACCCGGGAGCTCGAATTCAGTATACCGAAGCAA } \\
\text { CAACCAC }\end{array}$ \\
\hline $\mathrm{pbp} 1 * 5^{\prime}-\mathrm{R}$ & TTAAATGTTGCTCCAGGCTCGTATGTGTTTTG \\
\hline $\mathrm{pbp} 1 * 33^{\prime}-\mathrm{F}$ & GAGCCTGGAGCAACATTTAAATCAT ATGGGTTA \\
\hline $\mathrm{pbp} 1 * 3{ }^{\prime}-\mathrm{R}$ & $\begin{array}{l}\text { CCTCGCGTCGGGCGATATCGGATCCTTAGTCCGACTTATCC } \\
\text { TTGTC }\end{array}$ \\
\hline T25-pbp1-F & $\begin{array}{l}\text { CTGCAGGGTCGACTCTAGAGATGGCGAAGCAAAAAATTAA } \\
\text { AATTAAAAAAAATAAAATAG }\end{array}$ \\
\hline T25-pbp1pasta-R & $\begin{array}{l}\text { ACGTTGTAAAACGACGGCCGTTAAGATGTGTCATCTTTTGA } \\
\text { TTTACCTACATTTAAATATTTC }\end{array}$ \\
\hline VR47F & $\begin{array}{l}\text { AAGTTCTGTTTCAGGGCCCGGCGAAGCAGAAGATCAAGAT } \\
\text { TAAGAAAAAC }\end{array}$ \\
\hline VR47R & $\begin{array}{l}\text { ATGGTCTAGAAAGCTTTAATCGCTTTTATCCTTGTCGGTTT } \\
\text { TGC }\end{array}$ \\
\hline VR49F & ATGATTACCGGCCACAGCAAC \\
\hline VR49R & CGGGCCCTGAAACAGAACTTCCAG \\
\hline VR51 & AACACCTATGAGCCGGGCGCCACCTTCAAAAGCTATGGTC \\
\hline VR53 & GAGCAAAGACGATACCAGCTAAGCGGAGTACAGCAAGG \\
\hline VR57F & AGCAACGCGGAGTACAGCAAGGTGCCGGACGTTG \\
\hline
\end{tabular}




\begin{tabular}{|l|l|}
\hline OPPF20018F & $\begin{array}{l}\text { AAGTTCTGTTTCAGGGCCCGGCGAACGAGAAATACCTGGT } \\
\text { TAAGAACGCGC }\end{array}$ \\
\hline OPPF20018R & $\begin{array}{l}\text { AGATGTCGTTCAGGCCATCGCTTTTATCCTTGTCGGTTTTG } \\
\text { CTGTCGC }\end{array}$ \\
\hline
\end{tabular}




\begin{tabular}{ll}
\hline & SaPASTAPBP1 \\
\hline Data & \\
Resolution $(\AA)$ & 1.78 \\
Space group & $P 22_{1} 2_{1}$ \\
$a, b, c(\AA)$ & $39.8,81.4,89.6$ \\
$\alpha, \beta, \gamma\left({ }^{\circ}\right)$ & $90,90,90$ \\
$<\mathrm{I} / \sigma \mathrm{I}>^{\mathrm{a}}$ & $14.2(2.0)$ \\
Completeness $(\%)^{\mathrm{a}}$ & $99.9(99.8)$ \\
$\mathrm{Redundancy}^{\mathrm{a}}$ & $7.7(6.7)$ \\
$R_{\mathrm{p} . \mathrm{i} . \mathrm{m}}(\%)^{\mathrm{a}}$ & $3.0(39.1)$ \\
$R_{\mathrm{merge}}(\%)^{\mathrm{a}}$ & $6.0(66.0)$ \\
$\mathrm{CC}_{1 / 2}{ }^{\mathrm{a}}$ & $99.8(92.3)$
\end{tabular}

\section{Refinement}

$\begin{array}{ll}R_{\text {work }}(\%) & 18.7 \% \\ R_{\text {free }}(\%)^{\mathrm{b}} & 21.0 \%\end{array}$

No. of residues

Chain A: 116, Chain B: 117

No. of waters

Average $B$-factor $\left(\AA^{2}\right)$

Protein

Chain A: 45.1, Chain B: 48.0

Waters 47.6

R.m.s.d on ideal values

Bond lengths $(\AA) \quad 0.005$

Bond angle $\left(^{\circ}\right) \quad 0.755$

\section{Ramachandran}

Most favoured (\%) $\quad 98.69$

Additional allowed (\%) $\quad 1.31$

Outliers (\%) $\quad 0.0$

PDB ID 7061

1362 avalues in parentheses are for the highest resolution shell.

$1363{ }^{b}$ For determination of $R_{\text {free, }} 5 \%$ of reflections were randomly selected before refinement. 